\title{
THREE ESSAYS ON THE LABOR MARKET DETERMINANTS OF ACCESS TO EMPLOYEE BENEFITS
}

\author{
A Dissertation \\ presented to \\ the Faculty of the Graduate School \\ at the University of Missouri-Columbia \\ In Partial Fulfillment \\ of the Requirements for the Degree \\ Doctor of Philosophy \\ by \\ LESLIE HODGES \\ Dr. Colleen Heflin, Dissertation Supervisor \\ MAY 2017
}


(C) Copyright by Leslie Hodges 2017

All Rights Reserved 
The undersigned, appointed by the dean of the Graduate School, have examined the dissertation entitled

\section{THREE ESSAYS ON THE LABOR MARKET DETERMINANTS OF ACCESS TO EMPLOYEE BENEFITS}

presented by Leslie Hodges,

a candidate for the degree of doctor of philosophy,

and hereby certify that, in their opinion, it is worthy of acceptance.

Professor Colleen Heflin

Professor Peter Mueser

Professor Joan Hermsen

Professor Rajeev Darolia 
To my parents, Grant, and Avery. 


\section{ACKNOWLEDGEMENTS}

Many people deserve thanks for making this dissertation possible, manageable, and enjoyable. Above all, I owe a great deal of gratitude to my advisor, Colleen Heflin. She is a brilliant scholar and an exceptional mentor. In the fall of 2013, she kindled my interest in program evaluation, and she has been providing inspiration, encouragement, and a path forward ever since. I am truly fortunately to have had the opportunity to work with her and hope to continue to do so long into the future.

I would like to thank Peter Mueser for his time and patience. He spent many long afternoons reviewing labor economics (and sometimes basic math) with me. I always left our meetings with a better understanding of why my interpretation of something was not quite correct. Peter also spent a good deal of time and energy reading my work with a critical eye and providing detailed feedback, for which I am grateful.

I would like to thank Joan Hermsen for steering me toward "care work" and "good jobs / bad jobs,” for supporting an independent study on women and work, for providing opportunities to present my research in the Women's and Gender Studies Department, and for helping me write a strong grant proposal for the third essay of this dissertation.

I would like to thank Rajeev Darolia for being encouraging and critical. His tough questions_-"Which of these things should policy makers care about?” and "Why are you using this particular method?"-helped me articulate the importance of my research and prepared me for the job market.

I would like to thank the MU Population, Education, and Health Center for financially supporting my use of the MU Research Data Center (RDC) for the third essay of my dissertation, from which I hope many more great things will come. I would like to thank Jake Cronin, MU RDC Coordinator, for walking me through the steps of using the 
RDC several times and for never failing to be friendly when answering questions—-no matter how many times I asked them. I would also like to thank Ray Kuntz at the Agency for Healthcare Research and Quality for helping with the RDC proposal process and disclosure review.

I would like to thank Guy Adams for a seamless transition from political science to public affairs, and I would like to thank Dean Wechsler for welcoming me with open arms.

Finally, I would like to thank three very good friends: Erin Schliep, Rebecca Miller, and Eldar Rizvanov. To Erin and Rebecca: we have traveled many miles together, both literally and figuratively. Thanks for bringing advice and perspective during the hard times and for bring fun and adventure during the good times. To Eldar: I could not have made it through the first year of graduate school without you. 


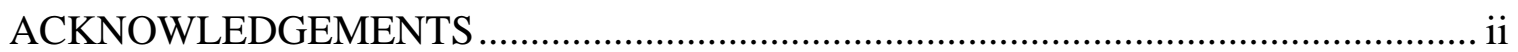

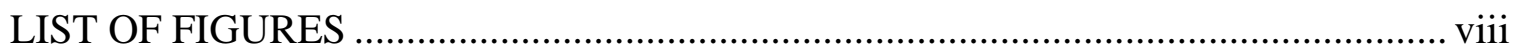

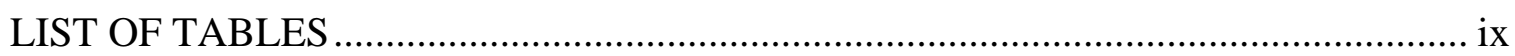

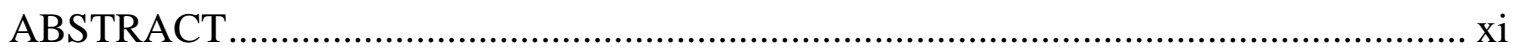

Chapter

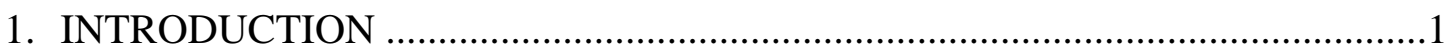

References

2. WHO IS COVERED BY UNEMPLOYMENT INSURANCE? ............................

Background

Overview of the UI program

Monetary eligibility for UI

Prior research and current study

Demographic characteristics and UI coverage

Job characteristics and UI coverage

Policy Changes and UI coverage

Data and Methods

Data

Sample

Methods

Results

Probit analysis

Policy changes

Sensitivity analysis 
Factors contributing to monetary eligibility for UI

Discussion

Conclusion

References

Appendix

3. WHY ARE WOMEN LESS LIKELY TO BE COVERED BY

UNEMPLOYMENT INSURANCE THAN MEN?

Background

Conceptual Framework

Work hours

Earnings

Risk of unemployment

Summary

Data and Methods

Data

Sample

Variables

Methods

Results

Sample characteristics

Probit analysis

Decomposition analysis

Sensitivity analysis

Factors contributing to monetary eligibility for UI

Discussion 
Conclusion

References

Appendix A

Appendix B

4. BRINGING HOME THE BACON OR THE BENEFITS? NEW EVIDENCE ON

NEW EVIDENCE ON FEMALE REPRESENTATION AND JOB COMPENSATION FROM THE MEDICAL EXPENDITURES PANEL

SURVEY

Compensating Differentials

Gendered Devaluation

Current Study and Contribution

Data and Methods

Data

Sample

Explanatory variables

Dependent variables

Models

Results

Sensitivity analysis

Discussion

Limitations

Conclusion

References

Appendix A

Appendix B 


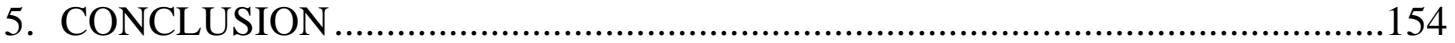

Barriers to Benefits

Pathways to Benefits and Directions for Future Research

References

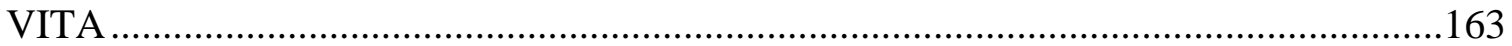




\section{LIST OF FIGURES}

Figure

Chapter 2

1. State Monetary Eligibility Determinants for UI................................................12

2. Monetary Eligibility for UI by Quarter ............................................................28 Chapter 3

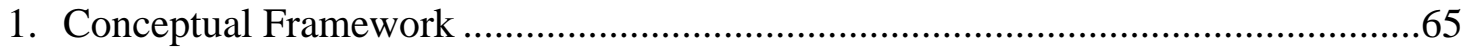

2. Pooled Decomposition of Gender Differences in UI Eligibility for Employed

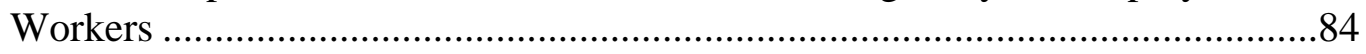

3. Pooled Decomposition of Gender Differences in UI Eligibility for Less-educated Employed Workers

4. Pooled Decomposition of Gender Differences in UI Eligibility for Unemployed Workers

5. Pooled Decomposition of Gender Differences in UI Eligibility for Less-educated Unemployed Workers

Chapter 4

1. Average Wages by Female Representation in a Detailed Occupation Group........121 


\section{LIST OF TABLES}

Table

Chapter 2

1. Summary Statistics

2. Predicting Monetary Eligibility for Employed Workers.

3. Change in the Percentage of Workers Ineligible for UI after ABP .36

4. Predicting Monetary Eligibility for UI for Employed Workers with Continuous Labor Force Participation 39

5. Workers’ Median Earnings and Employment Stability in the Base Period

6. Monetary Ineligibility for UI among the Employed by Job Group........................55

7. Summary Statistics for Current Workers with Continuous Labor Force Participation during the Base Period................................................................................56

8. Summary Statistics for All Employed Workers ..............................................57

9. Linear Probability Model Predicting Employed Workers' Monetary Eligibility for UI using Standard Base Period and Alternative Base Period Work History and Earnings

Chapter 3

1. Summary Statistics .78

2. Probit Regression Models Predicting Monetary Eligibility for UI .79

3. Probit Regression Models Predicting Less-educated Workers' Monetary Eligibility for UI

4. Summary Statistics Full Sample

5. Summary Statistics Less-educated Workers 
Chapter 4

1. Large Occupational Groups by Female Representation.....................................120

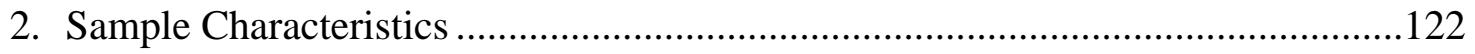

3. Job Compensation by Gender and Female Representation ................................125

4. The Effects of Female Representation on Job Compensation..............................129

5. The Effects of Female Representation on Hourly Wages and Total Compensation Controlling for Fringe Benefits .................................................................133

6. The Effects of Female Representation on Job Compensation by Gender..............135

7. The Effects of Female Representation on Job Compensation using Five Indicators of Female Representation (Integrated Jobs Omitted) ....................................147

8. The Effects of Female Representation on Job Compensation using Three Indicators of Female Representation (Predominately Male Jobs Omitted) .......................148

9. The Effects of Female Representation on Compensation using Percentage Female

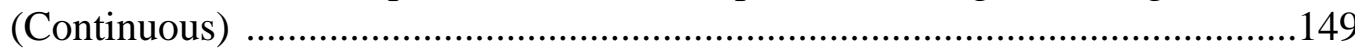

10. The Effects of Female Representation on Compensation using Percentage Female

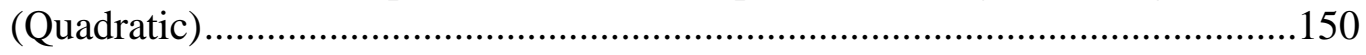

11. The Effects of Female Representation on Compensation using a Binary Indicator of Percentage Female (<50\% Female Omitted) ...............................................151

12. The Effects of Female Representation on Compensation using the Log Odds of Percentage Female (Continuous) ..................................................................152 


\title{
THREE ESSAYS ON THE LABOR MARKET DETERMINANTS OF ACCESS TO EMPLOYEE BENEFITS
}

\author{
Leslie Hodges
}

\author{
Dr. Colleen Heflin, Dissertation Supervisor
}

\begin{abstract}
Because employment is a central social policy goal, policy analysts and policy makers are interested in better understanding whether and how jobs meet people’s needs. To contribute to research in this area, this dissertation uses nationally representative survey data and regression analysis to empirically examine how the characteristics of workers and their jobs affect access to employee benefits. The first two essays focus on access to the unemployment insurance program, and the third essay focuses on access to employer provided health insurance coverage, paid leave, and pensions. Together these chapters identify barriers and pathways between employment and benefits after the Great Recession and highlight ways in which policy makers can broaden the protective effects of employment in the new economy.
\end{abstract}




\section{CHAPTER 1: INTRODUCTION}

When signing the Personal Responsibility and Work Opportunity Act (PWORA), President Bill Clinton stated, “The best anti-poverty program is still a job” (Clinton, 1996). Not only does employment shield households from poverty and economic insecurity by providing wage income, employment also protects many individuals and their households against economic risks by providing access to benefits including health insurance coverage, unemployment insurance, and retirement plans. Yet work does not guarantee economic security. At the same time that social policy has become increasingly centered on employment, many scholars have noted that work itself has become less secure (Kalleberg, 2009). Many jobs do not pay a wage high enough to bring a family of three above the federal poverty line (Kazis, 2001) and many more do not offer benefits such as health insurance coverage and pensions (Kalleberg, Reskin, \& Hudson, 2000). Consequently, policy analysts and policy makers face the challenge of helping to ensure that jobs meet people's needs.

In order to help policy makers identify ways to expand the protective effects of employment and meet people's needs, each of the following essays uses national survey data and regression analysis to empirically examine how the characteristics of workers and their jobs influence access to employee benefits. I define employee benefits as compensation received in addition to wage-income either directly from an employer or indirectly from employer contributions to a government sponsored program. The first two chapters focus on access to the Federal-State Unemployment Compensation Program, better known as Unemployment Insurance (UI), which is a complex social insurance program designed to protect workers against the loss of economic resources in the event of unexpected job loss. The fourth chapter focuses on access to fringe benefits include employer provided health insurance coverage, paid leave, and pensions. 
The second chapter identifies barriers in access to unemployment insurance by asking: Who is covered by UI? Using monthly individual-level data from the 2008 panel of the Survey of Income and Program Participation (SIPP) I compare current workers' earnings and work histories to states' monetary eligibility rules in order to estimate rates of UI coverage by major demographic and job groups from October 2009 to March 2013. I find that current workers have very high rates of UI coverage: Over 95\% would be monetarily eligible for benefits if they were to become unemployed. However, I also find that women, younger workers, less-educated workers, part-time workers, and workers in some service-related industries and occupations are less likely to be covered by UI than their counterparts. The second chapter also examines whether state programmatic changes to monetary eligibility criteria following the Great Recession increased rates of UI coverage. I find that states' implementation of an alternative base period rule for determining monetary eligibility decreased rates of ineligibility among current workers by $20 \%$.

The third chapter further investigates how workers characteristics and their positions in the labor market affect their access to unemployment insurance by asking: Why are women less likely to be covered by UI than men? I develop a detailed conceptual framework for why women's positions in the labor force may make them monetarily ineligible for UI benefits. Then, I empirically test this framework using monthly individual-level data from the 2004 and 2008 panels of the SIPP, which covers the period from January 2005 to March 2013. Similar to the findings from the second chapter, based on probit regression analysis, I find that working women are less likely to be covered by UI than working men, and that these gaps are larger for less-educated workers. ${ }^{1}$ I then use decomposition analysis to examine the factors contributing to these

\footnotetext{
${ }^{1}$ I define UI coverage as whether a worker is monetarily eligible to receive UI benefits based on their states’ work history and earnings requirements.
} 
gaps. I find that up to one third of the gender gaps in UI coverage can be attributed to distributional differences in working men and women's demographic and job characteristics, particularly differences in men and women's rates of part-time work and occupations, whereas two-thirds of these gaps can be attributed to differences in the labor market returns that men and women receive to their demographic and job characteristics. I conclude that reductions in the work hours and earnings needed to qualify for UI benefits would likely have the greatest impact on closing the gender gaps in UI coverage and expanding the protective effects of UI to more workers.

The fourth chapter examines how the gender composition of an occupation affects wages and benefits. Particularly, I investigate whether workers in predominately female occupations choose their jobs based on their non-pecuniary attributes and their preferences for certain types of market work or whether they face constraints that limit the labor market rewards (wages and benefits) they receive for doing women's work. Using annual individual-level data from the Medical Expenditures Panel Survey (MEPS) from 2007 to 2013 and occupation-level data from the Integrated Public Use Microdata Series (IPUMS), I find that in addition to having lower wages, workers in predominately female occupations are less likely to be offered employer health insurance coverage and are less likely to have paid vacation and pension plans than workers in predominately male occupations and gender integrated occupations. Although other explanations for differences in wage and non-wage compensation between male and female occupations cannot be completely ruled out, the results suggest that the inequalities between male and female occupations are greater when fringe benefits are taken into account.

In documenting access to benefits as a function of the characteristics of workers and their jobs, each of these essays address three broad challenges to the protective effects of employment. First, each of these essays captures structural changes to 
employment following the Great Recession through their use of data that was collected during this time period. Structural changes to employment during and after the Great Recession indicate a decline in the quality and quantity of employment opportunities for many Americans. During the Great Recession, job loss was particularly high among males in traditionally blue collar jobs, which were typically considered "good jobs" with high wages and fringe benefits. During the subsequent recovery, job creation primarily occurred in low-wage low-skilled sectors, which are often considered "bad jobs” with low pay, little or no fringe benefits, and short career ladders (Kalleberg et al., 2000). ${ }^{2}$

Additionally, each of these essays addresses how workers' gendered and racialized positions in the labor market affect the returns they receive for their work. Although black workers' UI coverage was similar to that of white workers, I find that Hispanic workers were more likely to be covered by UI than white workers. Yet, unemployed Hispanic workers are less likely to take-up UI benefits than white workers (Gould-Werth \& Shaefer, 2012; Michaelides \& Mueser, 2012). Additionally, while women's rates of labor market participation and earnings have increased significantly over the past fifty years, recent studies indicate a persistence of occupational gender segregation (men and women working in different jobs) and of the gender gap in pay (Blau \& Kahn, 2007; Cotter, Hermsen, \& Vanneman, n.d.). The third and fourth chapters of this dissertation investigate how these factors limit women's access to employee benefits. Chapter 3 explores how women's weaker labor market attachments and lower earnings make them less likely to be covered by UI (monetary eligible to receive

\footnotetext{
${ }^{2}$ In 2008 at the peak of the Great Recession, jobs in manufacturing (predominately male) declined by 10 percent, whereas jobs in service industries such as retail trade declined by only $5 \%$, jobs in professional and business services declined by about $7 \%$, and jobs in education and health services (predominately female) actually increased by about $2 \%$ (BLS, 2012).
} 
benefits). Chapter 4 explores differences in wages and fringe benefits between workers in predominately female occupations and workers in predominately male occupations.

Finally, each of these essays highlights how employment instability among disadvantaged workers (less-educated and part-time workers) in the labor market limits economic opportunities available to these workers by blocking access to employee benefits. Disadvantaged workers, particularly those who with less education and lower wages, may stand to gain the most from employee benefits but are most likely to be excluded, either because their employers do not offer them (as in the case of health insurance coverage) and/or because their wages and employment histories make them ineligible for participation in public programs, as in the case of UI. For example, in chapter 3, I find that less-educated working women are 3 percentage points less likely be have UI coverage than less-educated working men, and less-educated unemployed women are 7 percentage points less likely to have UI coverage than less-educated unemployed men. For less-educated employed workers, I find that 30\% of these differences are explained by women's overrepresentation in part-time work and $5 \%$ of these differences are explained by women and men working in different occupations. For less-educated unemployed workers, I find that $11 \%$ if these differences are explained by women's overrepresentation in part-time work and $14 \%$ of these differences are explained by women and men working in different occupations.

Of course, expanding the protective effects of employment given the current structure of the economy and recent shifts in the demographic characteristics of workers is no small feat. The policy levers that would expand access to a benefit when it is provided by an employer, such as mandates to provide health insurance coverage or paid leave, differ from the policy levers that would expand access to a benefit from a government program, such as programmatic changes to eligibility determinants for 
unemployment insurance. And, both suggest different ways in which expanded access might alter the behavior of employees and their employers. For example, increasing employment costs due to federal mandates that require employers to provide benefits could lead to fewer hires or changes in the terms under which workers in some firms are eligible for benefits. Increased access to UI could lead more employers to reduce workers' hours rather than engage in formal layoffs or firing. Nevertheless, developing successful policies to broaden the protective effects of employment begins with an understanding of the labor market in which people work and the characteristics of workers themselves and how this affects their economic opportunities, including their access to employee benefits, which is the primary purpose of this dissertation. 


\section{References}

Blau, F. D., \& Kahn, L. M. (2007). The gender pay gap have women gone as far as they can? The Academy of Management Perspectives, 21(1), 7-23.

BLS. (2012). The Recession of 2007-2009. Retrieved from Washington, DC: www.bls.gov/spotlight

Clinton, W. J. (1996) Text of President Clinton's Announcement on Welfare Legislation. Federal News Service. The New York Times, New York, NY. Retrieved from http://www.nytimes.com/1996/08/01/us/text-of-president-clinton-sannouncement-on-welfare-legislation.html

Cotter, D. A., Hermsen, J. M., \& Vanneman, R. (n.d.). Still Stalled? Occupational Gender Desegregation 1950-2010.

Gould-Werth, A., \& Shaefer, H. L. (2012). Unemployment Insurance participation by education and by race and ethnicity. Monthly Lab. Rev., 135, 28.

Kalleberg, A. L. (2009). Precarious work, insecure workers: Employment relations in transition. American Sociological Review, 74(1), 1-22.

Kalleberg, A. L., Reskin, B. F., \& Hudson, K. (2000). Bad Jobs in America: Standard and Nonstandard Employment Relations and Job Quality in the United States. American Sociological Review, 65(2), 256-278. doi:10.2307/2657440

Kazis, R. (2001). Opportunity and Advancement for Low-Wage Workers. In R. Kazis \& M. S. Miller (Eds.), Low-wage workers in the new economy. Washington, DC: The Urban Insitute.

Michaelides, M., \& Mueser, P. R. (2012). Recent trends in the characteristics of unemployment insurance recipients. Monthly Lab. Rev., 135, 28. 


\section{CHAPTER 2: WHO IS COVERED BY UNEMPLOYMENT INSURANCE?}

The effects of the 2007 and 2008 financial crisis on employment were severe and long-lasting. Beginning in mid-2008 the US unemployment rate began a historic climb, doubling from 5\% in January of 2008 to 10\% in October of 2010. Moving into the recovery period, job growth persistently lagged behind economic growth, keeping the unemployment rate above pre-recession levels until September of 2012 (US Bureau of Labor Statistics, 2015). The Federal-State Unemployment Compensation program, better known as Unemployment Insurance (UI), provided weekly benefits to millions of displaced workers during this time. From 2007 to 2010 alone, the number of new UI claims rose from around 8 million to 11.5 million, and program spending increased by over 300\% (Michaelides \& Mueser, 2012; Moffitt, 2013).

In the wake of the Great Recession, higher rates and longer durations of unemployment increased UI program participation and expenditures, as did federal stimulus legislation that was enacted in response to the economic crisis. The Emergency Unemployment Compensation Act of 2008 (EUC08) extended benefit lengths and the American Recovery and Reinvestment Act of 2009 (ARRA) expanded state eligibility criteria (Nicholson, Needels, \& Hock, 2014). Research on the program’s impact during the Great Recession suggests that receiving UI benefits kept workers from exiting the labor market (Farber \& Valletta, 2015; Young, 2012), shielded many American households from poverty (Arbeit, 2012; Bitler \& Hoynes, 2010; Moffitt, 2013; Vroman, 2010), and positively impacted the health and well-being of displaced workers and their families (Kuka, 2015).

Although the stabilizing role of UI during this most recent recession and recovery has been well documented, how economic instability affects workers’ abilities to access 
UI benefits when they need them is also important and less well studied. To contribute to research in this area, I use nationally representative longitudinal data from the 2008 Survey of Income and Program Participation (SIPP) and probit regression analysis to answer the question: Who is covered by unemployment insurance?

The paper begins with an overview of the UI program and a conceptual framework for why UI coverage might vary by demographic and job groups. I then use current workers’ earnings and work histories from the SIPP and states’ monetary eligibility rules to document rates of UI coverage by major demographic and job group from October 2009 through March 2013. I find that current workers have very high rates of UI coverage: Over 95\% would be monetarily eligible for benefits if they were to become unemployed. I also find that policy changes during the recovery successfully extended UI coverage to more workers. However, after controlling for other demographic and job characteristics, I find that women, younger workers, less-educated workers, parttime workers, and workers in some service-related industries and occupations are less likely to be covered by UI than their counterparts.

This study contributes to existing research in a number of ways. First, and foremost, it provides national-level estimates of employed workers' coverage against the risk of unemployment. This is similar to calculating national-level estimates of individuals' health care coverage against the risk of illness. Prior studies have documented rates of UI eligibility and UI receipt for unemployed persons only, which is similar to measuring health insurance coverage for sick persons only. The estimates of UI coverage are particularly relevant for informing UI policy because they capture the availability of UI to workers at a time when the risk of unemployment increased substantially. More than $7 \%$ of current workers in the sample were unemployed at some time between October 2009 and March 2013. Additionally, if the availability of benefits 
changes the behavior of workers, as much of the literature on moral hazard and optimal insurance implies, it is important to document current workers’ rates of UI coverage. Individuals who are not covered by UI may act strategically to avoid unemployment.

Second, by documenting rates of UI coverage, this study also evaluates whether programmatic changes following the Great Recession increased access to UI. I find that states’ implementation of an alternative base period rule for determining monetary eligibility decreased rates of ineligibility among current workers by $20 \% .^{3}$ Third, and finally, this study provides an example of how instabilities in work hours and earnings affect workers' eligibility for employed-based social programs and highlights the relative vulnerability of some groups of workers when it comes to coverage against the risk of unemployment. Although most workers are covered by UI, those less likely to be covered (e.g., women, less-educated workers, and part-time workers) face additional disadvantages in the labor market: They may earn less and lack fringe benefits such as paid time off, health insurance, and pensions.

\section{Background}

Overview of the UI program. The Federal-State Unemployment Compensation (UI) is a complex social insurance program designed to protect workers in the event of unexpected job loss. The primary goals of the program are to reduce hardship suffered by those who experience unemployment and to help stabilize the macro-economy during economic downturns (Nicholson \& Needels, 2006; Shaefer, 2010). UI is unique among social insurance programs in the United States because it is funded primarily through

\footnotetext{
${ }^{3}$ Most states use the first four of the five quarter prior to unemployment as the standard base period for determining monetary eligibility (DOL, 2014). A number of states also define an alternative base period (ABP) as the four quarters prior to the prior quarter of unemployment when individuals do not qualify for benefits under the conventional base period (DOL, 2014).
} 
employer rather than employee payroll taxes, ${ }^{4}$ and because it is mandated by federal law but administered and implemented almost entirely by states.

States pay UI benefits to qualifying individuals on a weekly basis, based on their prior earnings, the state method for calculating weekly benefit amount, and the state's minimum and maximum benefit amount. In order to receive weekly benefits, claimants must meet both monetary and non-monetary criteria. Monetary criteria stipulate the prior work hours and earnings needed to qualify for benefits. Non-monetary criteria identify whether the reason for unemployment qualifies as good cause. Once eligibility for UI and the amount of weekly benefits have been determined, beneficiaries also must meet guidelines for continuing eligibility. Broadly, these guidelines require that a UI recipient be available for work, actively seeking work, and willing to accept reasonable employment offers (Nicholson \& Needels, 2006).

There is general consensus that the UI program needs to have a broad reach across the labor force, especially during periods of economic crisis. However, there are also concerns that the availability of benefits may increase exits from employment among workers who would have otherwise stayed at their jobs and may increase the time that it takes for displaced workers to find new employment. By requiring workers to meet certain conditions in order to receive benefits, UI eligibility determinants strike a balance between providing income replacement to workers at need and avoiding issues of moral hazard.

Monetary eligibility for UI. Monetary criteria are key for examining how employment dynamics influence access to social programs, because they use workers' recent earnings and work histories to determine program eligibility. In order to be monetarily eligible for UI benefits, most states require a recent attachment to

\footnotetext{
${ }^{4}$ Alaska, New Jersey, and Pennsylvania collect contributions from employees as well as employers.
} 
employment during a standard base period, typically defined as the first four of the five quarters prior to unemployment. ${ }^{5}$ States then use one of four methods to determine whether work hours and earnings during the base period are sufficient to qualify for benefits.

As shown in Figure 1, most states use the "multiple of high quarter wages" method. This method requires that UI claimants have base period earnings greater than some multiple of their highest quarter of earnings during the base period, and that their total base period earnings are sufficiently high to qualify for the state's minimum weekly benefit amount. For example, an individual living in Missouri would be eligible for UI if her total earnings in the base period were 1.5 times greater than her highest quarter earnings, and if her highest quarter earnings were greater than $\$ 1,500$ and base period earnings were equal to or greater than $\$ 2,250$.

Figure 1. State Monetary Eligibility Determinants for UI

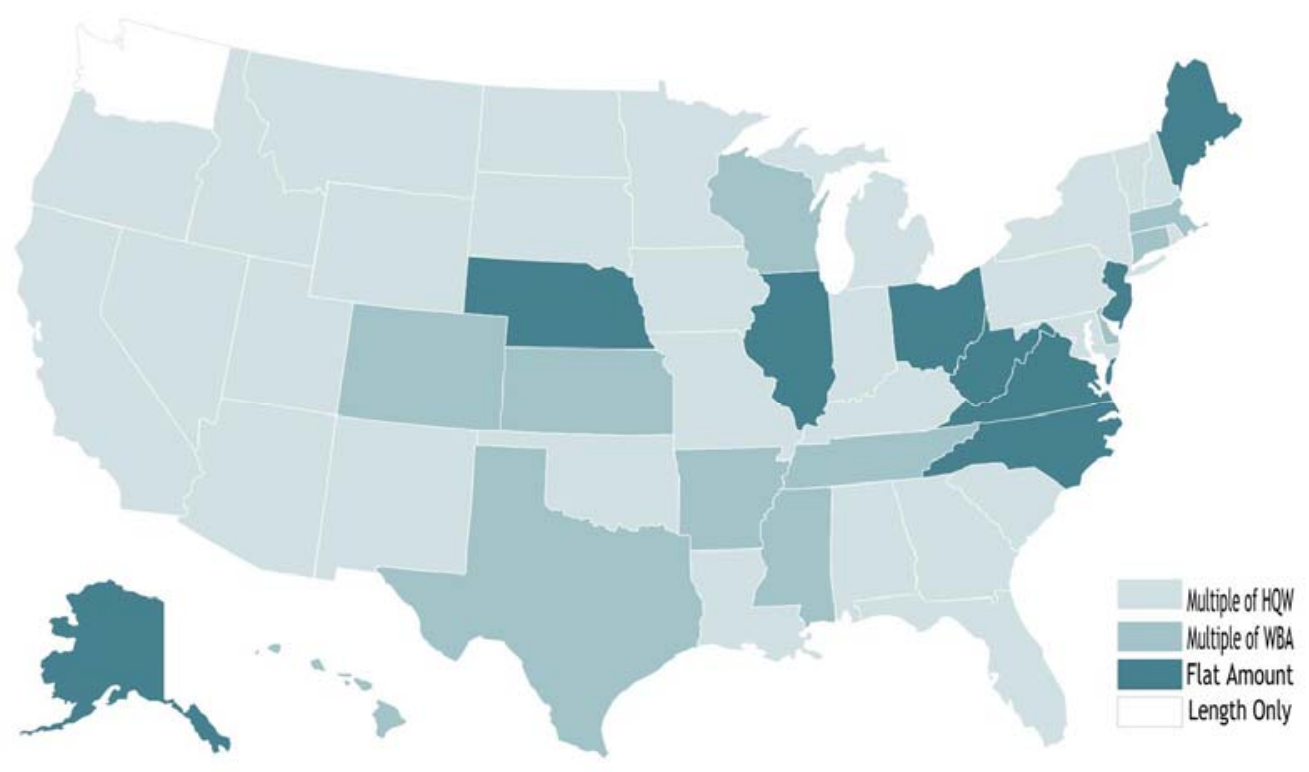

Notes: Author’s own coding based on states’ UI monetary eligibility rules (DOL, 2016).

\footnotetext{
${ }^{5}$ Two states MA and MN define the base period as the four quarter prior to unemployment (DOL, 2014).
} 
A second method that about ten states use to calculate monetary eligibility is the "multiple of the weekly benefit amount" method. In these states, claimants must have wages in more than one quarter of the base period, and have base period earnings greater than or equal to some multiple of the state's minimum weekly benefit amount. For instance, Kansas requires individuals to have wages in two quarters and base period earnings greater than 30 times the minimum weekly benefit amount (\$114 in 2013). This means that an individual must have earnings greater than $\$ 2,683$ in one quarter of the base period and earnings greater than $\$ 3,420$ in the base period in order to be monetarily eligible for UI in Kansas.

A much smaller group of states require claimants to have base period earnings greater than or equal to a set amount, such as a multiple of the state average weekly wage, state minimum wage, or a flat amount. Like the states using the first two methods, state programs using the flat amount method require that workers have earnings in more than one quarter of the base period. Illinois, for instance, requires that workers have earnings greater than $\$ 1,600$ in the base period with at least $\$ 440$ of these earnings outside the worker's highest earnings quarter. Finally, there is a fourth method for calculating eligibility that is used only by the state of Washington. This method assesses workers labor force attachment through work hours only. Specifically, claimants must have a minimum of 680 hours of employment and wages in the base period; with this method, there are no additional minimum earnings requirements.

Prior research and current study. Monetary eligibility rules help to balance program inclusivity with program size and cost, but may create gaps in the availability of UI to some groups of workers. For example, existing studies of access to UI among the unemployed find lower rates of UI receipt among less-educated low-wage workers (GAO, 2000; Shaefer, 2010), former welfare recipients (Shaefer \& Wu, 2011), part-time workers 
(Chan, Michaelides, \& Zhang, 2014; GAO, 2000; Shaefer, 2010; Vroman, 1998, 2002), and service-sector workers (Chan et al., 2014). This variation raises concerns because insuring certain demographic groups of workers at higher or lower rates is not part of the intended function of the UI program. In fact, a major social insurance principal is that all those facing the same risk should be members of the same insurance pool (Marmor, Mashaw, \& Pakutka, 2013). Therefore, identifying systematic variation in workers’ coverage against the risk of unemployment and identifying how this variation changes under different monetary eligibility rules is key for developing policies that help the UI program adhere to its social insurance principals and operate as intended for all workers.

Demographic characteristics and UI coverage. .UI coverage is determined by whether workers' labor force attachments, particularly their work amount and earnings, are sufficient to make them monetarily eligible for benefits. Because labor force attachments are closely related to workers’ demographic characteristics such as gender, education, age, race and ethnicity, marital status, and children, it is expected that UI coverage may also vary with workers’ demographic characteristics.

First, working women may be less likely to be covered by UI than working men because their labor force attachments (work hours and earnings) may differ from men's in ways that make them monetarily ineligible for benefits. For example, women are more likely to work part time, less likely to work overtime, and more likely to be absent from work than men. In 2015, women comprised 71.9 percent of part-time workers; women ages 25 to 54 worked less hours per week than men, 37.5 hours compared to 42.4 hours (BLS, 2016d); and twice as many women than men reported an absence from work in a given week, 1.6\% compared to 2.2\% (BLS, 2016a). Fewer work hours or frequent work interruptions may make it more difficult for working women to meet the monetary requirements necessary to qualify for UI benefits in the event of job loss. 
Earning less may also make it more difficult for women to meet monetary criteria. On average in 2015 women over the age of 25 had weekly wages of $\$ 752$ compared to \$922 for men (BLS, 2016b). Although women often earn less than men within the same occupations (Bielby \& Baron, 1986; Blau \& Kahn, 2007), women working in predominately female occupations also tend to earn less than males in predominately male occupations that require the same skills and level of education (England, 2005; Levanon, England, \& Allison, 2009). Consequently, even if they work a full forty-hour week, women may have more difficulty satisfying the earnings requirements than their male counterparts.

There is less reason to expect UI coverage (monetary eligibility) to vary by race and ethnicity. Existing literature suggests that although rates of UI receipt are lower for unemployed non-White workers relative to unemployed White workers, rates of monetary eligibility between the two groups are quite similar (Gould-Werth \& Shaefer, 2012). Nevertheless, any racial and ethnic differences in UI coverage would be cause for concern because non-White workers may ultimately have a greater need for UI. For example, Black workers tend to be at higher risk of unemployment (DOL, 2012) and black and Asian workers tend to experience longer spells of unemployment (Rothstein, 2013). Additionally, non-White workers may be disproportionately employed in lowwage jobs where scheduling changes from week to week and irregular work hours are common, which could affect their rates of UI coverage.

Of greater concern is access to UI among less-educated workers who often work in low-wage jobs (Gould-Werth \& Shaefer, 2013; Shaefer, 2010). ${ }^{6}$ Low-wage earners must work more hours to have the same earnings as high-wage earners, but they are also more likely to have non-traditional work hours, experience fluctuations in work hours

\footnotetext{
${ }^{6}$ According to the GAO (2011), approximately 60\% of low-wage earners have a high school diploma or less.
} 
from week to week, and experience unpaid work absences (Hill \& Ybarra, 2014; Kahne \& Mabel, 2010; Murnane, Bernhardt, \& Appelbaum, 2003). Consequently, the characteristics of these workers may put them at higher risk of unemployment but also at a lower probability of having coverage against unemployment.

Less-educated, low-wage workers may also be heavily concentrated in certain occupations and industries where employers reduce employees' hours rather than engage in formal layoffs when demand is low (Lambert, 2008). These flexible scheduling strategies can have important benefits for both employers and employees (Joyce, Pabayo, Critchley, \& Bambra, 2010). However, one unintended consequence may be the difficulty of establishing monetary eligibility for UI when workers become unemployed after a period in which their work hours (and wages) have been reduced.

Finally, factors such as age, marital status, and presence of children in the home may also influence workers' labor force participation patterns and earnings, and by extension rates of UI coverage. For example, rates of UI coverage may be lower among younger workers than older workers because young workers have shorter job tenures and tend to be underemployed based on their level of educational attainment (Abel, Deitz, \& Su, 2014). In 2014, the BLS reported that 7.9 years was the median tenure of workers ages 45 to 54, whereas 3.0 years was the median tenure of workers ages 25 to 34 (BLS, 2014a). Although a worker needs only a year of work history and earnings to qualify for UI, previous studies of UI receipt have found that the likelihood of take-up increases with job tenure (GAO, 2006) and age (Chan et al., 2014).

Rates of UI coverage may be higher among married workers. Married workers tend to earn more than non-married workers, a finding known as the marriage premium (de Linde Leonard \& Stanley, 2015; Killewald \& Gough, 2013). A GAO (2006) study found that unemployed married workers were 13 percent more likely to receive UI than 
unmarried workers. In addition to marriage, parenthood may also affect UI coverage, however the direction of this effect is less clear. Men’s wages have often been found to increase with fatherhood, whereas women's wages tend to decrease with motherhood (Budig \& England, 2001; Glauber, 2007; Killewald \& Gough, 2013). However, Shaefer and $\mathrm{Wu}(2011)$ find that monetary eligibility among unemployed single mothers increased more than monetary eligibility among unemployed single childless women following welfare reform.

Job characteristics and UI coverage. Because work history and earnings are used to determine monetary eligibility, workers' job characteristics certainly matter when it comes to UI coverage. Furthermore, factors such as part-time work, occupation, and industry are likely to attenuate demographic differences in UI coverage. For example, women are disproportionately represented among part-time workers; whereas non-White and less-educated workers are disproportionately employed in low-wage service occupations, and it is expected that these job characteristics influence labor force patterns more than the demographic characteristics of the workers themselves.

When it comes to UI coverage, part-time workers may have considerable difficulty establishing monetary eligibility for UI because working fewer hours may result in lower quarterly wages. In most cases part-time workers are subject to the same earnings and work history requirements as full-time workers (NELP, 2004). ${ }^{7}$ Several studies have found part-time work to be a barrier to UI among the unemployed (Chan et al., 2014; GAO, 2007; Gould-Werth \& Shaefer, 2013; Shaefer, 2010).

\footnotetext{
${ }^{7}$ Even if part-time workers do meet monetary eligibility criteria, they are often excluded from UI because of non-monetary eligibility criteria, specifically, requirements that claimants must be seeking full-time work. Prior to the Great Recession, about one-fifth of states had adopted provisions that allowed workers to claim benefits if they were seeking only part-time work. Following the Great Recession, the number of states with these provisions nearly tripled to 27 states (NELP, 2010).
} 
Requiring part-time workers to meet the same eligibility criteria as full-time workers may seem consistent with the intentions of UI policy to limit the availability of benefits to workers with strong recent labor force attachments. However, the exclusion of part-time workers from UI because of failure to meet monetary eligibility criteria is cause for concern if part-time work is a function of current labor market conditions rather than individual preferences. Studies of labor force participants following the Great Recession indicate that the number of workers working part time for economic reasons increased during the Great Recession and has not decreased appreciably in more recent years (Valletta \& Van Der List, 2015). If part-time workers do have significantly lower rates of monetary ineligibility, policies that broaden UI availability to part-time workers in all states may improve the responsiveness of the UI program to current labor market dynamics.

Previous research also indicates that UI receipt depends on the employment structure and employment dynamics across industry and occupation (Chan et al., 2014; GAO, 2006; Michaelides \& Mueser, 2013). With regard to UI coverage, I expect that a fairly high number of current workers in goods-producing industries, such as manufacturing, will be covered by UI. Goods-producing industries are associated with higher wages, cyclical employment patterns, and historic ties to the UI program (Michaelides \& Mueser, 2012). Conversely, I expect that fewer workers will be covered by UI in service-producing industries. Service industries are associated with lower average wages and fluctuating work schedules. In 2016, workers in goods-producing sectors had average weekly earnings of $\$ 1,083$, whereas workers in service-producing sectors had average weekly earnings of \$845 (BLS, 2016f). In 2015, the average total hours at work as 33.9 for workers in leisure and hospitality and 42.0 for workers in manufacturing (BLS, 2015). 
In addition to industry, occupation plays a large role in determining hours worked and earnings, so I expect that rates of UI coverage will vary by occupation as well. In 2014, median wages across occupations range from $\$ 19,130$ for food preparation and serving occupations to $\$ 97,230$ for management-related occupations (BLS, 2014b). In 2016, workers in service occupations had an average 34.7 hours per week compared to an average of 40.3 hours per week in management-related occupations (BLS, 2016c).

Changes to the structure of employment, i.e. declines in employment in heavy manufacturing and increases in employment in service-producing industries, and changes to the organization of work, i.e. rises in contingent work and flexible work strategies, raise important questions about how much control workers have over their work hours and earnings. For example, unlike employers in manufacturing industries, employers in service-producing industries may reduce employees’ hours rather than engage in formal layoffs to offset changes in demand (Lambert, 2008). Using data from the 2001 Current Population Survey, Lambert, Haley-Lock, and Henly (2012) report that more than onefourth of women and nearly two-thirds of men working in hourly-wage jobs would prefer to have more hours at work.

Additionally, low-wages and flexible scheduling practices tend to couple together. Certain service-related occupational groups, particularly food preparation and serving occupations, are typically characterized by low wages, limited work hours, and irregular job-scheduling practices (Prywes, 2000). Presumably the combination of such job characteristics would make satisfying states’ monetary eligibility criteria difficult for workers. However, it is not clear that ineligibilities for UI due to volatilities in work hours and earnings that stem from employer behaviors are in keeping with what policy makers have intended in their efforts to limit access to UI benefits. Nor is it clear that 
these workers and their households would not benefit from the income stabilizing effects of UI receipt in the event of job loss.

Policy changes and UI coverage. Finally, rates of UI coverage among employed workers may have been affected by the group of policy changes to state eligibility rules that followed the Great Recession. Through the Unemployment Insurance Modernization Act (UIMA) of the American Recovery and Reinvestment Act of 2009 (ARRA09), the federal government encouraged the modernization of state UI programs by setting aside $\$ 7$ billion dollars to be allocated across states conditional on changes to eligibility criteria (Whittaker \& Isaacs, 2014). In order to receive the first half of their share of the $\$ 7$ billion dollar stimulus funds, states were required to adopt an alternative base period (ABP) when making eligibility determinations. ${ }^{8}$ These policy changes were intended to expand access to UI, but there is limited evidence as to whether this occurred (GouldWerth \& Shaefer, 2013; O'Leary, 2011; Shaefer, 2010).

I are particularly interested in whether expansions of monetary eligibility criteria through states' adoptions of the alternative base period rule reduced wage and work history barriers to UI. Most states calculate eligibility for UI using work hours and earnings from a standard base period, defined as the first four of the five calendar quarters prior to unemployment. States that have an alternative base period rule can calculate eligibility for UI using work hours and earnings from the four quarters prior to unemployment when an individual fails to qualify for UI based on earnings and work hours from traditional base period (DOL, 2015).

\footnotetext{
${ }^{8}$ To receive the second portion of the federal stimulus funding, state governments could alter their eligibility determinants to allow displaced workers who were seeking part-time employment to claim benefits. Alternatively, states could provide additional benefits to permanently laid-off workers who were participating in job training programs, expand reasons for terminating employment that qualified as good cause, or incorporate dependent allowances into weekly benefit amounts (NELP, 2010; O'Leary, 2011).
} 
If expansions in monetary eligibility were successful in reducing wage and work history barriers to UI, I would expect rates of UI coverage to increase when I estimate monetary eligibility using both the standard base period definition and the alternative base period definition (in states where the rule applies). Approximately 19 programs in the UI system had adopted ABP rules prior to the Great Recession. Following the EUC08 legislation, an additional 21 states or territories adopted ABP rules (Gould-Werth \& Shaefer, 2013; O'Leary, 2011). Only ten states do not have ABP rules: Alabama, Arizona, Florida, Indiana, Mississippi, Missouri, North Dakota, Pennsylvania, Texas, and Wyoming. ${ }^{9}$

In the following section, I use data from the 2008 panel of the Survey of Income and Program Participation (SIPP) to estimate rates of monetary eligibility for UI among current workers by major demographic and job group from October 2009 to March 2013. This analysis documents the extent to which monetary eligibility criteria maximize UI coverage across the diverse population of workers at risk of unemployment. Of special concern is the program's reach to workers who face other disadvantages in the labor market, including women, less-educated workers, and part-time workers. Although these workers would likely benefit from the income stabilizing effects of UI receipt, economic instability prior to unemployment, particularly volatilities in work hours and earnings, may make them less likely to be covered by UI.

\section{Data and Methods}

Data. The 2008 SIPP panel is a longitudinal survey of a nationally representative sample of over 100,000 individuals in approximately 42,000 households conducted by

\footnotetext{
${ }^{9}$ Twenty-three states also have an extended base period that allows individuals to claim UI benefits if they have been unemployed during the traditional base period due to illness or injury. The extended base period (EBP) is typically defined as the four completed quarters prior to the standard base period. For the analysis I only estimate the effects of ABP rules.
} 
the Census Bureau and the Bureau of Labor Statistics. Respondents in the 2008 panel were interviewed either in person or by telephone every four months over the course of five years beginning in September 2008. In each wave of the interview, respondents age 15 and older were asked a set of core questions on labor-force participation, income, public-program participation, and demographics. Additionally, different waves of interviews contained questions on topics such as fertility, poverty, child care, and tax rebates, which were repeated with less frequency than the core interview questions.

Because it is possible to observe changes in respondents' employment behavior such as hours worked, wages earned, entry and exits from employment, and reasons for work absences or exits over time, the structure of SIPP is ideal for examining labor-force dynamics. Because of the sampling structure and the repetition of core interview questions over the duration of the survey, SIPP data can also be used as a sample of repeated cross-sections. I rely on the longitudinal structure of the SIPP to identify workers’ prior earnings and employment patterns; however, I treat the data as pooled cross-sections for the analysis.

Although the SIPP provides information about work history and thus allows employment patterns and eligibility for UI to be captured, as longitudinal survey data it also presents challenges. One challenge is attrition. Certain groups, such as low-income individuals drop out of the survey at higher rates than others, making attrition problematic because it is non-random (Czajka, Mabli, \& Cody, 2008; Vaughan \& Scheuren, 2002). To correct for attrition, I use person-level weights in the analysis, i.e., as individuals exit the survey, those who remain and have characteristics similar to those who have exited are given greater weight.

Another challenge when using panel data is seam bias. Individuals tend to report events and changes more often in the reporting month of a survey and less often the 
further they are asked to look back. The result is that when patterns are observed over time, transitions in employment, earnings, and program participation appear with greater frequency between the reporting month of an interview and the earliest reference month of the subsequent interview. One approach to correcting for seam bias is to collapse monthly observations into observations by wave, keeping only the information from the reporting month (Ham, Li, \& Shore-Sheppard, 2009). However, because monetary eligibility for UI is determined based on quarterly work history and earnings (aggregated from monthly reports), this approach is not possible, which may be a limitation of the study. ${ }^{10}$

Sample. In order to construct the sample, I used the first 14 waves of the SIPP 2008 panel to identify all individuals 1) who were part of the US civilian population, 2) who were between the ages of twenty-five and fifty-five (the ages at which individuals are expected to have their strongest attachments to the labor force), and 3) who were not active duty military. I then restricted this sample to individuals 4) who were employed in each month of the quarter in which monetary eligibility for UI was estimated, and 5) who had any labor force participation in the prior five quarters. ${ }^{11} \mathrm{I}$ excluded individuals who were currently employed but did not participate in the labor force in the five prior quarters. I also excluded individuals who were currently employed but did not participate continuously in the SIPP in during the prior five quarters.

The fourth quarter of 2009 was the first quarter where it was possible to determine which individuals met these conditions. I then identified the individuals who met these conditions in each subsequent quarter, and I allowed individuals to be included in the

\footnotetext{
${ }^{10}$ I collapse reference month observations into quarters (three-month periods). For each rotation group in the SIPP, there is one quarter in each year where monthly observations do not cross waves or do not contain responses from a reporting month.

${ }^{11}$ Workers continuously employed in a quarter had a job the entire month (but could have been absent from work with or without pay) for all three months of a quarter. The definition of any labor force participation includes any employment or unemployment in the five prior quarters.
} 
sample in each quarter that the above conditions were observed. Although eligibility determination depends on an individual's earnings and work history reports in the prior five quarters, I treat the estimates of eligibility in each quarter as independent from the estimates of eligibility in the prior quarter (i.e. as though in each quarter a new, nationally representative sample was drawn from the population). As a result, the main sample includes 25,500 individuals, slightly more than a quarter of all individuals interviewed in the SIPP, who contribute a minimum of one, a maximum of 15 , and a median of seven person-quarters to the study. ${ }^{12}$

Methods. I use the following reduced-form equation to obtain national-level estimates of employed workers' coverage against the risk of unemployment:

$$
\operatorname{Pr}\left(U I E_{i j t}=1 \mid X\right)=F\left(\alpha+W_{i t} \beta+\pi_{j}+\varphi_{t}\right),
$$

where $U I E_{i j t}$ is an indicator equal to 1 if a current worker $(i)$ residing in state $(j)$ at time $(t)$ is monetary eligibility for UI benefits, $\boldsymbol{X}$ is a vector of all independent variables included in the model, and $F$ is the standard normal cumulative distribution function (probit link). In the argument, $\boldsymbol{W}_{i t}$ is a vector of individual demographic characteristics, $\pi_{j}$ is a vector of binary indicators for each state, $\varphi_{t}$ is a vector of binary indicators for each quarter. Standard errors are clustered at the individual level to account for within-person autocorrelation that occurs due to repeated observations for individuals across quarters.

For each individual, I determine quarterly monetary eligibility for UI $\left(U I E_{i j t}=1\right)$ by comparing an individual's reported work history from their primary job

\footnotetext{
${ }^{12}$ I report descriptive statistics and rates of monetary ineligibility for the sample in Table 1 . I report descriptive statistics and rates of monetary ineligibility for the full sample of employed workers (30,762 unique individuals), including those who did not continuously participate in the SIPP and those who did not have any prior labor force attachments, in the appendix (Table 8).
} 
and total monthly earnings ${ }^{13}$ from all jobs in the first four of the five prior quarters ${ }^{14}$ to state monetary eligibility determinants that are provided in the Significant Provisions of State UI Laws, published online and updated annually by the US Department of Labor (DOL, 2015).

I followed each of the states’ primary qualifying formulas in each year as closely as possible and relied on the minimum wage amounts needed to qualify in the high quarter and the base period available in the monetary entitlement tables from the Significant Provision of State UI Laws to verify the calculations. ${ }^{15}$ For example, I coded an individual living in Missouri in 2009 as monetarily eligible for UI if she had total earnings in the first four of the five prior quarters that were 1.5 times greater than her highest quarter earnings in the first four of the five prior quarters, and if she had high quarter earnings greater than $\$ 1,500$ and total earnings equal to or greater than $\$ 2,250$. I coded an individual living in Kansas in 2009 as monetarily eligible if she had earnings in the first four of the five prior quarter that were 30 times greater than the minimum weekly benefit amount of $\$ 105$ (total earnings greater than or equal to $\$ 3150$ ) and earnings in at least two quarters. ${ }^{16}$

A vector of demographic characteristics $\left(\boldsymbol{W}_{i t}\right)$ includes binary indicators of sex (female=1), race and ethnicity (non-Hispanic white, non-Hispanic black, Asian, Other Race, or Hispanic of any race), education (less than a high school diploma; a high school

\footnotetext{
${ }^{13}$ Total monthly earnings from all jobs is obtained from the SIPP variable TPEARN, total person's earned income for the reference month.

${ }^{14}$ Two states, Massachusetts and Minnesota, use the prior four quarters as their standard base periods. I used the first four of the five prior quarters as the standard base period for all states and the four prior quarters as the alternative base period in states with ABP rules.

${ }^{15}$ I excluded Washington State from the analysis. Washington uses only hours of employment to determine monetary eligibility, requiring 680 hours of employment during the base period.

${ }^{16}$ For states that base eligibility on a flat amount, I used statewide average weekly wages available from the Quarterly Census of Employment (BLS, 2016e) and state minimum wages (DOL, 2016) where applicable. For states that used a worker's own average weekly wage to determine benefit eligibility, such as New Jersey, I based eligibility on the minimum wage amounts needed in the high quarter and base period to qualify for benefits and I used employment in at least two quarters as a proxy for 20 weeks of employment.
} 
diploma and no further education; a high school diploma and some college, including vocational training; or a four-year college degree or higher), marital status (never married, married, divorced or separated, or widowed), children in the household under 18 (yes=1), and age (25 to 34, 35 to 44,45 to 55 ). I categorize age into three groups in order to compare workers at the early stages of their work tenures with mid-career and latecareer workers and capture how the relationship between age and UI eligibility differs during different stages of the life course.

Because there is good reason to expect that labor force characteristics such as part-time work, industry, and occupation have a strong relationship with workers labor force attachments and by extension their rates of UI coverage, I include a vector of individual job characteristics, $\boldsymbol{Z}_{i t}$, to the equation 1 , so that

$$
\operatorname{Pr}\left(U I E_{i j t}=1 \mid \boldsymbol{X}\right)=F\left(\alpha+\boldsymbol{W}_{i t} \beta+\boldsymbol{Z}_{i t} \gamma+\boldsymbol{\pi}_{j}+\boldsymbol{\varphi}_{t}\right) .
$$

A vector of job characteristics includes a binary indicator for part-time work (yes $=1$ ) if a workers reports working less than 35 hours a week at their primary job at any time during the quarter. I also include binary indicators for the industry (13 industries) and occupational classifications (23 occupations) of respondents' primary jobs. I list industry and occupational groups in the appendix (Table 6). ${ }^{17}$

\section{Results}

In Table 1 I report quarterly averages of the percentage of current workers in the sample in each major demographic group. ${ }^{18}$ In each quarter between October 2009 and March 2013, on average $49.50 \%$ of the workers in the sample were female. This

\footnotetext{
${ }^{17}$ I combine occupation and industry into 248 categories for sensitivity analysis..

${ }^{18}$ The descriptive characteristics of the sample of current workers should approximate the characteristics of the experienced employed labor force. The sample is not intended to be representative of the total labor force (employed and unemployed workers).
} 
percentage is slightly higher than BLS reports that women represented about 48 percent of the employed labor force in 2010 (DOL, 2011).

\section{Table 1. Summary Statistics}

\begin{tabular}{|c|c|c|}
\hline & Sample Characteristics & Monetary Ineligibility \\
\hline \multicolumn{3}{|l|}{ Gender*** } \\
\hline Male & $50.50 \%$ & $3.20 \%$ \\
\hline Female & $49.50 \%$ & $5.35 \%$ \\
\hline \multicolumn{3}{|l|}{ Race \& Ethnicity *** } \\
\hline White Non-Hispanic & $70.81 \%$ & $4.22 \%$ \\
\hline Hispanic of Any Race & $12.30 \%$ & $4.04 \%$ \\
\hline Black Non-Hispanic & $9.83 \%$ & $4.81 \%$ \\
\hline Asian & $4.53 \%$ & $3.65 \%$ \\
\hline Other Race & $2.52 \%$ & $5.56 \%$ \\
\hline \multicolumn{3}{|l|}{ Age $e^{* * *}$} \\
\hline 45 to 55 & $40.43 \%$ & $4.04 \%$ \\
\hline 35 to 44 & $32.73 \%$ & $3.83 \%$ \\
\hline 25 to 34 & $26.81 \%$ & $5.14 \%$ \\
\hline \multicolumn{3}{|l|}{ Educational Attainment*** } \\
\hline Less than High School & $6.79 \%$ & $6.78 \%$ \\
\hline Graduated High School & $21.96 \%$ & $5.54 \%$ \\
\hline Some College & $34.37 \%$ & $4.39 \%$ \\
\hline Bachelor’s Degree or Higher & $36.89 \%$ & $2.93 \%$ \\
\hline \multicolumn{3}{|l|}{ Marital Status*** } \\
\hline Married & $64.26 \%$ & $3.75 \%$ \\
\hline Never Married & $21.18 \%$ & $5.44 \%$ \\
\hline Divorced/Separated & $13.48 \%$ & $4.61 \%$ \\
\hline Widow & $1.07 \%$ & $5.89 \%$ \\
\hline \multicolumn{3}{|l|}{ Children under 18 in Household } \\
\hline No & $47.91 \%$ & $4.24 \%$ \\
\hline Yes & $52.09 \%$ & $4.29 \%$ \\
\hline Observations (Avg. N) & 12,430 & \\
\hline
\end{tabular}

Notes: Quarterly averages from October 2009-March 2013. Sample restricted to US civilian population, age 25-55, with continuous employment during the quarter in which eligibility is simulated, who participated in the labor force anytime in the base period, and who participated continuously in the SIPP in the previous five quarters. Statistical significance for chi-square test of association by group, ${ }^{* * *} \mathrm{p}<0.001$, ${ }^{* *} \mathrm{p}<0.01,{ }^{*} \mathrm{p}<0.05$.

More than two-thirds of the workers in the sample were non-Hispanic white, 12.30\% were Hispanic of any race, and 9.83\% are non-Hispanic black. Additionally, 
$40.43 \%$ of the sample were between the ages of 45 and 55, 32.73\% were 35 to 44 , and about $26.81 \%$ were 25 to 34 .

Most workers in the sample were college graduates (36.89\%), followed by those with some college (34.37\%). Slightly more than one fifth of workers in the sample were high school graduates, and fewer than $7 \%$ of workers had less than a high school diploma. Almost two-thirds of workers in the sample were married, $21.18 \%$ were never married, and less than 14\% were divorced or separated. More than half (52.09\%) of workers in the sample lived in a household with children under the age of 18.

Figure 2. Monetary Ineligiblity for UI by Quarter

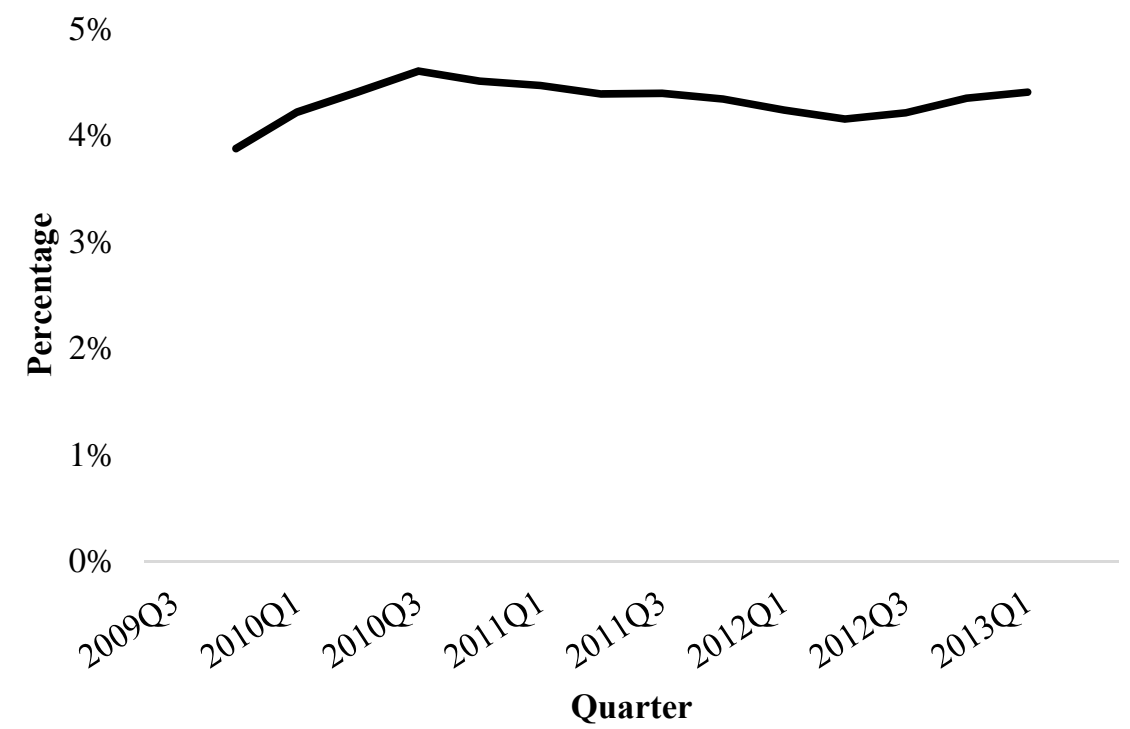

Notes: Author's own estimates from 2008 Survey of Income and Program Participation. Moving average of percentage of current workers monetary ineligible for UI by quarter. Current workers defined as individuals with continuous employment in the quarter in which eligibility is simulated, any labor force participation in the base period, and continuous participation in the SIPP in the prior five quarters.

After estimating monetary eligibility using state UI eligibility formulas, I find that on average 95\% of current workers were covered by UI. Figure 2 shows quarterly rates of monetary ineligibility for workers in the sample between October 2009 and March 2013. The rate of ineligibility remains fairly stable (between 4\% and 5\%) during the period, with a slight increase in ineligibility in the first three quarters of 2010 and again in 2012. 
Given that over 7 percent of current workers in the sample were unemployed at some point between October 2009 and June of 2013, with the highest rates of unemployment (8.42\%) in the first quarter of 2010 at the peak of the Great Recession, these estimates suggest that the UI program protects most workers against the risk of job loss.

Table 1 also reports the percentage of monetarily ineligible employed workers within each demographic group. These unadjusted quarterly averages suggest that female workers are nearly twice as likely to be ineligible for UI as male workers. In each quarter about $5.35 \%$ of female workers were ineligible for UI, compared to $3.20 \%$ of males.

I find that Hispanic workers of any race, non-Hispanic white workers, and nonHispanic black workers have similar rates of ineligibility, 4.04\%, 4.22\%, and 4.81\% respectively. Whereas, Asian workers have the lowest rates of ineligibility (3.65\%) and workers indicating other race have the highest rates (5.56\%). I find slightly greater differences in ineligibility for UI by education. College graduates have the lowest rates of ineligibility (2.93\%), followed by workers with some college (4.39\%), and then workers with a high-school diploma and no further education (5.54\%). As expected, workers with less than a high school diploma have the highest rates of ineligibility (6.78\%).

With regard to age differences, in Table 1 I observe the highest rates of ineligibility among the youngest group of workers, 5.14\% percent. Whereas, only 3.83\% of workers ages 35 to 44 are ineligible and $4.04 \%$ of workers ages 45 to 55 are ineligible. With regard to marital status, I observe higher rates of ineligibility among workers never married (5.44\%) and widowed (5.89\%), compared to those divorced or separated (4.61\%) or married (3.75\%). Finally, with regard to parenthood, rates of ineligibility are quite similar for workers with children under the age of 18 in their households (4.29\%) and workers without children in their households (4.24\%). 
Probit analysis. In Table 2 I report marginal effects from models predicting monetary eligibility for UI among employed workers. The marginal effect can be interpreted as the expected change in the likelihood of monetary eligibility for UI due to a discrete change in the category of the independent variable, holding all other variables at their means. In Model 1 I regress the probability of monetary eligibility on the demographic characteristics of workers. In Model 2 I regress the probability of monetary eligibility on both the demographic and job characteristics of workers. I include state and quarterly time dummies and person-level weights in both models, and I cluster standard errors at the individual level to account for repeated observations of individuals in different quarters. ${ }^{19}$

Recall that because women on average work fewer hours and earn less than men, I expect that working women will have lower rates of monetary eligibility than working men. Consistent with this expectation, when I account only for current workers’ demographic characteristics, I find that women are 2.4 percentage points less likely to be monetarily eligible for UI than men (see Table 2, Model 1). Once I control for current job characteristics, this difference remains significant but reduces to 1.1 percentage points (see Table 2, Model 2).

Although I do not expect to observe differences in monetary eligibility among employed workers by race and ethnicity, when I account for demographic characteristics only, I find that Hispanic workers of any race are 1.5 percentage points more likely to be eligible for UI than non-Hispanic white workers (Model 1). Once I account for workers’

\footnotetext{
${ }^{19}$ For sensitivity analysis, I estimated model 1 and model 2 using Stata's svy commands to ensure that I had properly accounted for the complex sampling structure of the SIPP. The results (point estimates and standard errors) were very similar for model 1 and nearly identical for model 2 . The results are available from the author upon request.
} 
job characteristics, I find that Hispanic workers are still more likely (.8 percentage points) to be monetarily eligible for UI than non-Hispanic white workers (Model 2).

Table 2. Predicting Monetary Eligibility for Employed Workers

\begin{tabular}{|c|c|c|c|c|c|c|c|}
\hline \multirow{2}{*}{ Variables } & \multirow[b]{3}{*}{ Female } & \multicolumn{3}{|c|}{ Model 1} & \multicolumn{3}{|c|}{ Model 2} \\
\hline & & Marginal & Effects & SE & Marginal & ffects & $\mathrm{SE}$ \\
\hline Gender (Male) & & -0.024 & $* * *$ & 0.002 & -0.011 & $* * *$ & 0.002 \\
\hline Race/Ethnicity & Hispanic & 0.015 & $* * *$ & 0.003 & 0.008 & $*$ & 0.003 \\
\hline \multirow[t]{3}{*}{ (White Non-Hispanic) } & Black Non-Hispanic & 0.004 & & 0.003 & -0.000 & & 0.003 \\
\hline & Asian & 0.002 & & 0.005 & -0.008 & & 0.005 \\
\hline & Other Race & -0.008 & & 0.005 & -0.005 & & 0.005 \\
\hline \multirow[t]{2}{*}{ Age (45 to 55) } & 35 to 44 & 0.003 & & 0.002 & 0.006 & * & 0.002 \\
\hline & 25 to 34 & -0.008 & $* * *$ & 0.002 & -0.004 & & 0.002 \\
\hline Educational & Less than High School & -0.044 & $* * *$ & 0.004 & -0.013 & $* *$ & 0.005 \\
\hline \multirow{3}{*}{$\begin{array}{l}\text { Attainment } \\
\text { (BA or Higher) }\end{array}$} & & & & & & & \\
\hline & High School Diploma & -0.030 & $* * *$ & 0.003 & -0.010 & $* *$ & 0.003 \\
\hline & Some College & -0.017 & $* * *$ & 0.002 & -0.004 & & 0.003 \\
\hline Marital Status & Never Married & -0.016 & $* * *$ & 0.003 & -0.012 & $* * *$ & 0.002 \\
\hline \multirow{2}{*}{ (Married) } & Divorced/Separated & -0.006 & & 0.003 & -0.001 & & 0.003 \\
\hline & Widowed & -0.013 & & 0.009 & -0.012 & & 0.009 \\
\hline Children (No) & Yes & -0.006 & $* *$ & 0.002 & -0.005 & * & 0.002 \\
\hline Part-time Work (No) & Yes & & & & -0.053 & $* * *$ & 0.002 \\
\hline Industry & Educational Services ${ }^{\mathrm{a}}$ & & & & -0.008 & & 0.005 \\
\hline \multirow[t]{11}{*}{ (Manufacturing) } & Retail Trade & & & & -0.019 & $* * *$ & 0.005 \\
\hline & Professional \& Management Services ${ }^{\mathrm{b}}$ & & & & -0.024 & $* * *$ & 0.005 \\
\hline & Arts, Entertainment, \& Recreation Services & & & & -0.019 & $* * *$ & 0.005 \\
\hline & Finance, Insurance, \& Real Estate & & & & -0.009 & & 0.005 \\
\hline & Public Administration & & & & 0.007 & & 0.007 \\
\hline & Construction & & & & -0.021 & $* *$ & 0.008 \\
\hline & Transportation \& Warehousing, \& Utilities & & & & -0.003 & & 0.005 \\
\hline & Other Services & & & & -0.022 & $* * *$ & 0.006 \\
\hline & Wholesale Trade & & & & -0.002 & & 0.007 \\
\hline & Information & & & & 0.002 & & 0.007 \\
\hline & Agriculture $^{c}$ & & & & -0.063 & $* * *$ & 0.009 \\
\hline Occupation & Office \& Administrative Support & & & & 0.002 & & 0.005 \\
\hline \multirow[t]{21}{*}{ (Production) } & Sales & & & & -0.003 & & 0.005 \\
\hline & Management & & & & 0.019 & ** & 0.006 \\
\hline & Education, Training, \& Library & & & & 0.004 & & 0.006 \\
\hline & Food Preparation \& Serving & & & & -0.006 & & 0.007 \\
\hline & Healthcare Practitioners \& Technical & & & & 0.026 & $* * *$ & 0.007 \\
\hline & Construction \& Extraction & & & & 0.009 & & 0.008 \\
\hline & Building \& Grounds Cleaning \& Maintenance & & & & -0.007 & & 0.006 \\
\hline & Business \& Financial & & & & 0.023 & $* * *$ & 0.006 \\
\hline & Transportation & & & & -0.001 & & 0.006 \\
\hline & Installation, Maintenance, \& Repair & & & & 0.009 & & 0.007 \\
\hline & Personal Care \& Services & & & & -0.024 & $* * *$ & 0.006 \\
\hline & Material Moving & & & & -0.016 & * & 0.007 \\
\hline & Healthcare Support & & & & -0.007 & & 0.007 \\
\hline & Computer \& Mathematical & & & & 0.031 & ** & 0.010 \\
\hline & Protective Service & & & & -0.004 & & 0.008 \\
\hline & Architecture \& Engineering & & & & 0.037 & $* * *$ & 0.008 \\
\hline & Community \& Social Service & & & & 0.021 & * & 0.008 \\
\hline & Arts, Design, Entertainment, Sports, \& Media & & & & 0.015 & & 0.008 \\
\hline & Farming, Fishing, \& Forestry & & & & 0.006 & & 0.013 \\
\hline & Life, Physical, \& Social Sciences & & & & 0.044 & $* * *$ & 0.011 \\
\hline & Legal & & & & 0.018 & & 0.010 \\
\hline \multicolumn{2}{|l|}{$\begin{array}{l}\text { Observations } \\
\text { (Clusters) }\end{array}$} & \multicolumn{3}{|c|}{$186,454(25,500)$} & \multicolumn{3}{|c|}{$186,454(25,500)$} \\
\hline
\end{tabular}

Notes: Time and state dummies included in regression analysis, but suppressed in output. Marginal effects shown with robust standard errors; ${ }^{* * *} \mathrm{p}<0.001,{ }^{* *} \mathrm{p}<0.01,{ }^{*} \mathrm{p}<0.05$. Sample restricted to US civilian labor force, age $25-55$, with continuous employment during the quarter in which eligibility is simulated, any labor force participation in the base period, and continuous participation in the SIPP in the previous five quarters. ${ }^{a}$ Educational services, health care, and social assistance. ${ }^{b}$ Professional, scientific, management, and administrative services. ${ }^{\mathrm{c}}$ Agriculture, forestry, fishing \& hunting, \& mining. 
As noted, of special concern are less-educated workers in low-wage jobs. These individuals must work more hours in order to have earnings similar to high-wage earners and in order to have earnings high enough to be monetarily eligible for UI if they become unemployed. Yet, educational variation in UI coverage is not as wide as one might expect. Controlling only for other demographic characteristics (Table 2, Model 1), relative to workers with bachelor's degrees or higher, workers with less than a high school diploma are 4.4 percentage points less likely to be monetarily eligible for UI, workers with high school diplomas are 3.0 percentage points less likely to be eligible for UI, and workers with some college are 1.7 percentage points less likely to be eligible for UI. Furthermore, the magnitudes of these differences shrink (to 1.3, 1.0, and .4 percentage points respectively) when I control for the job characteristics of workers (Table 2, Model 2). These findings suggest that much of the initially observed relationship between education and UI eligibility may be mediated by the job characteristics of workers and the association between these job characteristics and UI eligibility.

I also hypothesize that younger workers will be less likely to be eligible for UI than older workers. Following the Great Recession, older workers had job tenures nearly twice as long on average as younger workers (BLS, 2016) and many younger workers were underemployed based on their level of education (Abel et al., 2014). When I account for demographic characteristics (Table 2, Model 1), workers ages 25 to 34 are 0.8 percentage points less likely to be eligible for UI than workers ages 45 to 55 . I find no statistically significant difference in UI eligibility between workers ages 35 to 44 and workers ages 45 to 55 . When I account for workers' job characteristics (Table 2, Model 2), I find no statistically significant differences between workers ages 25 to 34 and workers ages 45 to 55, however I find that workers ages 35 to 44 are .6 percentage points more likely to be eligible for UI. 
Consistent with the expectation that being married may increase the likelihood of monetary eligibility, never-married employed workers are 1.6 percentage points less likely to be monetarily eligible for UI than married workers (Table 2, Model 1). This difference shrinks to 1.2 percentage points when I account for the job characteristics of workers (Table 2, Model 2). Contrary to the expectation that the presence of children in the household may increase the likelihood that a worker is monetary eligibility for UI, I find that workers in households with children under the age of 18 are less likely to be monetarily eligible for UI than workers without children in the household. The difference is small (.6), but statistically significant in both models.

Also in Table 2 I report differences in monetary eligibility by part-time work status, industry, and occupation. With regard to part-time work status, I expect that parttime workers will be less likely to be monetarily eligible for UI than full-time workers because individuals who work fewer hours per week are likely to have lower earnings than individuals who work more hours per week. Consistent with this expectation, I find that part-time workers in the sample are 5.3 percentage points less likely to be eligible for UI than full-time workers.

I report industry differences in monetary eligibility relative to the manufacturing sector. Employers and workers in manufacturing have historically been the most reliant on the UI program. Although trends over the past thirty years indicate an overall decline in employment in manufacturing, the sector continues to be associated with higher rates of business-cycle volatility than the service sector (Michaelides \& Mueser, 2013). Conversely, employers in service producing industries may rely less on the UI program because they are less likely to engage in formal layoffs to reduce labor costs. As expected most other industries do not appear to have statistically significant higher rates of eligibility than the manufacturing sector. However, the three service industries 
(professional, scientific, management, and administrative services, arts, entertainment, and recreation services, and other services) have rates of monetary eligibility about 2 percentage points lower than workers in manufacturing (see Table 2).

I report occupational differences in monetary eligibility relative to production occupations. I select production occupations as the omitted occupational groups because these occupations are associated with unionization and with business cycle volatility (Berman \& Pfleeger, 1997) workers in production occupations may be more reliant on the UI program. Workers in office and administrative service; sales; education, training, and library; food preparation and serving; construction and extraction; transportation; healthcare support; protective service; material moving; and farming, fishing, and forestry occupations all have likelihoods of monetary eligibility for UI similar to production occupations. In contrast, management; healthcare practitioners and technical; business and financial; computer and mathematical; architecture and engineering; and community and social service occupations all have rates of monetary eligibility about between 2 and 4 percentage points higher than production occupations. Personal care and service occupations and installation, maintenance, and repair occupations have lower likelihoods of UI eligibility than production occupations (Table 2). Although ineligibility is likely driven by a combination of work interruptions or lower earnings, it is worth nothing that the median annual wage for personal care and service occupations is $\$ 21,260$, about $\$ 10,000$ less than the median annual wage for production occupations, the omitted group (BLS, 2014b).

Policy changes. Next, I turn to examining the effect that post-recession policy changes had on UI coverage. Under the ARRA, the primary change to states' monetary eligibility criteria was the adoption of an alternative base period (ABP) rule where monetary eligibility could be determined based on earnings and work hours in the four 
quarters prior to unemployment when individuals failed to qualify for UI based on earnings and work hours from the first four of the five prior quarters (standard base period).

In order to examine whether state ABP implementations increase rates of UI coverage, I created an indicator of monetary eligibility under the ABP (UIE_ABP) equal to 1 if an individual living in a state $(j)$ in quarter $(t)$ was monetary eligibility for UI based on their earnings and work history in the four prior quarters provided that state $(j)$ had adopted an ABP rule at quarter $(t) .{ }^{20}$ I then combined this indicator with the original indicator of monetary eligibility based on the standard base period to estimate equation 3 .

$$
P R\left(U I E_{-} B o t h_{i j t} \mid X\right)=F\left(\alpha+\boldsymbol{W}_{i t} \beta+\boldsymbol{Z}_{i t} \gamma+\boldsymbol{\pi}_{j}+\boldsymbol{\varphi}_{t}\right),
$$

In equation 3, UIE_Both $h_{i j t}$ is equal to one if a currently working individual (i) in state $(j)$ at quarter $(t)$ is eligible for UI under the standard base period (UIE=1) or under the alternative base period $\left(U I E \_A B P=1\right)$. All explanatory variables are the same as equation 2. Standard errors are clustered at the individual level.

Table 3 reports the change in the percentage of workers ineligible for UI after state ABP expansions. ${ }^{21}$ Overall, the percentage of workers ineligible for UI decreased by .9 percentage points (20\%) with the inclusion of the alternative base period rules. For women, rates of monetary ineligibility decreased by 1.03 percentage points (or 18\%). For black non-Hispanic workers, Asian workers, and workers reporting other race, rates of ineligibility all decreased by more than one percentage point (or by $25.07 \%, 29.41 \%$, and $25.77 \%$ respectively).

\footnotetext{
${ }^{20}$ For all states that implemented the ABP, I used the last four quarters prior to unemployment as the alternative based period. Vermont defines the ABP as the three prior quarters plus any weeks of work in the quarter in which a claim is filed or as the prior four quarters. Massachusetts also includes earnings from the quarter of unemployment in their ABP definition.

${ }^{21}$ Probit regression results from model 3 are reported in the appendix (Table 9).
} 
Table 3. Change in the Percentage of Workers Ineligible for UI after ABP

\begin{tabular}{|c|c|c|c|c|}
\hline & $\begin{array}{c}\text { \% Ineligible under } \\
\text { Traditional BP }\end{array}$ & $\begin{array}{l}\text { \% Ineligible under } \\
\text { ABP \& BP }\end{array}$ & $\begin{array}{l}\text { Percentage Point } \\
\text { Difference }^{\mathrm{a}}\end{array}$ & $\begin{array}{l}\text { Percentage } \\
\text { Decrease }\end{array}$ \\
\hline Overall & $4.53 \%$ & $3.63 \%$ & 0.90 & $19.84 \%$ \\
\hline \multicolumn{5}{|l|}{ Gender } \\
\hline Male & $3.47 \%$ & $2.70 \%$ & 0.77 & $22.19 \%$ \\
\hline Female & $5.60 \%$ & $4.57 \%$ & 1.03 & $18.38 \%$ \\
\hline \multicolumn{5}{|l|}{ Race \& Ethnicity } \\
\hline White & $4.40 \%$ & $3.60 \%$ & 0.80 & $18.27 \%$ \\
\hline Hispanic of Any Race & $4.36 \%$ & $3.57 \%$ & 0.78 & $17.99 \%$ \\
\hline Black Non-Hispanic & $5.46 \%$ & $4.09 \%$ & 1.37 & $25.07 \%$ \\
\hline Asian & $4.08 \%$ & $2.88 \%$ & 1.20 & $29.41 \%$ \\
\hline Other Race & $5.74 \%$ & $4.26 \%$ & 1.48 & $25.77 \%$ \\
\hline \multicolumn{5}{|l|}{ Age } \\
\hline 45 to 55 & $4.21 \%$ & $3.49 \%$ & 0.72 & $17.11 \%$ \\
\hline 35 to 44 & $3.87 \%$ & $3.08 \%$ & 0.80 & $20.54 \%$ \\
\hline 25 to 34 & $5.64 \%$ & $4.40 \%$ & 1.24 & $21.91 \%$ \\
\hline \multicolumn{5}{|l|}{ Educational Attainment } \\
\hline Less than High School & $6.85 \%$ & $5.77 \%$ & 1.08 & $15.80 \%$ \\
\hline Graduated High School & $5.84 \%$ & $4.88 \%$ & 0.96 & $16.40 \%$ \\
\hline Some College & $4.66 \%$ & $3.67 \%$ & 0.99 & $21.32 \%$ \\
\hline Bachelor's Degree & $3.07 \%$ & $2.34 \%$ & 0.73 & $23.78 \%$ \\
\hline \multicolumn{5}{|l|}{ Marital Status } \\
\hline Married & $3.85 \%$ & $3.14 \%$ & 0.71 & $18.52 \%$ \\
\hline Never Married & $6.11 \%$ & $4.76 \%$ & 1.35 & $22.03 \%$ \\
\hline Divorced/Separated & $4.78 \%$ & $3.86 \%$ & 0.92 & $19.19 \%$ \\
\hline Widow & $6.48 \%$ & $4.71 \%$ & 1.77 & $27.35 \%$ \\
\hline \multicolumn{5}{|l|}{ Children under 18} \\
\hline No & $4.47 \%$ & $3.57 \%$ & 0.90 & $20.06 \%$ \\
\hline Yes & $4.59 \%$ & $3.69 \%$ & 0.90 & $19.65 \%$ \\
\hline \multicolumn{5}{|l|}{ Part-time Workers } \\
\hline No & $2.38 \%$ & $1.76 \%$ & 0.62 & $26.01 \%$ \\
\hline Yes & $10.46 \%$ & $8.79 \%$ & 1.67 & $15.98 \%$ \\
\hline
\end{tabular}

Notes: Rates of monetary ineligibility under the standard base period based on predicted probabilities obtained from probit regression analysis using Model 2. Rates of monetary ineligibility after implementation of the alternative base period based on predicated probabilities obtained from regression analysis using Model 3. ${ }^{a}$ All percentage point differences were statistically significant at the $99 \%$ level $(\mathrm{p}<.000)$.

Rates of ineligibility decreased the most for younger workers, by about 1.24 percentage points (21.91\%). Rates of ineligibility also decreased more for workers with 
less than a high school diploma (1.08 percentage points), than for high school graduates, workers with some college, and college graduates, although this translated into a smaller percentage decrease for workers with less than a high school diploma than for workers at higher levels of education (15.8\% relative to $16.40 \%, 21.32 \%$, and $23.78 \%$ ).

The use of the alternative base period as a supplement to the traditional base period when determining monetary eligibility also reduced rates of ineligibility among never married workers and widowed workers by more than a percentage point $(22.03 \%$ and 27.35\% respectively). Both individuals in households with children under 18 and those without children under 18, the reduction in ineligibility was .9 percentage points (about 20\%). Finally, part-time workers had a greater percentage point reduction in eligibility than full-time workers (1.67 compared to .62 percentage points), which translated into a 16\% decrease in ineligibility among part-time workers.

The results from the main analysis suggest two different but important factors regarding UI coverage. Although the overall variation in UI coverage by demographic and job group is not as large as one might expect. Nevertheless, women, less-educated, and part-time workers are less likely to be covered by UI than their counterparts. Second, state implementation of the alternative base period rule increased rates of UI coverage. For women, less-educated workers, and part-time workers in particular, monetary ineligibility decreased by a percentage point or more.

Sensitivity analysis. Because I require only that current workers have participated in the labor force any time during the prior five quarters, the main sample may contain workers that some policymakers and analysts would consider outside the UI program’s target population; specifically, currently employed workers with very weak prior labor-force attachments. In order to see whether and how monetary eligibility changes once workers with weaker labor force attachments are excluded from the sample, 
I conduct a sensitivity analysis that limits the sample to workers who participated in the labor force in each month of the base period. This is a more stringent identification of recent labor-force attachment than most states’ UI programs require. Therefore, if workers with strong attachments to the labor force have equal access to UI, I would expect to find little or no systematic variation in monetary eligibility by major demographic or job groups when I limit the analysis to current workers with continuous attachments to the labor force in the base period. ${ }^{22}$ Summary statistics for this sample are reported in the appendix (Table 7).

In Table 4 I report estimates of the differences in monetary eligibility for employed workers with continuous labor force participation in first four of the five prior quarters (the standard base period) by demographic and job group. The sample of consists of 24,129 individuals who contribute an average of seven person-quarters to the analysis. ${ }^{23}$ I find that currently working women with continuous recent labor force participation are less likely to be monetarily eligible for UI than men (by about 1 percentage point); however, this difference is not statistically significant after job characteristics are included in the model (see Table 4). Also, I find that Hispanic workers in this sample are more likely to be able to establish monetary eligibility, even after controlling for job characteristics. Hispanic workers may face other barriers to UI. Research by Michaelides and Mueser (2012) and Gould-Werth and Shaefer (2012) indicates that take-up of UI benefits among unemployed Hispanics is lower than take-up among white workers. This suggest that factors other than work history and earnings, such as information about the availability of UI benefits, play a substantial role in

\footnotetext{
22 Continuous labor force participation includes spell of employment and unemployment.

${ }^{23}$ State and quarterly time dummies are included in all models and standard errors are clustered at the individual level to account for repeated observations of individuals in different quarters.
} 


\section{determining whether these worker, who fall with the UI program's target population of}

\section{workers' with strong labor force attachments, ultimately take-up UI.}

Table 4. Predicting Monetary Eligibility for UI for Employed Workers with Continuous Labor Force Participation

\begin{tabular}{|c|c|c|c|c|c|c|c|}
\hline \multirow{2}{*}{ Variables } & \multirow[b]{3}{*}{ Female } & \multicolumn{3}{|c|}{ Model 1} & \multicolumn{3}{|c|}{ Model 2} \\
\hline & & Marginal E & fects & $\mathrm{SE}$ & Marginal & Effects & $\mathrm{SE}$ \\
\hline Gender (Male) & & -0.009 & $* * *$ & 0.002 & -0.003 & & 0.002 \\
\hline Race/Ethnicity & Hispanic & 0.009 & $* *$ & 0.003 & 0.009 & $* *$ & 0.003 \\
\hline \multirow[t]{3}{*}{ (White Non-Hispanic) } & Black Non-Hispanic & 0.003 & & 0.003 & 0.003 & & 0.003 \\
\hline & Asian & -0.002 & & 0.005 & -0.003 & & 0.005 \\
\hline & Other Race & 0.003 & & 0.005 & -0.003 & & 0.004 \\
\hline \multirow[t]{2}{*}{ Age (45 to 55) } & 35 to 44 & 0.007 & $*$ & 0.002 & 0.007 & $* * *$ & 0.002 \\
\hline & 25 to 34 & 0.005 & & 0.002 & 0.007 & $* *$ & 0.002 \\
\hline Education & Less than High School & -0.027 & $* * *$ & 0.004 & -0.008 & $*$ & 0.004 \\
\hline \multirow[t]{2}{*}{ (BA or Higher) } & High School Diploma & -0.019 & $* * *$ & 0.003 & -0.007 & $* *$ & 0.003 \\
\hline & Some College & -0.010 & $* * *$ & 0.002 & -0.003 & & 0.002 \\
\hline Marital Status & Never Married & -0.016 & $* * *$ & 0.003 & -0.012 & $* * *$ & 0.002 \\
\hline \multirow[t]{2}{*}{ (Married) } & Divorced/Separated & -0.006 & & 0.003 & -0.004 & & 0.003 \\
\hline & Widowed & -0.011 & & 0.008 & -0.011 & & 0.008 \\
\hline Children (No) & Yes & -0.004 & $*$ & 0.002 & -0.003 & & 0.002 \\
\hline Part-time Work (No) & Yes & & & & -0.036 & $* * *$ & 0.002 \\
\hline Industry & Educational Services $^{\mathrm{a}}$ & & & & -0.006 & & 0.004 \\
\hline \multirow[t]{11}{*}{ (Manufacturing) } & Retail Trade & & & & -0.014 & $* * *$ & 0.004 \\
\hline & Professional \& Management Services ${ }^{\mathrm{b}}$ & & & & -0.019 & $* * *$ & 0.004 \\
\hline & Arts, Entertainment, \& Recreation Services & & & & -0.011 & $*$ & 0.005 \\
\hline & Finance, Insurance, \& Real Estate & & & & -0.012 & $*$ & 0.005 \\
\hline & Public Administration & & & & -0.001 & & 0.006 \\
\hline & Construction & & & & -0.014 & $*$ & 0.007 \\
\hline & Transportation \& Warehousing, \& Utilities & & & & -0.003 & & 0.004 \\
\hline & Other Services & & & & -0.014 & $* *$ & 0.005 \\
\hline & Wholesale Trade & & & & -0.004 & & 0.006 \\
\hline & Information & & & & 0.001 & & 0.006 \\
\hline & Agriculture $^{\mathrm{c}}$ & & & & -0.049 & $* * *$ & 0.007 \\
\hline Occupation & Office \& Administrative Support & & & & 0.005 & & 0.004 \\
\hline \multirow{21}{*}{ (Production) } & Sales & & & & -0.001 & & 0.005 \\
\hline & Management & & & & 0.013 & $*$ & 0.005 \\
\hline & Education, Training, \& Library & & & & 0.006 & & 0.006 \\
\hline & Food Preparation \& Serving & & & & -0.003 & & 0.006 \\
\hline & Healthcare Practitioners \& Technical & & & & 0.030 & $* * *$ & 0.007 \\
\hline & Construction \& Extraction & & & & 0.005 & & 0.007 \\
\hline & Building \& Grounds Cleaning ${ }^{\mathrm{d}}$ & & & & 0.001 & & 0.005 \\
\hline & Business \& Financial & & & & 0.020 & $* * *$ & 0.006 \\
\hline & Transportation & & & & 0.003 & & 0.005 \\
\hline & Installation, Maintenance, \& Repair & & & & 0.005 & & 0.006 \\
\hline & Personal Care \& Services & & & & -0.014 & $*$ & 0.006 \\
\hline & Material Moving & & & & -0.009 & & 0.006 \\
\hline & Healthcare Support & & & & -0.000 & & 0.007 \\
\hline & Computer \& Mathematical & & & & 0.020 & $* *$ & 0.007 \\
\hline & Protective Service & & & & -0.001 & & 0.007 \\
\hline & Architecture \& Engineering & & & & 0.024 & $* * *$ & 0.007 \\
\hline & Community \& Social Service & & & & 0.021 & $* *$ & 0.007 \\
\hline & Arts, Design, \& Entertainment ${ }^{\mathrm{e}}$ & & & & 0.011 & & 0.007 \\
\hline & Farming, Fishing, \& Forestry & & & & 0.011 & & 0.011 \\
\hline & Life, Physical, \& Social Sciences & & & & 0.050 & $* * *$ & 0.009 \\
\hline & Legal & & & & 0.016 & $*$ & 0.008 \\
\hline Observations (Clusters) & & 176,12 & $(24,1$ & & 176 , & $23(24,1$ & \\
\hline
\end{tabular}

Notes: Coefficients on time and state dummies no shown. Marginal effects shown with clustered robust standard errors; ${ }^{* * *} \mathrm{p}<0.001,{ }^{* *} \mathrm{p}<0.01,{ }^{*} \mathrm{p}<0.05$. Sample of workers with continuous employment during the quarter in which eligibility is simulated and continuous participation in the labor force in the base period. a Educational services, health care, and social assistance. b Professional, scientific, management, and administrative services. ${ }^{\mathrm{c}}$ Agriculture, forestry, fishing \& hunting, \& mining. ${ }^{\mathrm{d}}$ Building and grounds cleaning and maintenance. ${ }^{\mathrm{e}}$ Arts, design, entertainment, sports, and media. 
The sensitivity analysis also shows that compared to college graduates, current workers with a recent history of continuous labor force participation are less likely to be covered by UI at lower levels of educational attainment (see Table 4). However, once job characteristics are taken into account, the magnitudes of these differences decrease by about 1 percentage point for each group of less-educated workers. Also in this subsample, age group differences in eligibility nearly reversed, with the younger groups of workers .6 percentage points more likely to be covered than the older group of workers. In terms of marital status, the direction and magnitude of the coefficients are similar to those in the main analysis; as demonstrated in Table 4, in both models never married workers are less likely to be eligible for UI than married workers.

For part-time workers, the difference in eligibility relative to full-time workers attenuates when I restrict the sample to workers with continuous labor-force participation. Part-time workers in this group are 3.6 percentage points less likely to be eligible for UI than full-time workers (see Table 4). Additionally, variation in monetary eligibility across industry and occupation, much like variation across demographic groups, is quite small for workers in the subsample. Similar to the rates of eligibility for the main sample, compared to the manufacturing industry, workers in retail trade; professional, scientific, management, and administrative services; arts, entertainment, and recreation services; finance, insurance, and real estate; construction; other services; and agriculture, forestry, fishing and hunting, and mining have statistically lower likelihoods of monetary eligibility. Compared to production occupations, business and financial occupations, computer and mathematical occupations, architecture and engineering occupations, and community and social services occupations; healthcare practitioners and technical occupations; and life, physical, and social science occupations all have higher rates of eligibility. 
Finally, in an additional sensitivity analysis (not shown) I further restrict the sample to individuals with continuous employment in the base period. For this subsample, I expect only earnings to influence group differences in monetary eligibility, because the sample definition excludes current workers with recent employment instability. For current workers with continuous employment in the base period, women are less likely to be eligible for UI than men, whereas Hispanic workers and workers of other races are more likely to be eligible for UI than non-Hispanic white workers. Younger workers are about 1 percentage point more likely to be eligible for UI than older workers and, perhaps most importantly, there is no statistically significant difference in the likelihood of eligibility among workers with different levels of education. Part-time workers are still about 3 percentage points less likely to be eligible for UI.

Factors contributing to monetary eligibility for UI. Because the analysis presented here is purely descriptive, the results do not directly identify the labor-market mechanisms contributing to differences in eligibility by demographic or job groups. However, it may be of some interest to examine differences in employment stability and earnings by demographic and job groups, keeping in mind that UI coverage depends on the combination of both factors. Table 5 reports the quarterly averages of current workers' median earnings, the percentage of current workers reporting at least one month of unemployment, and the percentage reporting at least one month of time out of the labor force during the base period.

In terms of gender differences in employment stability and earnings, female workers in the main sample have lower median base period earnings $\mathbf{\$ 2 9 , 1 2 0}$ relative to $\$ 39,722$ ) and more frequently report time out of the labor force than male workers (6.30\% relative to 3.93\%). However, male workers more frequently report unemployment than female workers (4.49\% relative to $3.73 \%)$. 
Table 5. Workers' Median Earnings and Employment Stability in the Base Period

\begin{tabular}{|c|c|c|c|}
\hline & $\begin{array}{c}\text { Median Earnings } \\
(\$)\end{array}$ & $\begin{array}{c}\text { One or more months } \\
\text { of unemployment } \\
(\%)\end{array}$ & $\begin{array}{c}\text { One of more months } \\
\text { out of labor force } \\
\text { (\%) }\end{array}$ \\
\hline \multicolumn{4}{|l|}{ Gender } \\
\hline Female & $\$ 29,120$ & 3.73 & 6.30 \\
\hline Male & $\$ 39,722$ & 4.49 & 3.93 \\
\hline \multicolumn{4}{|l|}{ Race } \\
\hline White & $\$ 37,530$ & 3.66 & 4.57 \\
\hline Hispanic & $\$ 22,813$ & 5.35 & 7.07 \\
\hline Black & $\$ 26,996$ & 5.74 & 5.99 \\
\hline Asian & $\$ 41,674$ & 3.44 & 5.85 \\
\hline Other Race & $\$ 30,945$ & 5.41 & 5.75 \\
\hline \multicolumn{4}{|l|}{ Age } \\
\hline 45 to 55 & $\$ 36,990$ & 3.62 & 3.45 \\
\hline 35 to 44 & $\$ 36,329$ & 3.75 & 4.76 \\
\hline 25 to 34 & $\$ 27,833$ & 5.27 & 7.99 \\
\hline \multicolumn{4}{|l|}{ Educational Attainment } \\
\hline Less than High School & $\$ 18,199$ & 6.75 & 7.95 \\
\hline High School Diploma & $\$ 25,667$ & 5.13 & 5.67 \\
\hline Some College & $\$ 31,050$ & 4.66 & 4.97 \\
\hline BA or Higher & $\$ 51,208$ & 2.51 & 4.34 \\
\hline \multicolumn{4}{|l|}{ Marital Status } \\
\hline Married & $\$ 37,617$ & 3.32 & 4.34 \\
\hline Never Married & $\$ 26,547$ & 5.91 & 6.81 \\
\hline Divorced/Separated & $\$ 31,113$ & 4.92 & 4.61 \\
\hline Widowed & $\$ 27,368$ & 5.80 & 4.79 \\
\hline \multicolumn{4}{|l|}{ Children in Household } \\
\hline No & $\$ 33,450$ & 4.41 & 4.93 \\
\hline Yes & $\$ 34,660$ & 3.83 & 5.27 \\
\hline \multicolumn{4}{|l|}{ Worked Part Time } \\
\hline No & $\$ 38,207$ & 3.23 & 3.69 \\
\hline Yes & $\$ 19,532$ & 6.79 & 9.28 \\
\hline
\end{tabular}

Notes: Unadjusted quarterly averages of individuals' median earnings and labor force participation during the traditional base period. Sample defined as workers age 25-55 with continuous employment during the quarter in which eligibility was simulated, any labor force participation in the base period, and continuous participation in the SIPP in the previous five quarters.

In terms of racial and ethnic differences in employment stability and earnings, the results in Table 5 do not indicate any particularly clear patterns. For example, the probit estimates suggest that Hispanic workers are more likely to be eligible for UI than nonHispanic white workers, yet Hispanic workers earn nearly $\$ 15,000$ less than non- 
Hispanic white workers and the percentages of Hispanic workers reporting unemployment and time out of the labor force are greater than the percentages for nonHispanic white workers.

Although the probit estimates suggest that non-Hispanic black and non-Hispanic white workers have similar rates of monetary eligibility for UI, non-Hispanic black workers have base period earnings about \$10,000 below non-Hispanic white workers and the percentages of non-Hispanic black workers reporting unemployment and time out of the labor force are greater than the percentages for non-Hispanic white workers.

The differences in employment stability and earnings by education show a much clearer pattern. As education increases, base period earnings increase and employment instability decreases. Current workers with less than a high school diploma have the lowest base period earnings, about $\$ 18,199$, and those with a bachelor's degree or higher had earnings nearly three times higher, about $\$ 51,208$. Additionally, $6.75 \%$ of workers with less than a high school education report at least one month of unemployment in the base period, while only $2.51 \%$ of those with a bachelor's degree or higher report a month or more of unemployment. Nearly $8 \%$ of workers with less than a high school diploma report time out of the labor force during the base period, compared to $4.34 \%$ of workers with a bachelor's degree or more.

In terms of age group differences, the estimates of employment stability and earnings are consistent with theoretical expectations that both of these factors increase with age. Median base period earnings for workers ages 45 to 55 and workers ages 35 to 44 are about $\$ 10,000$ greater than earnings for workers ages 25 to 34. Also, more current workers between the ages 25 to 34 report unemployment than workers ages 45 to 55, and more than twice as many report time out of the labor force. For marital status, the estimates of earnings are consistent with theoretical expectations that married workers 
have higher wages. The estimates also suggest that married workers less frequently report unemployment or time out of the labor force. For households with children and under 18, median earnings, reports of unemployment, and time out of the labor force are quite similar.

Finally, consistent with the expectation that working fewer hours corresponds with lower wages, part-time workers had median base period earnings of $\$ 19,532$, whereas full-time workers had median base period earnings of $\$ 38,207$. Additionally, $6.79 \%$ of part-time workers in the main sample report at least one month of unemployment in the base period, compared to 3.23\% of full-time workers; and over $9 \%$ of part-time workers report at least one month out of the labor force during the base period, compared to only 3.69\% of full-time workers.

\section{Discussion}

The risk of experiencing at least one spell of involuntary unemployment while working is nearly universal for Americans (Marmor et al., 2013), and the UI program is the primary source of income support available to workers when they lose their jobs. The current study evaluates UI performance by providing national-level estimates of workers’ coverage against the economic risk of unemployment during the Great Recession, a time in which the risk of unemployment increased significantly for most workers. The results of the main analysis demonstrate the broad reach of UI coverage across the employed labor force. I find that over 95\% of current workers in the sample would be monetarily eligible for UI benefits if they were to become unemployed.

Additionally, this study examines the effectiveness of UI policy changes following the Great Recession. I find that state expansions of monetary eligibility criteria under the ARRA increase rates of UI coverage. Specifically, the use of an alternative 
base period to determine monetary eligibility for workers who fail to qualify for benefits under the standard base period decreased rates of ineligibility by $20 \%$ during the recovery period. In terms of bringing the UI program in line with social insurance principals of universal availability, ABP implementation increased access to UI among women, lesseducated workers, and part-time workers; however, ABP implementation did not eliminate the variation in UI coverage by major demographic and job group (see Appendix Table 9).

When considered alongside previous studies of UI eligibility and UI receipt among the unemployed, the findings highlight the relative vulnerability of some groups of workers. I find that volatilities in work hours and earnings of women, less-educated workers, part-time workers, and workers make these workers less likely to be covered by UI than their counterparts. Importantly, these workers also tend to have difficulty with non-monetary components of establishing benefit eligibility.

Unemployed women may be excluded from UI because of their reasons for exiting employment (e.g., quitting a job to take up family care responsibilities) and unemployed part-time workers may be excluded because of requirements that claimants seek full-time work. ${ }^{24}$ Although part-time workers in the sample were only 5 percentage points less likely to be eligible for UI, other studies have shown that part-time workers are much less likely to receive benefits (Vroman, 1998, 2002) and that working part time reduces the rates of UI receipt for demographic groups such as women, less educated workers, and younger workers (Chan et al., 2014).

Similarly, the disadvantages faced by less-educated and low-wage workers in the labor market, including lack of control over work hours and work scheduling, and shorter

\footnotetext{
${ }^{24}$ Following the Great Recession, about 32 states adopted changes to non-monetary eligibility determinants in order to receive ARRA stimulus funds compared to 40 states who previously had or adopted changes to monetary eligibility determinants (Gould-Werth \& Shaefer, 2013; O'Leary, 2011).
} 
job tenures, may make it difficult for these workers to satisfy monetary eligibility criteria. Although variations in monetary eligibility by educational attainment presented in the main analysis may seem small, barriers due to monetary eligibility are compounded by barriers due to non-monetary eligibility and lack of knowledge of the UI program. GouldWerth and Shaefer (2013) find that the criteria of being a job leaver versus a job loser and lack of knowledge about the availability of benefits both contribute to lower rates of UI receipt for less-educated workers.

\section{Conclusion}

As employment remains central to social citizenship in the United States, and yet disparities in the labor market persist, it is important to identify how economic instability interacts with policy design to determine access to social programs. In this paper, I used current workers' work histories and earnings and state UI eligibility rules to estimate monetary eligibility among the employed as a proxy for UI coverage. I found that between 2009 and 2013, a vast majority of workers were covered by the UI program, i.e. they could have established monetary eligibility for UI had they become unemployed. In the case of UI, these findings suggest that UI coverage has a broad reach across the employed labor force and that, in terms of modifications to monetary eligibility rules, the program has been fairly responsive to changes in the structure of employment and the composition of the labor force.

In terms of larger conversations on the consequences of economic instability for access to the social safety net, I find that the labor force attachments of women, part-time workers, and workers in some service-related occupations and industries affect their rates of UI coverage. This suggests that labor-market disadvantages, such as lower wages, employment instability, and higher risks of unemployment, may translate into disadvantages in access to income support from social programs. Future research in this 
area should focus on identifying the economic, social, and policy mechanisms determining differences in access to UI for specific population groups. Each of these mechanisms suggests a different process through which employment dynamics and UI program design shape the economic opportunities of U.S. workers. 


\section{References}

Abel, J. R., Deitz, R., \& Su, Y. (2014). Are recent college graduates finding good jobs? Current Issues in Economics and Finance, 20(1).

Arbeit, C. A. (2012). Unemployment insurance reduced child poverty during the Great Recession (8). Retrieved from University of California, Davis: http://poverty.ucdavis.edu/sites/main/files/fileattachments/policy_brief_arbeit_ui.pdf

Berman, J., \& Pfleeger, J. (1997). Which industries are sensitive to business cycles. Monthly Lab. Rev., 120, 19.

Bielby, W. T., \& Baron, J. N. (1986). Sex Segregation Within Occupations. American Economic Review, 76(2), 43. Retrieved from http://proxy.mul.missouri.edu/login?url=http://search.ebscohost.com/login.aspx?d irect $=$ true $\& \mathrm{db}=\mathrm{buh} \& \mathrm{AN}=4496351 \&$ site=eds-live $\&$ scope=site

Bitler, M. P., \& Hoynes, H. W. (2010). The State of the Social Safety Net in the Post-Welfare Reform Era. Brookings Papers on Economic Activity(2), 71-147. Retrieved from http://proxy.mul.missouri.edu/login?url=http://search.ebscohost.com/login.aspx?d irect=true \&db=buh\&AN=59669939\&site=eds-live\&scope=site

Blau, F. D., \& Kahn, L. M. (2007). The Gender Pay Gap: Have Women Gone as Far as They Can? Academy of Management Perspectives, 21(1), 7-23. doi:10.5465/AMP.2007.24286161

BLS. (2014a). Employee Tenure in 2014 [Press release]. Retrieved from http://www.bls.gov/news.release/pdf/tenure.pdf

BLS (Producer). (2014b, 8/2/2015). Occupational Employment and Wages in 2014 on the Internet. The Economics Daily. Retrieved from http://www.bls.gov/opub/ted/2015/occupational-employment-wages-2014.htm

BLS. (2015). Persons at work in nonagricultural industries by class of worker and usual full- or part-time status. Retrieved from Washington, DC: http://www.bls.gov/cps/cpsaat21.pdf 
BLS (Producer). (2016a, 7/31/2016). Absences from work of employed full-time wage and salary workers by age, sex, race, and Hispanic or

Latino ethnicity. Household Data Annual Averages. Retrieved from http://www.bls.gov/cps/cpsaat46.pdf

BLS (Producer). (2016b, 7/29/2016). Median weekly earnings of full-time wage and salary workers by selected characteristics. Household Data Annual Averages. Retrieved from http://www.bls.gov/cps/cpsaat37.htm

BLS. (2016c). Persons at work by occupation, sex, and usual full- or part-time status. Retrieved from Washington, DC: http://www.bls.gov/web/empsit/cpseea28.pdf

BLS (Producer). (2016d, 7/31/2016). Persons at work in nonagricultural industries by age, sex, race, Hispanic or Latino ethnicity, marital status, and usual full- or parttime status. Household Data Annual Averages

Retrieved from http://www.bls.gov/cps/cpsaat22.htm

BLS. (2016e). Quarterly Census of Employment and Wages. Retrieved from http://www.bls.gov/cew/

BLS (Producer). (2016f, 7/29/2016). Table B-3. Average hourly and weekly earnings of all employees on private nonfarm payrolls by industry sector, seasonally adjusted. Economic News Release. [Table] Retrieved from http://www.bls.gov/news.release/empsit.t19.htm

Budig, M. J., \& England, P. (2001). The wage penalty for motherhood. American Sociological Review, 204-225.

Chan, M., Michaelides, M., \& Zhang, S. (2014). Who Receives Unemployment Insurance? Research in Applied Economics, 6(3), 98.

Czajka, J. L., Mabli, J., \& Cody, S. (2008). Sample loss and survey bias in estimates of Social Security beneficiaries: A tale of two surveys. Washington, DC: Mathematica Policy Research, Inc.

de Linde Leonard, M., \& Stanley, T. (2015). Married with children: What remains when observable biases are removed from the reported male marriage wage premium. Labour Economics, 33, 72-80. 
DOL. (2011). Women's Employment During the Recovery. Retrieved from https://www.dol.gov/_sec/media/reports/femalelaborforce/

DOL. (2012). The African-American Labor Force in the Recovery. Retrieved from Washington, DC:

https://www.dol.gov/_sec/media/reports/BlackLaborForce/BlackLaborForce.pdf

DOL. (2014). Unemployment Compensation: Federal-State Partnership. Washington, DC Retrieved from http://www.ows.doleta.gov/unemploy/pdf/chronfedlaws.pdf.

DOL. (2015). Comparison of State Unemployment Insurance Laws Retrieved from http://www.unemploymentinsurance.doleta.gov/unemploy/pdf/. Retrieved 8/5/2015, from US Department of Labor, Employment and Training Administration http://www.unemploymentinsurance.doleta.gov/unemploy/pdf/

DOL. (2016). Changes in Basic Minimum Wages in Non-Farm Employment Under State Law: Selected Years 1968 to 2016. Retrieved from Washington, DC: https://www.dol.gov/whd/state/stateMinWageHis.htm

England, P. (2005). Gender Inequality in Labor Markets: The Role of Motherhood and Segregation. Social Politics: International Studies in Gender, State and Society(2), 264. Retrieved from http://proxy.mul.missouri.edu/login?url=http://search.ebscohost.com/login.aspx?d irect=true $\& \mathrm{db}=$ edspmu\&AN=edspmu.S1468289305202649\&site=edslive\&scope $=$ site

Farber, H. S., \& Valletta, R. G. (2015). Do Extended Unemployment Benefits Lengthen Unemployment Spells? Evidence from Recent Cycles in the US Labor Market. Journal of Human Resources, 50(4), 873-909. Retrieved from http://proxy.mul.missouri.edu/login?url=http://search.ebscohost.com/login.aspx?d irect $=$ true $\& \mathrm{db}=\mathrm{edswss} \& \mathrm{AN}=000364437100002 \&$ site $=$ eds-live \&scope $=$ site

GAO. (2000). Unemployment Insurance Role as Safety Net for Low-Wage Workers is Limited (GAO-01-181). Retrieved from Washington, DC: http://www.gao.gov/products/GAO-01-181

GAO. (2006). Unemployment Insurance: Factors Associated with Benefit Receipt. Retrieved from Washington, DC: 
GAO. (2007). Unemployment Insurance: Low-Wage and Part-Time Workers Continue to Experience Low Rates of Receipt. Retrieved from Washington, DC:

GAO. (2011). Gender Pay Differences: Progress Made, but Women Remain Overrepresented among Low-Wage Workers. Retrieved from Washington, DC:

Glauber, R. (2007). Marriage and the motherhood wage penalty among African Americans, Hispanics, and Whites. Journal of Marriage and Family, 69(4), 951961.

Gould-Werth, A., \& Shaefer, H. L. (2012). Unemployment Insurance Participation by Education and by Race and Ethnicity [article] (pp. 28).

Gould-Werth, A., \& Shaefer, H. L. (2013). Do Alternative Base Periods Increase Unemployment Insurance Receipt Among Low-Educated Unemployed Workers? Journal of Policy Analysis and Management, 32(4), 835. Retrieved from http://proxy.mul.missouri.edu/login?url=http://search.ebscohost.com/login.aspx?d irect $=$ true $\& \mathrm{db}=\mathrm{edb} \& \mathrm{AN}=90146560 \&$ site=eds-live $\&$ scope $=$ site

Ham, J. C., Li, X., \& Shore-Sheppard, L. (2009). Seam bias, multiple-state, multiple-spell duration models and the employment dynamics of disadvantaged women. Retrieved from

Hill, H. D., \& Ybarra, M. A. (2014). Less-Educated Workers' Unstable Employment: Can the Safety Net Help? Fast Focus. No. 19-2014. Institute for Research on Poverty.

Joyce, K., Pabayo, R., Critchley, J. A., \& Bambra, C. (2010). Flexible working conditions and their effects on employee health and wellbeing. The Cochrane Library. doi:10.1002/14651858.CD008009.pub2

Kahne, H., \& Mabel, Z. (2010). Single Mothers and Other Low Earners: Policy Routes to Adequate Wages. Poverty and Public Policy, 2(3). doi:http://onlinelibrary.wiley.com/journal/10.1002/\%28ISSN\%2919442858/issues

Killewald, A., \& Gough, M. (2013). Does specialization explain marriage penalties and premiums? American Sociological Review, 0003122413484151. 
Kuka, E. (2015). Quantifying the Benefits of Social Insurance: Unemployment Insurance and Health. Job Market Paper.

Lambert, S. J. (2008). Passing the buck: Labor flexibility practices that transfer risk onto hourly workers. Human Relations, 61(9), 1203-1227.

Lambert, S. J., Haley-Lock, A., \& Henly, J. R. (2012). Schedule flexibility in hourly jobs: Unanticipated consequences and promising directions. Community, Work \& Family, 15(3), 293-315.

Levanon, A., England, P., \& Allison, P. (2009). Occupational feminization and pay: Assessing causal dynamics using 1950-2000 US census data. Social Forces, 88(2), 865-891.

Marmor, T. R., Mashaw, J. L., \& Pakutka, J. (2013). Social Insurance: America’s Neglected Heritage and Contested Future: CQ Press.

Michaelides, M., \& Mueser, P. R. (2012). Recent trends in the characteristics of unemployment insurance recipients. Monthly Labor Review, 135(7), 28.

Retrieved from

http://proxy.mul.missouri.edu/login?url=http://search.ebscohost.com/login.aspx?d irect $=$ true \&db=f5h\&AN=79344395\&site=eds-live\&scope=site

Michaelides, M., \& Mueser, P. R. (2013). The role of industry and occupation in recent US unemployment differentials by gender, race, and ethnicity. Eastern Economic Journal, 39(3), 358-386.

Moffitt, R. A. (2013). The Great Recession and the Social Safety Net. Annals of the American Academy of Political and Social Science, 650(1), 143-166. Retrieved from http://proxy.mul.missouri.edu/login?url=http://search.ebscohost.com/login.aspx?d irect $=$ true $\& \mathrm{db}=$ edswss $\& \mathrm{AN}=000326234000007 \&$ site $=$ eds-live $\&$ scope $=$ site

Murnane, R. J., Bernhardt, A. D., \& Appelbaum, E. (2003). Low-wage America : how employers are reshaping opportunity in the workplace: New York : Russell Sage, (C)2003.

NELP (Producer). (2010, 7/29/2016). UI Modernization Update. Retrieved from http://nelp.org/content/uploads/UnemploymentInsuranceModernizationUpdate.pd $\mathrm{f}$ 
Nicholson, W., \& Needels, K. (2006). Unemployment Insurance: Strengthening the Relationship between Theory and Policy, 47.

Nicholson, W., Needels, K., \& Hock, H. (2014). Unemployment Compensation during the Great Recession: Theory and Evidence. National Tax Journal, 67(1), 187-218.

O'Leary, C. J. (2011). Benefit payment costs of Unemployment Insurance modernization: Estimates based on Kentucky administrative data.

Prywes, R. W. (2000). The United States labor force: A descriptive analysis: Greenwood Publishing Group.

Rothstein, D. S. (2013). Long-term unemployment over men's careers. BLS Beyond the Numbers, 2(21). Retrieved from http://www.bls.gov/opub/btn/volume2/pdf/long-term-unemployment-over-mens-careers.pdf

Shaefer, H. L. (2010). Identifying key barriers to unemployment insurance for disadvantaged workers in the United States. Journal of Social Policy, 39(03), 439460.

Shaefer, H. L., \& Wu, L. (2011). Unemployment Insurance and Low-Educated, Single, Working Mothers before and after Welfare Reform, 205.

Valletta, R. G., \& Van Der List, C. (2015). Involuntary part-time work: Here to stay? FRBSF Economic Letter.

Vaughan, D., \& Scheuren, F. (2002). Longitudinal Attrition in SIPP and SPD. US Census Bureau, SIPP Working Paper, 242.

Vroman, W. (1998). Labor Market Changes and Unemployment Insurance Benefit Availability: US Department of Labor, Employment and Training Administration, Unemployment Insurance Service.

Vroman, W. (2002). Low benefit recipiency in state unemployment insurance programs: US Department of Labor, Employment and Training Administration, Office of Policy and Research. 
Vroman, W. (2010). The Great Recession, Unemployment Insurance, and Poverty. Reducing Poverty and Economic Distress after ARRA,” Washington, DC, January, 15.

Whittaker, J. M., \& Isaacs, K. P. (2014). Unemployment insurance: programs and benefits.

Young, C. (2012). Losing a Job: The Nonpecuniary Cost of Unemployment in the United States. Social Forces, 91(2), 609-634. Retrieved from http://proxy.mul.missouri.edu/login?url=http://search.ebscohost.com/login.aspx?d irect=true \&db=buh\&AN=95750455\&site=eds-live\&scope=site 


\section{Appendix}

Table 6. Monetary Ineligibility for UI among the Employed by Job Group

\begin{tabular}{|c|c|c|c|}
\hline Worked Part Time*** & \multicolumn{2}{|r|}{ Occupation*** } & \multirow[b]{2}{*}{$4.56 \%$} \\
\hline No & $2.30 \%$ & $\begin{array}{r}\text { Office \& Administrative } \\
\text { Support }\end{array}$ & \\
\hline Yes & $10.03 \%$ & Sales \& Related & $5.68 \%$ \\
\hline Industry*** & & Management & $2.43 \%$ \\
\hline $\begin{array}{r}\text { Educational Services, Health Care, \& Social } \\
\text { Assistance }\end{array}$ & $4.25 \%$ & $\begin{array}{r}\text { Education, Training, \& } \\
\text { Library }\end{array}$ & $4.29 \%$ \\
\hline \multirow[b]{3}{*}{ Professional, Scientific, Mgmt., \& Admin. Services } & $6.16 \%$ & Production & $3.47 \%$ \\
\hline & $2.18 \%$ & $\begin{array}{r}\text { Food Preparation \& Serving } \\
\text { Related }\end{array}$ & $8.23 \%$ \\
\hline & $4.67 \%$ & $\begin{array}{r}\text { Healthcare Practitioners \& } \\
\text { Technical }\end{array}$ & $2.00 \%$ \\
\hline Arts, Entertainment, \& Recreation Services & $7.71 \%$ & Construction \& Extraction & $4.31 \%$ \\
\hline Finance, Insurance, \& Real Estate & $2.93 \%$ & $\begin{array}{r}\text { Building \& Grounds } \\
\text { Cleaning \& Maintenance }\end{array}$ & $7.26 \%$ \\
\hline \multirow[b]{3}{*}{ Transportation \& Warehousing, \& Utilities } & $1.90 \%$ & Business \& Financial & $2.26 \%$ \\
\hline & $4.24 \%$ & Transportation & $3.94 \%$ \\
\hline & $3.23 \%$ & $\begin{array}{r}\text { Installation, Maintenance, \& } \\
\text { Repair }\end{array}$ & $2.64 \%$ \\
\hline Other services & $7.23 \%$ & Personal Care \& Service & $12.58 \%$ \\
\hline Wholesale Trade & $2.51 \%$ & Material Moving & $7.06 \%$ \\
\hline Information & $2.05 \%$ & Healthcare Support & $6.60 \%$ \\
\hline \multirow[t]{8}{*}{ Agriculture, Forestry, \& Mining } & $12.07 \%$ & Computer \& Mathematical & $1.22 \%$ \\
\hline & & Protective Service & $3.24 \%$ \\
\hline & & Architecture \& Engineering & $1.18 \%$ \\
\hline & & $\begin{array}{r}\text { Community \& Social } \\
\text { Service }\end{array}$ & $2.79 \%$ \\
\hline & & $\begin{array}{r}\text { Arts, Design, Entertainment, } \\
\text { Sports, \& Media }\end{array}$ & $3.49 \%$ \\
\hline & & $\begin{array}{r}\text { Life, Physical, \& } \\
\text { Social Science }\end{array}$ & $1.07 \%$ \\
\hline & & Legal & $2.78 \%$ \\
\hline & & $\begin{array}{r}\text { Farming, Fishing, \& } \\
\text { Forestry }\end{array}$ & $12.63 \%$ \\
\hline
\end{tabular}

Notes: Quarterly averages from October 2009-March 2013. Sample restricted to workers age 25-55, with continuous employment during the quarter in which eligibility was simulated, any labor force participation in the base period, and continuous participation in the SIPP in the previous five quarters. Statistical significance for chi-square test of association by group, ${ }^{* * *} \mathrm{p}<0.001,{ }^{* *} \mathrm{p}<0.01,{ }^{*} \mathrm{p}<0.05$. 
Table 7. Summary Statistics for Current Workers with Continuous Labor Force Participation during the Base Period

\section{Sample Characteristics Monetary Ineligibility}

Gender***

$\begin{array}{rrr}\text { Male } & 51.16 \% & 2.26 \% \\ \text { Female } & 48.84 \% & 3.17 \%\end{array}$

Race \& Ethnicity ***

White Non-Hispanic

Hispanic

Black Non-Hispanic

Asian

Other Race

Age***

$$
\begin{aligned}
& 45 \text { to } 55 \\
& 34 \text { to } 44 \\
& 25 \text { to } 34
\end{aligned}
$$

Educational Attainment***

$$
\begin{array}{r}
\text { Less than High School } \\
\text { Graduated High School } \\
\text { Some College } \\
\text { Bachelor's Degree or Higher }
\end{array}
$$

Marital Status***

$$
\begin{array}{r}
\text { Married } \\
\text { Never Married } \\
\text { Divorced/Separated } \\
\text { Widow }
\end{array}
$$

Children in Household***
$71.17 \%$

$12.07 \%$

$9.74 \%$

$4.52 \%$

$2.51 \%$

$41.16 \%$

$32.88 \%$

$25.95 \%$

$6.59 \%$

$21.83 \%$

$34.41 \%$

$37.17 \%$

$64.59 \%$

$2.31 \%$

$20.81 \%$

$3.54 \%$

$13.51 \%$

$3.22 \%$

$1.09 \%$

$3.87 \%$
$2.95 \%$

$2.38 \%$

$2.72 \%$
$2.80 \%$

$2.15 \%$

$2.74 \%$

$2.03 \%$

$3.63 \%$

$4.07 \%$

$3.71 \%$

$2.79 \%$

$1.79 \%$

$$
\begin{aligned}
& \text { No } \\
& \text { Yes }
\end{aligned}
$$$$
47.99 \%
$$

Notes: Quarterly averages from October 2009-March 2013. Sample restricted to workers ages 25-55, with continuous employment during the quarter in which eligibility was simulated, continuous participation in the labor force in the base period, and continuous participation in the SIPP in the previous five quarters. Statistical significance for chi-square test of association by group, ${ }^{* * *} \mathrm{p}<0.001,{ }^{* *} \mathrm{p}<0.01,{ }^{*} \mathrm{p}<0.05$. 
Table 8. Summary Statistics for All Employed Workers

Gender***

$\begin{array}{rrr}\text { Male } & 50.44 \% & 5.82 \% \\ \text { Female } & 49.56 \% & 8.40 \%\end{array}$

Race \& Ethnicity ***

White Non-Hispanic

Hispanic

Black Non-Hispanic

Asian

Other Race

Age***
$69.71 \%$

$10.39 \%$

$12.63 \%$

$4.60 \%$

$2.65 \%$

$27.98 \%$

25 to 34

Educational Attainment***

$$
\begin{array}{r}
\text { Less than High School } \\
\text { Graduated High School } \\
\text { Some College } \\
\text { Bachelor's Degree or Higher }
\end{array}
$$

Marital Status***

$$
\begin{array}{r}
\text { Married } \\
\text { Never Married } \\
\text { Divorced/Separated } \\
\text { Widow }
\end{array}
$$

Children in Household

$$
\begin{aligned}
& \text { No } \\
& \text { Yes }
\end{aligned}
$$

Observations (Avg. N)
$32.66 \%$

$39.36 \%$

$\begin{array}{rr}6.77 \% & 10.23 \% \\ 22.60 \% & 8.99 \% \\ 34.45 \% & 7.28 \% \\ 36.19 \% & 5.15 \%\end{array}$

$63.40 \%$

$6.12 \%$

$21.74 \%$

$9.36 \%$

$13.81 \%$

$7.87 \%$

$1.05 \%$

$9.13 \%$

$6.44 \%$

$6.14 \%$

$7.15 \%$

$6.57 \%$

$9.40 \%$

$9.22 \%$

Notes: Quarterly averages from October 2009-March 2013. Sample restricted to workers (US civilian labor force) age $25-55$. Statistical significance for chi-square test of association by group, ${ }^{* * *} \mathrm{p}<0.001$, $* *$ $\mathrm{p}<0.01,{ }^{*} \mathrm{p}<0.05$. 
Table 9. Linear Probability Model Predicting Employed Workers' Monetary Eligibility for UI using Standard Base Period and Alternative Base Period Work History and Earnings

\begin{tabular}{|c|c|c|c|c|}
\hline \multirow{2}{*}{\multicolumn{2}{|c|}{ Variables }} & \multicolumn{3}{|c|}{ Model 3} \\
\hline & & \multicolumn{2}{|c|}{ Marginal Effects } & \multirow{2}{*}{$\begin{array}{c}\text { SE } \\
-0.002\end{array}$} \\
\hline Gender (Male) & Female & -0.010 & $* * *$ & \\
\hline Race & Hispanic of Any race & 0.009 & $* *$ & -0.003 \\
\hline \multirow{3}{*}{ (Non-Hispanic white) } & Non-Hispanic black & 0.004 & & -0.003 \\
\hline & Asian & -0.004 & & -0.005 \\
\hline & Other Race & -0.001 & & -0.005 \\
\hline Age & 35 to 44 & 0.006 & $* *$ & -0.002 \\
\hline (45 to 55) & 25 to 34 & 0.000 & & -0.002 \\
\hline \multirow{3}{*}{$\begin{array}{l}\text { Education } \\
\text { (BA or higher) }\end{array}$} & Less than High School & -0.011 & $* *$ & -0.004 \\
\hline & High School Diploma & -0.01 & $* * *$ & -0.003 \\
\hline & Some College & -0.003 & & -0.003 \\
\hline \multirow{3}{*}{$\begin{array}{l}\text { Marital Status } \\
\text { (Married) }\end{array}$} & Never Married & -0.009 & $* * *$ & -0.002 \\
\hline & Divorced/Separated & -0.001 & & -0.003 \\
\hline & Widowed & -0.005 & & -0.009 \\
\hline Children (No) & Yes & -0.004 & $*$ & -0.002 \\
\hline Part-time (No) & Yes & -0.045 & $* * *$ & -0.002 \\
\hline $\begin{array}{l}\text { Observations } \\
\text { (Clusters) }\end{array}$ & & \multicolumn{3}{|c|}{$186,454(25,500)$} \\
\hline
\end{tabular}

Notes: Industry, occupation, state, and time dummies included in regression analysis, but suppressed in output. Marginal effects reported with cluster robust standard errors; ${ }^{* * *} \mathrm{p}<0.001,{ }^{* *} \mathrm{p}<0.01,{ }^{*} \mathrm{p}<0.05$. Sample restricted to workers age 25-55 with continuous employment during the quarter in which eligibility was simulated, any labor force participation in the base period, and continuous participation in the SIPP in the previous five quarters. 


\section{CHAPTER 3: WHY ARE WOMEN LESS LIKELY TO BE COVERED BY UNEMPLOYMENT INSURANCE THAN MEN?}

During the most recent recession and recovery, the Federal-State Unemployment Compensation Program (UI) provided weekly benefits to millions of American workers who lost their jobs. From 2007 to 2010 the number of new UI claims rose from around 8 million to 11.5 million, and program spending increased by over 300\% (Michaelides \& Mueser, 2012; Moffitt, 2013). Studies of UI program participants find that UI plays a critical role in keeping workers from exiting the labor market (Farber \& Valletta, 2015; Young, 2012), shields many American households from poverty (Arbeit, 2012; Bitler \& Hoynes, 2010; Moffitt, 2013; Vroman, 2010), and has a positive impact on the health and well-being of displaced workers and their families (Kuka, 2015; Kukla-Acevedo \& Heflin, 2014).

Yet, because women's labor force attachments may differ from men's in ways that make them ineligible for benefits, there is good reason to think that working women may not be able to access UI at the same rates as working men. Prior research has documented that some groups of workers, such as less educated workers and low-wage earners (GAO, 2000; Shaefer, 2010), former welfare recipients (Boushey \& Wenger, 2006; Shaefer \& Wu, 2011), and part-time workers (Chan, Michaelides, \& Zhang, 2014; GAO, 2000; Vroman, 1998, 2002) have greater difficulty meeting UI eligibility criteria and accessing UI benefits than others. It is likely that barriers for this groups disproportionately affects women because approximately $60 \%$ of low-wage workers are women (GAO, 2011), and 67\% of part-time workers are women (BLS, 2016d).

Given the importance of participation in UI to workers’ economic security and wellbeing, but given women's weaker position in the labor market, it is important to how 
gender affects workers' access to UI. To contribute to research in this area, I use nationally representative longitudinal data from the 2004 and 2008 panels of the Survey of Income and Program Participation to answer two questions: Is there a gender gap in UI coverage? If so, what are the factors contributing to the gender gaps in UI coverage?

In the first section of the paper, I provide a brief overview of the UI program and a conceptual framework for why working women may not be covered by UI at the same rates as working men. Then, I empirically test this framework using workers' earnings and work histories from the SIPP and states' monetary eligibility rules to estimate rates of monetary eligibility for UI as a proxy for UI coverage. Based on probit regression analysis, I find that working women are less likely to be covered by UI than working men, and that these gaps are larger for less-educated workers. ${ }^{25}$ Based on decomposition analysis, I find that up to one third of the gender gaps in UI coverage can be attributed to distributional differences in working men and women's demographic and job characteristics, particularly differences in rates of part-time work and occupations, whereas two thirds of these gaps can be attributed to differences in the labor market returns that men and women receive to their demographic and job characteristics.

By focusing on gender differences in UI coverage, the likelihood that a worker is monetary eligible for benefits based on their work hours and earnings, this paper extends current conversations on the consequences of gender disparities in the labor market beyond the gender wage gap. Much like wages, having UI coverage may influence women's decisions to remain in the labor market after experiencing job loss and influence their decision-making about investments in future educational and job-training opportunities. Additionally, by demonstrating how workers' gendered position in the labor market positions affect their access unemployment insurance, this paper provides an

\footnotetext{
${ }^{25}$ I define workers as monetary eligible for UI if they meet their states' work history and earnings requirements during the first four of the five quarters prior to unemployment.
} 
example of the uneven distribution of employment-based social protections across the labor force. ${ }^{26}$ In terms of programmatic changes to UI design that could increase rates of coverage among working women, the result from the decomposition analysis suggest that reducing the wage and work history requirements needed for UI program eligibility and adopting separate UI monetary eligibility determinants for part-time workers would likely have the greatest impact on closing the gender gaps in UI coverage.

\section{Background}

Although some workers may be at greater risk of unemployment than others, evidence from longitudinal survey data suggests that the likelihood of experiencing at least one spell of involuntary unemployment while working is nearly universal for Americans (Marmor, Mashaw, \& Pakutka, 2014).The Federal-State Unemployment Compensation (UI) program, a public social insurance program, is the main source of income support available to workers when they experience job loss. Because the UI program is mandated at the federal level, but it is administered and implemented at the state level, states pay UI benefits to qualifying individuals on a weekly basis. ${ }^{27}$

The primary goals of the UI program are to reduce hardships suffered by unemployed workers and their families and to stabilize the national economy during times of economic crisis when rates of joblessness increase (Nicholson \& Needels, 2006; Nicholson, Needels, \& Hock, 2014; Wandner \& Stengle, 1997). There is general consensus that in order to meet these goals, UI needs to have a broach reach across the

\footnotetext{
${ }^{26}$ Measuring UI coverage rather than UI take-up (i.e. whether an unemployed worker receives benefits), allows me to separate the effects of workers' labor force attachments from other factors that have been shown to influence access to UI such as workers' reasons from exiting employment and their knowledge of the availability of benefits (Shaefer 2010, Gould-Werth \& Shaefer, 2011).

${ }^{27}$ The weekly benefit amount is determined by length of work history and earnings, the state method for calculating weekly benefit amount, and the state's minimum and maximum benefit amount. In most states individuals can receive benefits for up to 26 weeks. Two states have higher benefit durations and eight states have lower benefit durations (Whittaker \& Isaacs, 2014). During the Great Recession, federal legislation extended benefit durations, up to 99 weeks in some cases.
} 
labor force. At the same time, theories of optimal insurance raise concerns that the availability of UI benefits increases the unemployment rate, increases the duration of unemployment spells, and suppresses job creation. In order to provide income support to workers at need and simultaneously avoid issues of moral hazard, states limit benefit amounts and benefit durations, and they require workers to meet certain conditions in order to receive benefits.

In order to receive weekly UI benefits, claimants must meet both monetary and non-monetary criteria. Monetary criteria stipulate the minimum prior labor force attachment (work hours and earnings) a worker must have in the period prior to unemployment to qualify for benefits. Most states use the first four of the five calendar quarters prior to the quarter of unemployment as the base period for determining whether a worker's labor force attachment meets monetary eligibility conditions (DOL, 2014). ${ }^{28}$

Non-monetary criteria identify whether a worker's reason for unemployment qualifies as involuntary. Most states require UI recipients to be job losers, individuals who have become unemployed due to layoff or employer bankruptcy, rather than job leavers, individuals who have voluntarily exited from employment. Once eligibility for UI and the amount of weekly benefits have been determined, beneficiaries also must meet guidelines for continuing eligibility. Broadly, these guidelines require that a UI recipient be available for work, actively seeking work, and willing to accept reasonable employment offers (NELP, 2010; Nicholson \& Needels, 2006). ${ }^{29}$

\footnotetext{
${ }^{28} \mathrm{~A}$ number of states also define an alternative base period (ABP) as the four quarters prior to unemployment when individuals do not qualify for benefits under the conventional base period (DOL, 2014).

${ }^{29}$ Importantly, multiple job holders may claim UI benefits as long as they are seeking more work and their wages are less than or equal to their benefit amount. For these individuals, the weekly benefit amount is adjusted to account for earnings from their second job. In most cases total earnings (wages and weekly benefit amount) cannot be greater than one and a half times the weekly benefit amount. This rule applies similarly to individuals who work only one job but have had their hours reduced and for workers who find limited work with a new employer and are seeking additional work.
} 
UI eligibility criteria are used to limit UI access to workers with strong recent labor force attachments who have become involuntarily unemployed, but they are not intended to systematically exclude any specific demographic group of workers. Nevertheless, existing studies suggest non-monetary eligibility criteria disproportionally limit access to UI among some groups of unemployment workers. Rates of UI receipt tend to be lower among less-educated low-wage workers (GAO, 2000; Shaefer, 2010; Stettner, Boushey, \& Wenger, 2005), former welfare recipients (Boushey \& Wenger, 2006; Shaefer \& Wu, 2011), Hispanic workers (Gould-Werth \& Shaefer, 2012), and parttime workers (Chan et al., 2014; GAO, 2000; Vroman, 1998, 2002). In the following section, I discuss reasons why working women and men may differ in their rates of UI coverage.

\section{Conceptual Framework}

UI coverage is determined by whether workers’ labor force attachments, particularly their work amounts and earnings, are sufficient to make them monetarily eligible for benefits. Workers' labor force attachments, and by extension their rates of UI coverage, are closely related to their demographic and job characteristics such as education, age, race and ethnicity, marital status, children, part-time work status, occupation, and industry. Consequently, UI coverage may not be gendered if workers’ demographic and job characteristics and their labor force attachments do not vary by gender.

Along these lines, there has been a lively debate regarding the declining significance of gender when it comes to labor market outcomes (Blau, Brinton, and Grusky, 2006), because similarities between the employment experiences of men and women have increased over the last fifty years, due to women's gains in educational, 
occupational, and earnings attainment. In fact, today, nearly half of all workers are women (Blau \& Kahn, 2007; BLS, 2015a), women appear to be staying in the labor force for longer than in the past (Hollister \& Smith, 2014), women are completing college at the same or higher rates as men (Ge \& Yang, 2013), and women are having less children and/or delaying child birth (DiPrete \& Buchmann, 2013). These growing similarities in men and women's demographic and job characteristics suggest that women and men should have increasingly similar rates of UI coverage.

Alternatively, there is good reason to expect that gender continues to be an important factor in distinguishing workers' job characteristics and their work hours and earnings, which are used determine monetary eligibility for UI benefits. Trends from the early 2000s indicate both a slowing of gender integration by industry and occupation (Blau, Brummund, \& Liu, 2013; del Río \& Alonso-Villar, 2015; Levanon, England, \& Allison, 2009) and a slowing of the closing of the gender wage gap (Blau \& Kahn, 2007; Cha \& Weeden, 2014; England, 2010), despite women’s important gains in prior decades. Furthermore, there is evidence of a deceleration in the growth of gender egalitarian attitudes, measured by questions related to the acceptability and suitability of women's work outside the home, beginning in the mid-1990s (Cotter, Hermsen, \& Vanneman, 2011). These patterns indicate persistent differences in men and women's job characteristics and labor force attachments, which may lead to gender differences in UI coverage.

Given that gender is a significant factor that distinguishes workers' demographic and job characteristics and their labor force attachments (employment behaviors), Figure 1 outlines two possible sources of gender differences in UI coverage. First, distributional differences in men and women's demographic and job characteristics may contribute to gender differences in UI coverage, if these demographic and job characteristics are 
strongly associated with workers' labor force attachments. Second, gender may directly influence UI coverage if gender changes the labor market returns that workers receive for a given set of demographic and job characteristics.

Figure 1. Conceptual Framework

Different Characteristics (X)

Different distributions of demographic and job

characteristics by gender

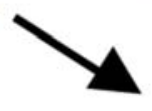

Workers'

Labor Force

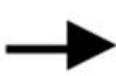

Gender Gap in UI

Attachments

Coverage

Different Returns ( $\beta$ )

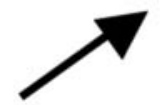

Different labor market returns to

demographic and job characteristics by

gender

Work Hours. Basing eligibility on a worker’s labor force attachment may affect women differently than men, because women may be more likely than men to work fewer hours or to have more work interruptions. In 2015, 71.9 percent of part-time workers were women; additionally, men ages 25 to 54 worked an average of 42.4 hours per week, whereas women worked an average of 37.5 hours per week (BLS, 2016d). Furthermore, in 2015, full-time working women ages 25 to 54 reported an absence from work in a given week nearly twice as often as full-time working men of the same age, 3.8\% compared to 1.9\% (BLS, 2016a). These differences in work absences may occur because responsibilities for household production and informal care-taking, disproportionately fall to women (Gornick \& Meyers, 2003). Of those reporting an absence, $42 \%$ of women reported the cause to be unrelated to their own illness or injury, such as child care problems, other family or personal obligations, civic or military duty, and maternity paternity leave, compared to $26 \%$ of men. 
Women may work fewer hours than men or choose to work part-time because they have different preferences for time allocation. However, women's (and men’s) work hours may also be influenced by their employers' behaviors, and by whether or not they are covered by paid family leave policies and child care subsidies. The literature on the employment experiences of less-educated women indicate that their work hours and work schedules are largely determined by their employers (Alexander \& Haley-Lock, 2013; Golden, 2015; Lambert, 2008), and that they often desire to work more hours than they are scheduled (Alexander \& Haley-Lock, 2013; Golden, 2015; Watson, Frohlich, \& Johnston, 2014). Additionally, less-educated women may have little say when it comes to choosing between work and family obligations if they lack stable child care arrangements (Adams \& Rohacek, 2010; Hofferth \& Collins, 2000; Edward D. Lowe \& Weisner, 2004; Edward D Lowe, Weisner, \& Geis, 2003), access to caretaking support from a spouse or another family member (Kimmel \& Powell, 2001; Edward D. Lowe \& Weisner, 2004), or paid time off to cover work absences for childbirth and caretaking (Hill, 2013; Ybarra, 2013). In 2000 the GAO reported that someone who exited employment due to changes in a child care arrangement, but was otherwise available for work, would be eligible for UI benefits in only 18 states (GAO, 2000).

Earnings. In addition to work hours, earnings prior to unemployment determine eligibility for unemployment insurance. This emphasis on prior earnings raises concerns for women because they earn less than men on average. In 2015 women over the age of 25 had average weekly wages of $\$ 752$ compared to $\$ 922$ for men (BLS, 2016c). Although gender differences in wages persist at all levels of educational attainment, overall wages are considerably lower for workers with a high school diploma or less. Therefore, when it comes to eligibility for unemployment insurance wage differences 
between less educated men and women may be especially critical. ${ }^{30}$ In 2014, the median weekly earnings of women with a high school diploma were $23 \%$ lower than the median earnings of men with a high school diploma, \$578 compared to \$751 (BLS, 2015a).

Of course, there are a number of reasons why women may earn less than men. Some of these reasons may have to do with observable differences in women and men's demographic and job characteristics, such as differences in rates of part-time work, occupation, and industry. For example, workers in predominately female occupations tend to have lower wages than workers in predominately male occupations that require similar levels of skills and education (England, 2005; Levanon et al., 2009). Although in 2015 about half of workers in service occupations were women and about half were men, $87 \%$ of workers in healthcare support occupations (a subgroup of service occupations) were women with average median wages of $\$ 490$; whereas, nearly $80 \%$ of workers in protective service occupations (such as firefighters) were men with average weekly wages of \$851 (BLS, 2016b). If gender differences in earnings occur because of selection into occupations, industries, and part-time work status, then accounting for these observable job characteristics should explain a good portion of any negative relationship between gender (being a woman) and unemployment insurance coverage.

However, these distributional differences in job characteristics will not fully explain gender gaps in UI coverage if earnings differences occur because the labor market responds differently to men and women with a given set of observable job characteristics. For example, occupational segregation has decreased over time in professional and managerial occupations, yet the wage gap has not (Cotter, Hermsen, Vanneman, 2012). Additionally, differences in men and women’s responsibilities for

\footnotetext{
${ }^{30}$ In 2014, the median weekly earnings of full-time wage and salary workers ages 25 and older with a high school diploma and no further education were $56 \%$ of the median weekly earnings of full-time wage and salary workers with a bachelor's degree or higher (BLS, 2015b).
} 
aspects of household production such as informal caretaking may reduce women's earnings relative to men's even if the proportion of men and women with young children in the home is quite similar. There is good evidence that women's work hours and earnings decrease as their hours committed to informal caretaking increase (Carmichael \& Charles, 2003), and that full-time working women are less likely to work overtime than men (Cha \& Weeden, 2014).

Risk of Unemployment. In addition to contributing to gender differences in earnings, men and women are likely to be employed in occupations and industries that are associated with different risks of unemployment (Michaelides \& Mueser, 2013). In 2008 at the peak of the Great Recession, jobs in manufacturing (predominately male) declined by 10 percent, whereas jobs in service industries such as retail trade declined by only $5 \%$, jobs in professional and business services declined by about $7 \%$, and jobs in education and health services (predominately female) actually increased by about $2 \%$ (BLS, 2012). In fact, most of men's job losses relative to women's during this most recent recession can be explained by gender sorting across occupation and industry (Sahin \& Willis, 2011). Consequently, the women most likely to be covered by unemployment insurance may work in occupations and industries where they are less likely to become unemployed; whereas, the men most likely to be covered by UI may work in occupations and industries in the risk of unemployment is much higher, especially during economic downturns. This may lead to a larger gap in UI coverage among unemployed women and men than among employment women and men.

Furthermore, the sensitivity of an occupation or industry to the businesses-cycle may affect employers' strategies for reducing labor costs and their reliance on the UI program as a source of income support for their employees. In workplaces where unemployment is predictable and formal layoffs are common, employers may take 
additional steps to inform their employees about the availability of benefits (GouldWerth, 2016). Conversely, in service-producing sectors where flexible work arrangements are used, it may be more common for employers reduce workers' hours rather than formal layoffs to offset changes in demand (Lambert, 2008). Although flexible scheduling strategies have important benefits for employers and employees, they may affect UI coverage by weakening workers’ labor force attachments. In a recent study of patterns in UI receipt, Chan et al. (2014) find that although half of new job losers in their data were previously employed in service-producing sectors, they represented less than a third of UI recipients.

Summary. In the following section, I empirically examine gender differences in UI coverage by using data from the 2004 and 2008 panels of the Survey of Income and Program Participation (SIPP). Because UI coverage is determined by whether a worker's labor force attachment, particularly their work amount and earnings, is sufficient to make her monetarily eligible for benefits, and because there is empirical evidence that men and women differ in their job characteristics and their labor force attachments, I expect that working women will be less likely to be covered by UI than men, and I expect that this gap in UI coverage will be larger among less-educated men and women.

As for the possible factors contributing to these gaps, if jobs largely determine work hours and earnings, then I expect that gender differences in UI coverage will be mostly explained by distributional differences in women and men's job characteristics. For example, over $70 \%$ of part-time workers are women, and half of women (or men) would have to change jobs in order for men and women to be evenly distributed across occupational groups (Bailey \& DePrete, 2016). Of course, gender may directly affect work hours and earnings, in which case gender differences in UI coverage will be explained by differences in the labor market returns that men and women receive to their 
demographic and job characteristics. For example, unmeasured characteristics including workers preferences and abilities may directly lead to differences in earnings, work hours, and unemployment risks between working men and women with the same set of observable characteristics.

\section{Data and Methods}

Data. The Survey of Income and Program Participation is a longitudinal survey of a nationally representative sample of individuals and households in the U.S. conducted by the Census Bureau and the Bureau of Labor Statistics. The 2004 SIPP panel includes approximately 110,700 individuals in 43,500 households, and the 2008 SIPP panel includes approximately 105,600 individuals in 42,000 households. Individuals were interviewed either in person or by telephone every four months. For the 2004 panel, individuals were interviewed over a three year period beginning in February 2004. For the 2008 panel, individuals were interviewed over five year period beginning in September 2008. In each wave of the interview, individuals age 15 and older were asked a set of core questions on labor force participation, income, public program participation, and demographics. ${ }^{31}$

Because it is possible to observe changes in individuals' employment behavior such as hours worked, wages earned, entry and exits from employment, and reasons for work absences or exits over time, the structure of SIPP is ideal for examining labor force dynamics. Because of the sampling structure and the repetition of core interview questions over the duration of the survey, SIPP data can also be used as a sample of repeated cross-sections. Both of these factors are important for the structure of the analysis below.

\footnotetext{
${ }^{31}$ Additionally, different waves of interviews contained questions on topics such as fertility, poverty, child care, and tax rebates, which were repeated with less frequency than the core interview questions.
} 
Although the SIPP provides information about work history, allowing employment patterns and eligibility for UI to be captured, there are known challenges when using longitudinal survey data. One challenge is attrition. While low-income individuals are intentionally oversampled in the SIPP, these individuals drop out of the survey at higher rates than other individuals, making attrition problematic because it is nonrandom (Czajka, Mabli, \& Cody, 2008; Vaughan \& Scheuren, 2002). To correct for attrition, I include person-level weights in the analysis. As individuals exit the survey, those who remain and have characteristics similar to those who have exited are given greater weight.

Seam bias creates another challenge when using panel data. Individuals tend to report events more accurately in the reporting month of a survey and less accurately the further they are asked to look back. The result is that when patterns are observed over time, changes and transitions appear with greater frequency between the reporting month of an interview and the earliest reference month of the subsequent interview. One approach to correcting for seam bias is to collapse monthly observations into observations by wave, keeping only the information from the reporting month (Ham, Li, \& Shore-Sheppard, 2009). Because monetary eligibility for UI is based on quarterly work history and earnings, this approach is not possible, which may be a limitation of the study..$^{32}$

Sample. Using the 2004 and 2008 SIPP panels, for each quarter I identify all individuals who are part of the U.S. civilian population; who are not active duty military or recently separated from military service and unemployed; who are twenty-five or older and fifty-five or younger, the ages at which individuals are expected to have their

\footnotetext{
${ }^{32}$ I collapse reference period observations into quarters (3 month periods). For each rotation group in the SIPP, one quarter of observations in each year do not cross waves and do not contain the responses during the reporting month. All other quarters cross waves, but also contain responses from a reporting month. Quarters not containing responses from a reporting month should be affected by seam bias more than quarters containing response from a reporting month.
} 
strongest attachments to the labor force; and who have uninterrupted participation in the SIPP in the five prior quarters. The first quarter of 2005 is the first quarter where it is possible to identify whether individuals in the 2004 panel meet this condition, and the third quarter of 2009 is the first quarter where it is possible to identify whether individuals in the 2008 SIPP panel meet this condition. From this sample, I identify all currently employed workers (Group A) and all unemployed workers (Group B).

Employed workers are individuals who report continuous employment in the quarter in which monetary eligibility for UI is estimated. I include SIPP individuals in the analysis each time they meet this criteria. Therefore, the sample includes 54,633 individuals, who contribute a minimum of 1 and a maximum of 15 person-quarters to the study with a median of 5 person-quarters. The sample of less-educated employed workers includes 17,288 individuals, who contribute a minimum of 1 and a maximum of 15 person-quarters to the study, with a median of 5 person-quarters.

Unemployed workers are individuals who report unemployment at any time in the quarter in which monetary eligibility for UI is estimated. I include SIPP individuals in the analysis each time they meet this criteria. This sample includes 8,058 individuals, who contribute a minimum of 1 and a maximum of 11 person-quarters to the study, with a median of 1 person-quarter. The sample of less-educated unemployed workers includes 3,184 individuals, who contribute a minimum of 1 and a maximum of 10 person-quarters to the study, with a median of 2 person-quarters.

Variables. I estimate monetary eligibility for UI (UIE) using individual's work history and earnings in the first four of the five prior quarters and state monetary eligibility formulas from 2005 to 2013 provided in the Comparison of State UI Laws, which are published online by the U.S. Department of Labor and updated annually (BLS, 2015). For example, in order to be monetarily eligible for UI in Missouri, claimants must 
have base period earning 1.5 times greater than their high quarter earnings. So, an individual in the sample between the ages 25 to 55 living in Missouri in the second quarter of 2010, who had continuous participation in the SIPP from January 2009 to April 2010, would be eligible for UI if (1) her total earnings in the base period (January 2009 to December 2009) were 1.5 times greater than her highest quarter earnings during the base period, and (2) her highest quarter earnings were greater than $\$ 1,500$ and base period earnings were equal to or greater than $\$ 2,250$.

All explanatory variables used in the analysis are binary variables. The primary explanatory variable of interest is the sex of the respondent, coded 1 if the respondent is female and 0 if the respondent is male. I also include indicators of race and ethnicity (non-Hispanic white, non-Hispanic black, Asian, other race, or Hispanic of any race), age (25 to 34, 35 to 44, or 45 to 55), education (less than a high school diploma, high school diploma and no further education, a high school diploma and some college, or a four year college degree or higher), marital status (never married, married, divorced/separated, or widowed), and whether there are children under 18 years of age in the home (yes=1). In terms of the job characteristics of workers, I include an indicator for part-time work (yes = 1) if a workers reports working less than 35 hours a week at their primary job at any time during the quarter. I also include an indicator of industry (13 industries) and occupational classifications (23 occupations) based on individuals’ primary jobs.

Methods. In order to identify whether there are gender differences in access to UI, I first examine whether or not working men and women differ in their likelihood of monetary eligibility based on the following expression,

$$
\operatorname{Pr}\left(U I E_{\text {ist }}=1 \mid X\right)=F(X \beta)=F\left(\alpha+\tau \text { female }_{i t}+\pi_{s}+\varphi_{t}\right)
$$


where $U I E_{\text {ist }}$ is an indicator equal to 1 if a worker $(i)$ in group $r$ ( $r$ =employed or unemployed) residing in state $(s)$ at time $(t)$ is monetarily eligible for UI, $X$ is a vector of all the explanatory variables in the model, $\beta$ is a vector of coefficients on the explanatory variables in the model plus an intercept term, $\mathrm{F}$ is the standard normal cumulative distribution function (probit link), Female $_{i t}$ is a binary indicator of whether a worker ( $i$ ) is female (1) or male (0), $\pi_{s}$ is a set of indicators for each state and $\varphi_{t}$ is a set of indicators for each quarter. I cluster errors at the individual level to account for withinperson autocorrelation that occurs due to repeated observations for individuals across quarters.

The strength of the relationship between gender and eligibility for UI may change if gender is associated with another demographic characteristic that is a strong predictor of UI eligibility. Therefore, in a second model, I add a vector of individual demographic characteristics ( $W_{i t}$ ) including binary indicators of race and ethnicity, age, education, marital status, and children under 18 to equation 1 and examine how the gender coefficient changes

$$
\operatorname{Pr}\left(U I E_{i s t}=1 \mid X\right)=F(X \beta)=F\left(\alpha+\tau \text { female }_{i t}+W_{i t} \gamma+\pi_{s}+\varphi_{t}\right)
$$

Although I do not particularly expect the demographic characteristics of workers to change the relationship between gender and monetary eligibility, there is good reason to expect that job characteristics such as part-time work, industry, and occupation do vary by gender and have a strong relationship to monetary eligibility. For example, as discussed above, I would expect any observed gender difference in eligibility for unemployment insurance to be sensitive to the addition of occupation and industry covariates, if working in certain occupations and industries is strongly associated with UI eligibility, and if there is a strong relationship between gender and the occupations and industries in which workers are likely to be employed. Therefore, in a third model, I add 
a vector of labor force characteristics $\left(Z_{i t}\right)$ including binary indicators of part-time work status, occupation, and industry to equation 2 and examine how the gender coefficient changes:

$\operatorname{Pr}\left(U I E_{\text {ist }}=1 \mid X\right)=F\left(X \beta^{*}\right)=F\left(\alpha+\tau\right.$ female $\left._{i t}+W_{i t} \gamma+Z_{i t} \delta+\pi_{s}+\varphi_{t}\right)$

Equation 3 is the full specification of the relationship between eligibility for unemployment insurance and workers demographic and job characteristics.

Next, I use decomposition analysis to examine the factors contributing to gender differences in access to UI. Conceptualizing this exercise in terms of just one indicator, a portion of difference in men and women's average likelihoods of monetary eligibility for UI could be explained by the fact that men and women have different rates of part-time work. Part-time workers differ from full-time workers in their labor force attachments. Therefore, if more women than men work part-time, this should explain at least some of the gender difference in UI eligibility.

Another portion of the overall difference in UI may be related to group differences in the returns to part-time status. For example, if gender directly determines the strength of a part-time worker's labor force attachment, i.e. if men who work part time earn more on average than women who work part time or work more hours than women who work part time, then a portion of the overall gender difference in monetary eligibility for UI would not be expected to change if the same number of men and women worked part time.

In order to examine how group differences in characteristics and group differences in coefficients contribute to gender differences in monetary eligibility for UI, I use an extension of a traditional linear decomposition analysis technique to nonlinear models (Yun, 2000, 2004, 2005). For the analysis, I use characteristics and coefficients 
from probit models where monetary eligibility for UI is estimated separately for males and females:

$$
U I E^{j}=F\left(X^{j} \beta^{j}\right)=F\left(\alpha+W^{j}{ }_{i t} \gamma^{j}+Z^{j}{ }_{i t} \delta^{j}+\pi_{s}^{j}+\varphi_{t}{ }^{j}\right) .
$$

In equation $4, \mathrm{j}=$ males or females, $X$ is a vector of the demographic, job, state, and time characteristics for group $\mathrm{j} ; \beta$ is a vector of the coefficients for the demographic, job, state, and time characteristics, including the intercept term; and F is the standard normal cumulative distribution function. Because I am specifically interested in whether there are gender differences in access to UI, but I do not necessarily assume that the determinants of access to UI always disfavor women, I estimate the decomposition using pooled coefficients $\left(\beta^{*}\right)$ from equation 3 above as the base (Jann, 2008). ${ }^{33}$ The results of the decomposition analysis using estimates of $\beta^{*}$ capture the determinants of access to UI if gender were not a factor in the labor market.

The contribution of differences in women and men’s demographic and job characteristics (the explained portion) and the contribution of gender differences in the returns to these characteristics (the unexplained portion) to the overall difference in the proportion of men and women who are monetarily eligible for UI can be expressed as:

$$
\begin{gathered}
\left.\overline{U I E^{m}}-\overline{U I E^{f}}=\overline{\left[F\left(X^{m} \beta^{m}\right)\right.}-\overline{F\left(X^{f} \beta^{f}\right)}\right] \\
=\left[\overline{F\left(X^{m} \beta^{*}\right)}-\overline{F\left(X^{f} \beta^{*}\right)}\right]+\left\{\left[\overline{F\left(X^{f} \beta^{*}\right)}-\overline{F\left(X^{f} \beta^{f}\right)}\right]+\left[\overline{F\left(X^{m} \beta^{m}\right)}-\overline{F\left(X^{m} \beta^{*}\right)}\right]\right\}
\end{gathered}
$$

where the overbar represents the sample average of the specification of $\mathrm{F}(X \beta)$.

${ }^{33} \beta^{*}$ is a vector of the coefficients on gender, other demographic characteristics (race/ethnicity, age, education, marital status, children under 18), job characteristics (part-time work, occupation, and industry), state, and time, plus the intercept term from equation 3. 
The first term on the right hand side of equation 5 (in brackets) reflects the change in the overall difference in monetary eligibility if men and women had the same distribution of characteristics as the sample as a whole, i.e. if gender were not a factor in the labor market. The final term (in braces) reflects the change in the overall difference in UI eligibility if men and women had the same returns to their characteristics $\left(\beta^{j}\right)$ as the sample as a whole $\left(\beta^{*}\right)$. I report the results from the estimations of the pooled nonlinear decomposition model (equation 5) for employed and unemployed workers below.

\section{Results}

Sample characteristics. The gender distribution for each group of labor force participants is reported in Table 1. On average from 2005 to 2013, 49.59\% of employed workers were female, $49.91 \%$ of unemployed workers were female. For the subsample of less educated workers, those with a high school diploma or less, $43.77 \%$ of employed workers were female, $45.39 \%$ of unemployed workers were female.

In terms of differences in UI eligibility by gender, for the full sample of employed workers, $92.53 \%$ of women and $95.20 \%$ of men were eligible for UI. In contrast, fewer unemployed workers were eligible for UI: $67.87 \%$ of unemployed women and $76.66 \%$ of unemployed men. For the subsample of less-educated employed workers, 90.73\% of women and 94.20\% of men were eligible for UI. For less-educated unemployed workers, $64.89 \%$ of women and $74.74 \%$ of men were eligible for UI. ${ }^{34}$

The estimates of monetary eligibility among the less-educated unemployed are slightly lower than estimates from (Shaefer, 2010), who finds that 85\% of less-educated unemployed workers are eligible for using data from the 2001 SIPP. Differences in the rates of eligibility among the unemployed from the 2001 SIPP and my sample from the

\footnotetext{
${ }^{34}$ Summary statistics show in the appendix (Tables 4 and 5).
} 
2008 SIPP may have to do changes in employment among less educated workers

following the Great Recession. ${ }^{35}$ Between December 2007 and January 2010 employment for workers with less than a high school diploma decreased by more than 40,000 workers per month, whereas monthly employment grew slightly during this same period for workers with a bachelor’s degree or more (Sahin \& Willis, 2011).

Table 1. Summary Statistics

\begin{tabular}{rcc}
\hline & \multicolumn{2}{c}{ All Workers } \\
Male & Employed & Unemployed \\
Female & $50.41 \%$ & $50.09 \%$ \\
& $49.59 \%$ & $49.91 \%$ \\
Male & Workers Monetarily & Eligible for UI \\
Female & $95.20 \%$ & $76.66 \%$ \\
& $92.53 \%$ & $67.87 \%$ \\
Avg. N & 12,312 & 527 \\
& \multicolumn{2}{c}{ Less educated Workers } \\
& Employed & Unemployed \\
Male & $56.23 \%$ & $54.61 \%$ \\
Female & $43.77 \%$ & $45.39 \%$ \\
& & \\
& Less-educated Workers Monetarily Eligible for UI & $74.74 \%$ \\
Male & $94.20 \%$ & $64.89 \%$ \\
Female & $90.73 \%$ & 214 \\
& & \\
Avg. N & 3,643 &
\end{tabular}

Notes: Unadjusted quarterly averages from January 2005-December 2007 and October 2009-October 2013. All workers defined as US civilian population, age 25-55, with continuous participation in the SIPP in the prior five quarters. Less-educated workers defined as US civilian population, age 25-55, with continuous participation in the SIPP in the prior five quarters, and reporting a high school diploma or less as highest level of educational attainment.

\footnotetext{
${ }^{35}$ Additionally, Shaefer (2010) uses annual earnings to estimate monetary eligibility, whereas I create a measure of quarterly earnings from individuals' monthly earnings.
} 
Probit analysis. The results from probit regression predicting monetary eligibility for UI based on equations 1, 2, and 3 above are reported in Table 2 for employed workers (Group A) and unemployed workers (Group B). For all groups, I report the average marginal effect of the gender difference in monetary eligibility for UI (female=1), which can be interpreted as a change in the likelihood of monetary eligibility due to a discrete change in the category of the independent variable, holding all other variables at their means.

Table 2. Probit Regression Models Predicting Monetary Eligibility for UI

\begin{tabular}{rcc}
\hline & Group A: Employed & Group B: Unemployed \\
\hline & \multicolumn{2}{c}{ Model 1 Gender Only ${ }^{\mathrm{a}}$} \\
Marginal Effect & -0.029508 & -0.088269 \\
Standard Error & $(0.001544)$ & $(0.009210)$ \\
Significance & $* * *$ & \\
& & \\
& Model 2 Gender + Demographics & \\
& -0.031647 & -0.086116 \\
Marginal Effect & $(0.001558)$ & $(0.009383)$ \\
Standard Error & $* * *$ & $* * *$ \\
Significance & & \\
& Model 3 Gender + Demographics+ Job Characteristics ${ }^{\mathrm{a}}$ \\
Marginal Effect & -0.017375 & -0.057904 \\
Standard Error & $(0.001820)$ & $(0.012380)$ \\
Significance & $* * *$ & $* * *$ \\
& & 8,058 \\
Clusters & 54,633 & 14,752 \\
$\mathrm{~N}$ & 344,734 &
\end{tabular}

Notes. Sample restricted to US civilian population, age 25-55, who participated in the SIPP continuously in five prior quarters. Employed defined as workers with continuous employment during the quarter in which eligibility is estimated. Unemployed workers defined as workers reporting unemployment in any month of the quarter in which eligibility is estimated. ${ }^{a}$ All models include state and time dummy variables. ${ }^{b}$

Marginal effects shown with robust standard errors in parentheses. ${ }^{* * *} \mathrm{p}<0.001,{ }^{* *} \mathrm{p}<0.01,{ }^{*} \mathrm{p}<0.05$.

The estimate from the regression of gender on monetary eligibility for UI, controlling for state and time, confirms the expectation that employed women will be less likely to be monetarily eligible for UI than employed women men. I find that employed 
women are 2.95 percentage points less likely to be monetarily eligible for UI than employed men. The magnitude of the gender difference in UI eligibility for employed workers increases slightly to 3.16 percent, once I account for the other demographic characteristics of employed workers. However, the gap reduces to 1.74 percentage points when I account for workers' job characteristics. This suggests that more than half of the raw gender differences in UI eligibility among the employed can be attributed to workers’ job characteristics.

Again, the estimate from the regression of gender on monetary eligibility for UI, controlling for state and time, confirms my expectations that unemployed women will be less likely to be monetarily eligible for UI than unemployed men. I find that unemployed women are 8.83 percentage points less likely to be eligible than unemployed men. Similar to the change in the gender estimate for employed workers, the magnitude of the gender difference in UI eligibility among unemployed workers increases to 8.61 percentage points when I account for unemployed workers’ other demographic characteristics. However, the gap shrinks to 5.8 percentage points when I account for unemployed workers’ job characteristics. Based on the differences in the estimates from the first and third regression models, about $30 \%$ of the raw gender differences in UI eligibility among the unemployed can be attributed to job characteristics.

Taken together, the findings from the probit regression analysis (Table 2) have interesting implications for the role of gender in access to UI and for the performance of the UI program. Access to UI does not appear to be gender neutral. Rather, the remaining gender difference in UI eligibility once workers’ job characteristics are included suggest that women's labor force attachments directly affect their access to UI. However, it appears that at least some portion of the gender gap in UI coverage is related to differences in men and women’s job characteristics. 
Because I expect that gender differences in access to UI may be more pronounced for less-advantaged workers, I repeat the above analysis for the subsample of lesseducated workers. Like Table 2, Table 3 reports the results predicting gender differences in monetary eligibility for UI for less-educated employed workers (Group A) and lesseducated unemployed workers (Group B).

Table 3. Probit Regression Models Predicting Less-educated Workers’ Monetary Eligibility for UI

\begin{tabular}{|c|c|c|}
\hline & $\begin{array}{c}\text { Group A: } \\
\text { Less-educated Employed }\end{array}$ & $\begin{array}{c}\text { Group B: } \\
\text { Less-educated Unemployed }\end{array}$ \\
\hline & \multicolumn{2}{|c|}{ Model 1 Gender Only ${ }^{\mathrm{a}}$} \\
\hline $\begin{array}{r}\text { Marginal } \\
\text { Effect }^{b}\end{array}$ & -0.038630 & -0.100788 \\
\hline Standard Error & $(0.003107)$ & $(0.014525)$ \\
\hline \multirow[t]{2}{*}{ Significance } & $* * *$ & $* * *$ \\
\hline & \multicolumn{2}{|c|}{ Model 2 Gender + Demographics ${ }^{\mathrm{a}}$} \\
\hline Marginal Effect & -0.041039 & -0.096909 \\
\hline Standard Error & $(0.003145)$ & $(0.014720)$ \\
\hline \multirow[t]{2}{*}{ Significance } & $* * *$ & $* * *$ \\
\hline & \multicolumn{2}{|c|}{ Model 3 Gender + Demographics+ Job Characteristics ${ }^{\mathrm{a}}$} \\
\hline Marginal Effect & -0.026642 & -0.065457 \\
\hline Standard Error & $(0.003880)$ & $(0.019963)$ \\
\hline Significance & $* * *$ & $* *$ \\
\hline Clusters & 17,288 & 3,184 \\
\hline $\mathrm{N}$ & 101,997 & 5,984 \\
\hline
\end{tabular}

Notes. Sample restricted to US civilian population, age 25-55, who participated in the SIPP continuously in five prior quarters, and who reported a high school diploma or less as their highest level of educational attainment. Employed defined as workers with continuous employment during the quarter in which eligibility is estimated. Unemployed workers defined as workers reporting unemployment in any month of the quarter in which eligibility is estimated. ${ }^{a}$ All models include state and time dummy variables. ${ }^{b}$

Marginal effects shown with robust standard errors in parentheses. ${ }^{* * *} \mathrm{p}<0.001,{ }^{* *} \mathrm{p}<0.01,{ }^{*} \mathrm{p}<0.05$.

The results predicting UI eligibility for less-educated employed workers mirror the results from the full sample of employed workers, but as expected, are slightly greater 
in magnitude. In the regression of gender on UI eligibility (Model 1), controlling for state and time, I find that less-educated employed women are 3.86 percentage points less likely to be eligible for UI than less-educated employed men. This difference increase slightly 4.10 percentage points, when I control for workers’ demographic characteristics. However, once I include job characteristics, less-educated employed women are only 2.66 percentage points less likely to be monetarily eligible for UI than less-educated unemployed men. For less-educated employed workers, the inclusion of job characteristics reduces the gender difference in UI eligibility from model 1 by about one third.

I expect the gender gap in UI coverage to be the greatest between less educated unemployed women and men. In addition to have lower wages, because the labor force attachments of less educated women may be characterized by shorter tenures in the labor force followed by longer tenures out of the labor force rather than by transitions from employer to employer and short-term changes in employment status (Damaske \& Frech, 2016; Killewald \& Zhou, 2015). The results, reported in Table 3, suggest that lesseducated unemployed women are 10.08 percentage points less likely to be eligible than unemployed men. This difference reduces to 9.69 percentage points when I include additional demographic characteristics (Model 2). After I include job characteristics

(Model 3), less-educated unemployed women remain 6.55 percentage points less likely to be eligible for UI than less-educated unemployed men. In this case, it appears that about $36 \%$ of the raw gender difference in UI eligibility for unemployed workers is channeled through part-time work status, industry, and occupation.

\section{Decomposition analysis.}

The results of the decomposition of gender differences in monetary eligibility for UI are reported in Figure 2 and Figure 3 for employed workers and Figure 4 and Figure 5 
for unemployed workers. In each figure the detailed contributions (in percentages) of the distributional differences in the demographic and job characteristics of workers to the gender gaps in UI eligibility are shown in black. The aggregate characteristics and returns effects are reported below the figures, as are the predicted probabilities of UI eligibility for both groups and difference between the two groups.

For employed workers (Figure 2), less than a third (29.59\%) of gender differences in UI eligibility for employed workers are explained by group differences in characteristics (mean values of $X^{j}$ ); whereas over two thirds (70.41\%) of gender differences are explained by group differences in coefficients $\left(\beta^{j}\right)$. Consistent with the results of the regression analysis, differences in the mean values of the demographic characteristics, race (.40\%), age (-0.24\%), education (-3.72\%), marital status (-0.28\%), and children in the home (0.28\%) contribute very little to the observed difference in UI eligibility between less-educated employed men and women. However, it is worth noting that the estimate for marital status reflects women's higher levels of educational attainment relative to men. If the composition of education was the same for women as for the sample as a whole, then the gap in monetary eligibility would be expected to increase by nearly $4 \%$.

Aside from marital status, differences in the mean values of job characteristics explain most of the overall gender difference in eligibility. In particular, if men and women's rates of part-time work status were equal to the rates of part-time status for the full population of employed workers, then the gender gap in UI eligibility among the employed would decrease by $28.92 \%$. If men and women’s occupational distributions were the same as the occupational distribution for the full population of employed workers, then the gender gap in UI eligibility would decrease by $5.74 \%$. It is interesting to note, however, that this pattern does not also hold for industry. If the distributions of 
employed men and women by industry matched the distribution of the full population of employed workers by industry, the gender gap in UI eligibility would increase by $2.37 \%$.

Figure 2. Pooled Decomposition of Gender Differences in UI Eligibility for Employed Workers

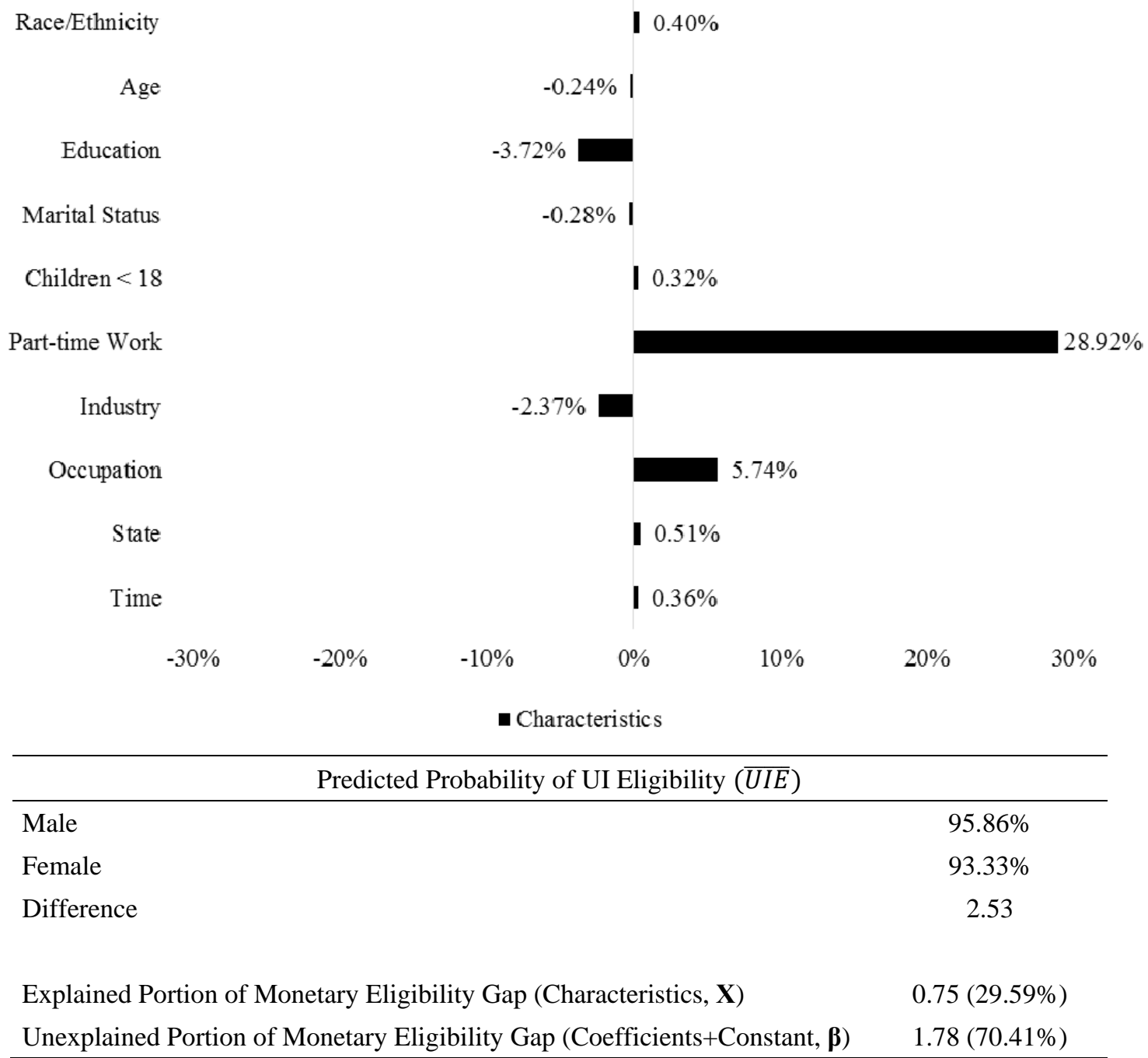

Notes Nonlinear decomposition analysis of gender differences in UI eligibility for employed workers. Reference group coefficients are pooled estimates from the full model (equation 3) predicting UI eligibility for employed men and women and including a dummy variable from gender. Characteristics effect shown in black, coefficients effect shown in gray.

Figure 3 shows the results of the pooled decomposition analysis (equation 5) of gender differences in UI eligibility for the subset of employed workers whose highest level of education is a high school diploma or less. The results suggest that only $16.91 \%$ 
of gender differences in UI eligibility for less-educated employed workers are explained by group differences in characteristics (mean values of $X^{j}$ ), and $83.09 \%$ of gender differences are explained by group differences in coefficients $\left(\beta^{j}\right)$.

Figure 3. Pooled Decomposition of Gender Differences in UI Eligibility for Lesseducated Employed Workers*

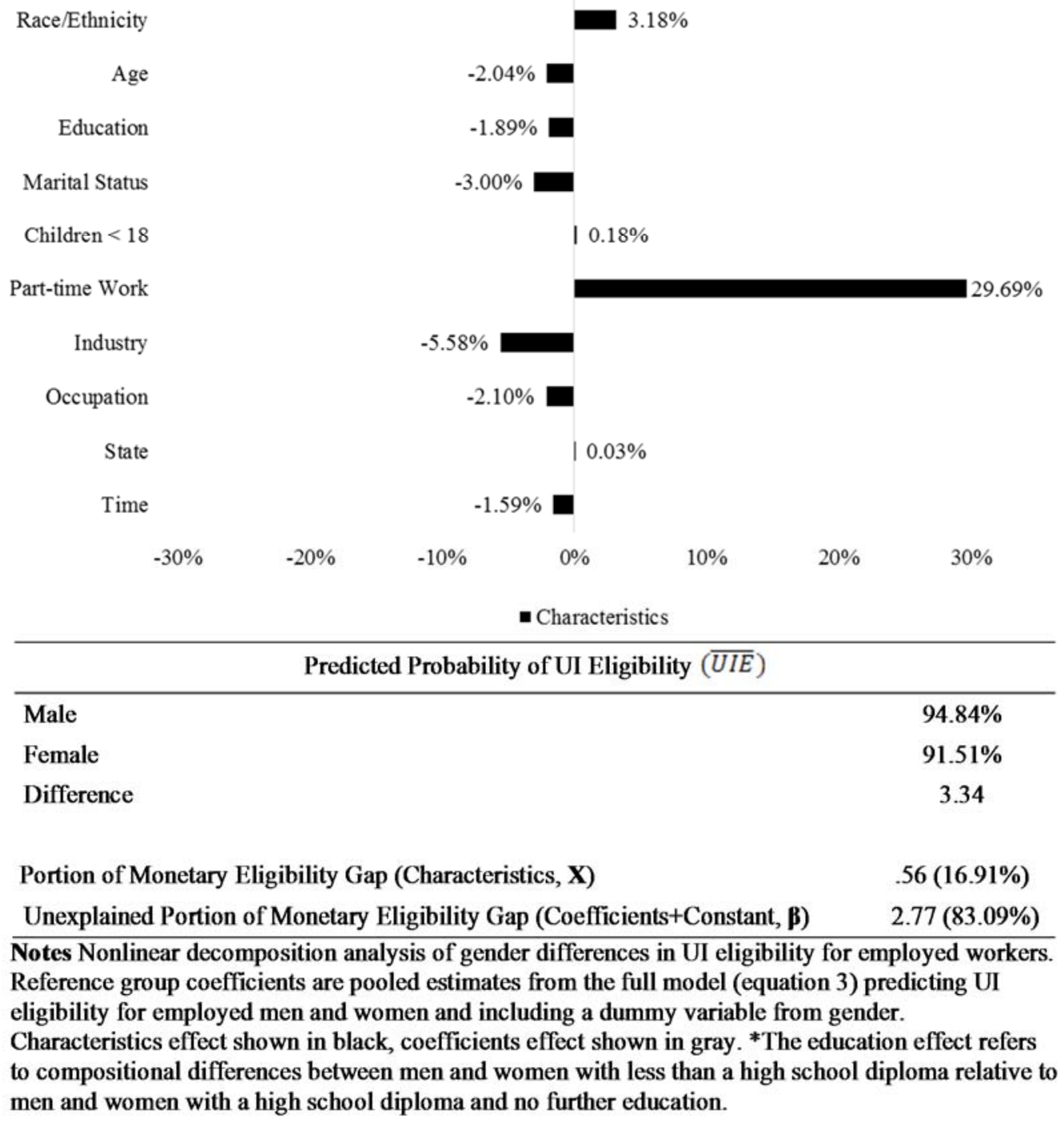

\begin{tabular}{lc}
\multicolumn{2}{c}{ Predicted Probability of UI Eligibility $(\overline{U I E})$} \\
\hline Male & $94.84 \%$ \\
Female & $91.51 \%$ \\
Difference & 3.34 \\
& \\
Portion of Monetary Eligibility Gap (Characteristics, X) & $.56(16.91 \%)$ \\
Unexplained Portion of Monetary Eligibility Gap (Coefficients+Constant, $\boldsymbol{\beta})$ & $2.77(83.09 \%)$ \\
\hline
\end{tabular}

Notes Nonlinear decomposition analysis of gender differences in UI eligibility for employed workers. Reference group coefficients are pooled estimates from the full model (equation 3) predicting UI eligibility for employed men and women and including a dummy variable from gender. Characteristics effect shown in black, coefficients effect shown in gray. ${ }^{*}$ The education effect refers to compositional differences between men and women with less than a high school diploma relative to men and women with a high school diploma and no further education.

Again, differences in the mean values of the demographic characteristics, race (3.18\%), age (-2.04\%), education (-1.89\%), marital status (-3\%), and children in the home $(0.18 \%)$ contribute very little to the observed difference in UI eligibility between 
less-educated employed men and women, and differences in the mean values of job characteristics explain most of the overall difference in eligibility. In particular, if men and women had the same rates of part-time work status, then the gender gap in UI eligibility would decrease by $29.69 \%$, an estimate very similar to the results of the decomposition analysis for the full population of employed workers. It is interesting to note, however, that this pattern does not also hold for industry and occupation. If lesseducated employed men and women were distributed equally across industries, the gender gap in UI eligibility would presumably increase by $5.58 \%$, and if less-educated employed men and women were distributed equally across occupations, the gender gap in UI eligibility would increase by $2.10 \%$.

The differences in the contribution of the employment structure (occupation and industry) to the gender gap in UI eligibility among all employed workers compared to the contribution of the employment structure to the gender gap in eligibility for less educated works highlights an interesting relationship between occupational segregation and wages. Occupational segregation has decreased over time in professional and managerial occupations but not in working class occupations (Cotter, Hermsen, Vanneman, 2012). Yet, the wage gap is greater for workers profession and managerial occupations relative to workers in blue-collar occupations (BLS, 2016e). In a similar fashion, occupational segregation is less pronounced among workers with higher levels of educational attainment (Blau et al., 2013). However, in 2014 the median wages for women with a bachelor's degree or higher were $75 \%$ of the median wages for men with a bachelor's degree or higher, whereas the median wages for women with less than a high school diploma were $79 \%$ of the median wages for men with less than a high school diploma (BLS, 2016c). 
Figure 4 shows the results of the decomposition analysis of gender differences in UI eligibility for unemployed workers using pooled regression coefficients (equation 5). The results suggest that $35.34 \%$ of gender differences in UI eligibility for unemployed workers are explained by group differences in characteristics and $64.66 \%$ of gender differences are explained by group differences in coefficients.

Figure 4. Pooled Decomposition of Gender Differences in UI Eligibility for Unemployed Workers

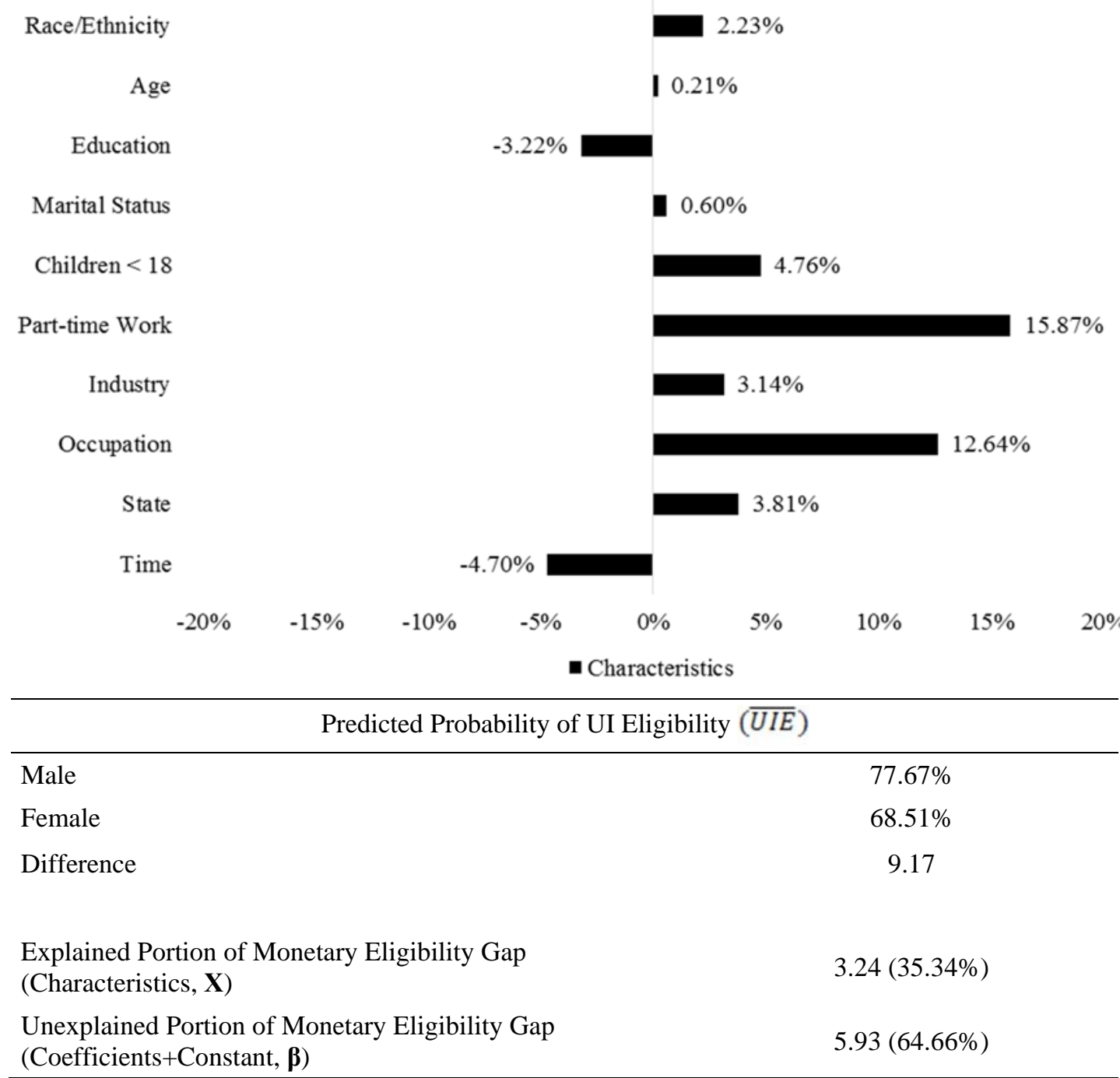

Notes: Nonlinear decomposition analysis of gender differences in UI eligibility for unemployed workers. Reference group coefficients are pooled estimates from the full model (equation 3) predicting UI eligibility for unemployed men and women and including a dummy variable from gender. Characteristics effect shown in black, coefficients effect shown in gray. 
Differences in the mean values of the demographic characteristics, race (2.23\%), age (0.21\%), educational attainment (-3.22\%), marital status $(0.60 \%)$ contribute very little to the observed difference in UI eligibility between unemployed men and women. However, the estimate for children in the home is particularly noteworthy. If the unemployed women had the same rates of children under 18 as the group as a whole, then the gender gap in eligibility UI for unemployed workers would be reduced by nearly 5\%. This suggests that motherhood disproportionately affects unemployed women's likelihood of being covered by UI.

Turning to differences in the mean values of job characteristics among unemployed workers, if unemployed men and women had the same rates of part-time work status, then the gender gap in UI eligibility would decrease by $15.87 \%$. If men and women had the same occupational distribution, then the gender gap in UI eligibility would decrease by $12.64 \%$. If unemployed men and women had the same distribution across industries, the gender gap in UI eligibility would decrease by 3.14\%.

Figure 5 shows the results of the pooled decomposition analysis of gender differences in UI eligibility for subset of unemployed workers whose highest level of education is a high school diploma or less. The aggregate results are very similar to the results for unemployed workers and suggest that $28.10 \%$ of gender differences in UI eligibility for less educated unemployed workers are explained by group differences in characteristics, and $71.90 \%$ of gender differences are explained by group differences in coefficients. 
Figure 5. Pooled Decomposition of Gender Differences in UI Eligibility for Lesseducated Unemployed Workers

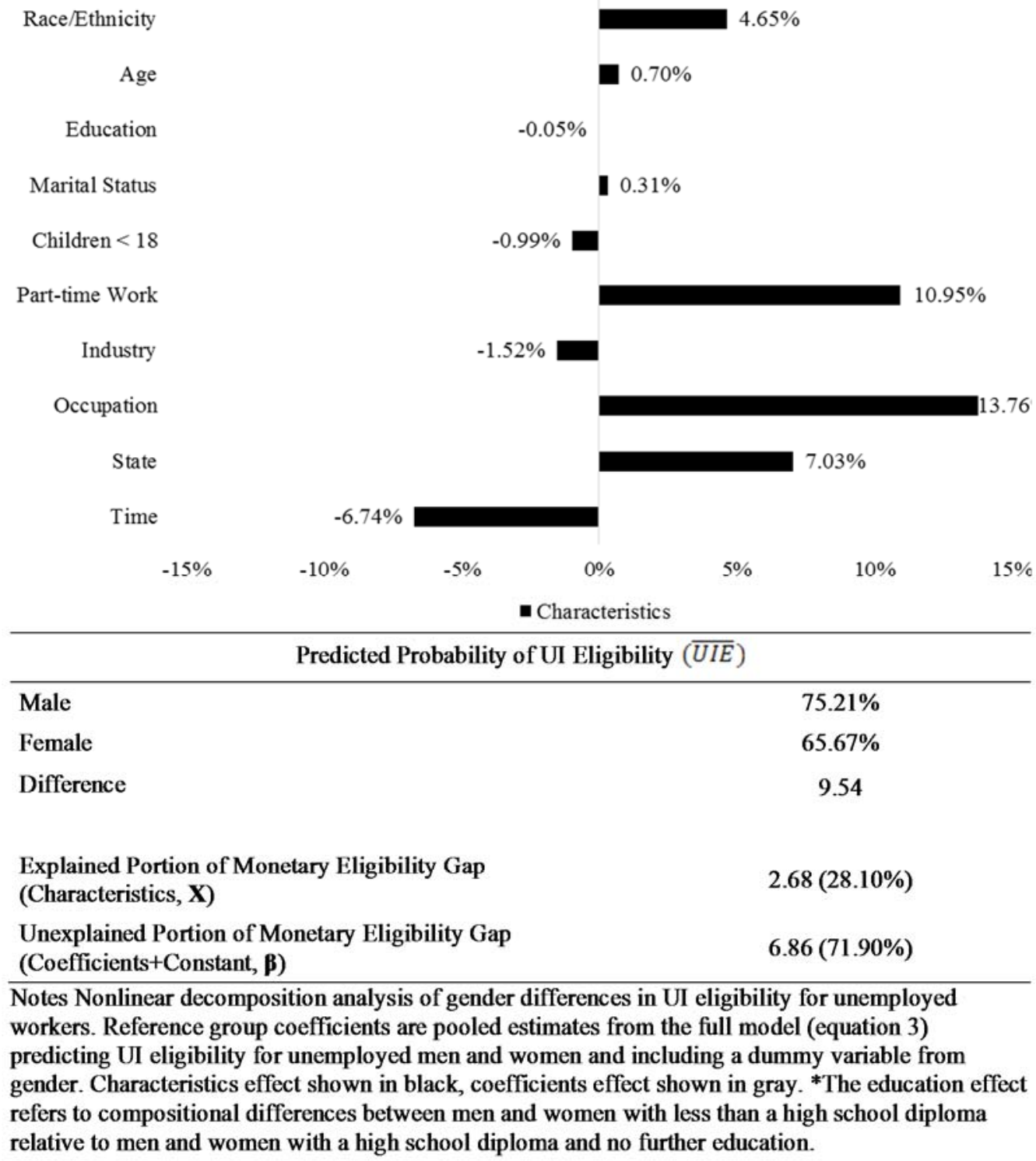

Male

Female

Difference

Explained Portion of Monetary Eligibility Gap (Characteristics, $\mathbf{X}$ )

Unexplained Portion of Monetary Eligibility Gap (Coefficients+Constant, $\boldsymbol{\beta}$ )

Notes Nonlinear decomposition analysis of gender differences in UI eligibility for unemployed workers. Reference group coefficients are pooled estimates from the full model (equation 3) predicting UI eligibility for unemployed men and women and including a dummy variable from gender. Characteristics effect shown in black, coefficients effect shown in gray. ${ }^{*}$ The education effect refers to compositional differences between men and women with less than a high school diploma relative to men and women with a high school diploma and no further education.

Differences in the mean values of the demographic characteristics, race/ethnicity (4.65\%), age (.70\%), education (-0.05\%), marital status (0.31\%), and children under 18 (0.99\%) contribute very little to the observed difference in UI eligibility between lesseducated unemployed men and women. Whereas differences in the mean values of job characteristics explain most of the overall difference in eligibility. In particular, if lesseducated unemployed men and women had the same rates of part-time work status, then 
the gender gap in UI eligibility would decrease by $10.95 \%$. If these same men and women were distributed similarly across occupations, then the gender gap in UI eligibility would also decrease by $13.76 \%$. It is interesting to note, however, that this pattern does not also hold for distributional differences between men and women across industries. If less-educated unemployed men and women were distributed equally across industries, the gender gap in UI eligibility would presumably increase by $1.52 \%$.

The role of occupation and industry in contributing to the gender gap in eligibility for both groups of unemployed workers is consistent with the argument that the employment structure, and potentially the flexible work strategies used by employers in some service-related occupations, may affect the likelihood that women are covered by unemployed insurance. However, distributional differences in men and women's rates of part-time work are the largest contributors to the gender gap in monetary eligibility for employed and unemployed workers.

\section{Discussion}

In this paper, I hypothesized that gender differences in women and men’s labor force attachments may lead to gender differences in UI coverage. I find that employed and unemployed women are less likely than their male counterparts to be monetarily eligible for UI. . If an employed woman became unemployed tomorrow, she would be 1.7 percentage points less likely to be covered by UI than an employed man, net of her reasons for unemployment. An employed women with a high school diploma or less would be 2.7 percentage points less likely to be covered by unemployment insurance than a less-educated employed man. These estimates of UI coverage serve as important indicators of how women's labor force attachments affect their access to economic resources, and they highlight women's relative vulnerability when it insurance against the risk of unemployment. 
To this end, it important to consider how a gender gap in UI coverage might impact women’s long-term economic opportunities. Access to the unemployment insurance program may contribute to women's continued labor force participation by keeping them in the labor force when they become unemployed (GAO, 2006). Access to UI may also increase women's lifetime earnings and decrease their earnings volatility by helping them find a better employee-employer fit (Acemoglu \& Shimer, 2000).

Furthermore, policies that support women in terms of balancing work-life responsibilities are likely to encourage women's investments in education and training and strengthen their attachments to the labor force. Finally, access to UI may improve women's poverty status. The CBO (2010) estimates that UI benefits reduced the national poverty rate in 2009 by about 1 percentage point.

The results of the decomposition analysis demonstrate how workers characteristics interact with program design to determine who has access to safety net programs, which may assist policymakers and research when considering the ways in which program participation could be broadened. For example, many states’ eligibility determinants, such as earnings thresholds and full-time work search requirements, may limit UI coverage of part-time workers. Women are disproportionately represented among part-time workers and this explains 30\% of employed women and $16 \%$ of unemployed women's lower rates of UI coverage relative to employed and unemployed men. Consequently, having separate provisions for part-time workers in UI eligibility determination may increase working women's rates of UI coverage.

Of course, one reason for the absence of provisions for part-time workers in many states may that part-time work may be due to differences in individual preferences. Indeed, although more women than men report part-time work, $79.7 \%$ of part-time workers (both women and men) report working part-time by choice (BLS, 2016d). If 
these workers are not eligible for unemployment insurance, this is largely in line with the program's intentions. Conversely, it is possible that individuals work part-time because of labor market constraints. For example, in 2015 20.3\% of part-time workers ages 25 to 54 reported working less than 34 hours due to economic conditions. Of these workers, 51\% were women (BLS, 2016d). Though not as great in number as those reporting parttime work by choice, the proportions of part-time workers in these categories increased following the most recent recession and have not decreased appreciably since (Valletta \& Van Der List, 2015). If individuals who are working part-time due to labor market conditions are not covered by unemployment insurance, it less clear that this is in keeping with what policymakers have intended.

I also find that over two thirds of the gender differences in employed and unemployed workers’ monetary eligibility are due to differences in the labor market returns that men and women receive for their characteristics, which translate into women’s weaker labor force attachments. Because most of the gender gaps in UI coverage have to do with unobservable factors that contribute to wage and work history differences between men and women, rather than targeting specific groups of workers (such as part-time workers), a more gender-neutral policy response might be to reduce the monetary requirements needed for any workers to qualify for benefits. This would likely lead to the largest increases in women's access to UI and increase the mediating role of UI when it comes to income stratification in the labor market. It is also possible that work force policies targeted toward making women's earnings more comparable to the earnings of men in the same jobs, or with the same levels of educational attainment and relative skills, could have the added benefit of increasing women's rates of UI coverage. Future research in this area may want to include women's rates of UI coverage as an important employed outcome when evaluating the effects of equal pay for equal work 
policies, such as the Senate Bill No. 358 passed in California in 2015, on (California State Senate, 2016).

\section{Conclusion}

Increasing women's rates of UI coverage may improve women's access to UI and by extension their short and long-term economic wellbeing. The results of this study suggest that men and women differ systematically in their rates of UI coverage, both while employed and at risk of becoming unemployed, and when they experience unemployment. Women's rates of UI coverage could be expanded through policies that focus on increasing access for specific job groups, particularly part-time workers and workers in service-related occupations. However, larger increase in women’s UI coverage could likely be achieved through policies that address variation in workers' labor force attachments more broadly, such as relaxing work hours and earnings criteria. To fully capture the benefits of increasing women's access to UI, future research in this area will want to investigate how UI coverage and UI receipt influence women's labor force attachments, income stability, occupational attainment, and lifetime earnings. 


\section{References}

Acemoglu, D., \& Shimer, R. (2000). Productivity Gains from Unemployment Insurance. European Economic Review, 44(7), 1195-1224.

doi:http://www.sciencedirect.com/science/journal/00142921

Adams, G., \& Rohacek, M. (2010). Child care instability: Definitions, context, and policy implications. Paper presented at the Workshop Session C2.

Alexander, C., \& Haley-Lock, A. (2013). Not Enough Hours in the Day: Work Hour Insecurity and a New Approach to Wage and Hour Regulation. Georgia State University College of Law, Legal Studies Research Paper(2013-24).

Arbeit, C. A. (2012). Unemployment insurance reduced child poverty during the Great Recession (8). Retrieved from University of California, Davis:

http://poverty.ucdavis.edu/sites/main/files/fileattachments/policy_brief_arbeit_ui.pdf

Bitler, M. P., \& Hoynes, H. W. (2010). The State of the Social Safety Net in the Post-Welfare Reform Era. Brookings Papers on Economic Activity(2), 71-147. Retrieved from http://proxy.mul.missouri.edu/login?url=http://search.ebscohost.com/login.aspx?d irect $=$ true $\& \mathrm{db}=$ buh\&AN=59669939\&site=eds-live \&scope $=$ site

Blau, F. D., Brummund, P., \& Liu, A. Y.-H. (2013). Trends in Occupational Segregation by Gender 1970-2009: Adjusting for the Impact of Changes in the Occupational Coding System. Demography, 50(2), 471-492. doi:10.1007/s13524-012-0151-7

Blau, F. D., \& Kahn, L. M. (2007). The Gender Pay Gap: Have Women Gone as Far as They Can? Academy of Management Perspectives, 21(1), 7-23. doi:10.5465/AMP.2007.24286161

BLS. (2012). The Recession of 2007-2009. Retrieved from Washington, DC: www.bls.gov/spotlight

BLS. (2015a). Highlights of Women's Earnings in 2014. Retrieved from Washington, DC: http://www.bls.gov/opub/reports/womens-earnings/archive/highlights-ofwomens-earnings-in-2014.pdf 
BLS. (2015b). Median weekly earnings by educational attainment in 2014 on the Internet The Economics Daily. Retrieved from http://www.bls.gov/opub/ted/2015/median-weekly-earnings-by-education-genderrace-and-ethnicity-in-2014.htm

BLS (Producer). (2016a, 7/31/2016). Absences from work of employed full-time wage and salary workers by age, sex, race, and Hispanic or

Latino ethnicity. Household Data Annual Averages. Retrieved from http://www.bls.gov/cps/cpsaat46.pdf

BLS (Producer). (2016b, September 23, 2016). Median Weekly Earnings of Full-time Wage and Salary Workers by Detailed Occupation and Sex. Household Data Annual Averages. [Table] Retrieved from http://www.bls.gov/cps/cpsaat39.htm

BLS (Producer). (2016c, 7/29/2016). Median weekly earnings of full-time wage and salary workers by selected characteristics. Household Data Annual Averages. Retrieved from http://www.bls.gov/cps/cpsaat37.htm

BLS (Producer). (2016d, 7/31/2016). Persons at work in nonagricultural industries by age, sex, race, Hispanic or Latino ethnicity, marital status, and usual full- or parttime status. Household Data Annual Averages

Retrieved from http://www.bls.gov/cps/cpsaat22.htm

BLS. (2016e). Women's earnings 83 percent of men's, but vary by occupation. The Econoimcs Daily. Retrieved from http://www.bls.gov/opub/ted/2016/womensearnings-83-percent-of-mens-but-vary-by-occupation.htm

Boushey, H., \& Wenger, J. B. (2006). Unemployment insurance eligibility before and after welfare reform. Journal of poverty, 10(3), 1-23.

Conditions of employment: gender wage differential, California Secretary of State, Pub. L. No. SB 358 § 1197.5, Chapter 546, Statutes of 2015 Stat. (2016).

Carmichael, F., \& Charles, S. (2003). The opportunity costs of informal care: does gender matter? Journal of Health Economics, 22(5), 781-803. doi:http://dx.doi.org/10.1016/S0167-6296(03)00044-4

CBO. (2010). Unemployment Insurance Benefits and Family Income of the Unemployed (21922). Retrieved from Washington, DC: https://www.cbo.gov/publication/21922 
Cha, Y., \& Weeden, K. A. (2014). Overwork and the Slow Convergence in the Gender Gap in Wages. American Sociological Review, 79(3), 457-484. doi:10.1177/0003122414528936

Chan, M., Michaelides, M., \& Zhang, S. (2014). Who Receives Unemployment Insurance? Research in Applied Economics, 6(3), 98.

Cotter, D., Hermsen, J. M., \& Vanneman, R. (2011). The End of the Gender Revolution? Gender Role Attitudes from 1977 to 2008. American Journal of Sociology, 117(1), 259-289. doi:10.1086/658853

Czajka, J. L., Mabli, J., \& Cody, S. (2008). Sample loss and survey bias in estimates of Social Security beneficiaries: A tale of two surveys. Washington, DC: Mathematica Policy Research, Inc.

Damaske, S., \& Frech, A. (2016). Women's Work Pathways Across the Life Course. Demography, 53(2), 365-391. doi:10.1007/s13524-016-0464-z

del Río, C., \& Alonso-Villar, O. (2015). The Evolution of Occupational Segregation in the United States, 1940-2010: Gains and Losses of Gender-Race/Ethnicity Groups. Demography, 52(3), 967-988. doi:10.1007/s13524-015-0390-5

DiPrete, T. A., \& Buchmann, C. (2013). The rise of women. The Growing Gender Gap in Education and what it Means for American Schools. New York, NY: Russell Sage Foundation.

DOL. (2014). Unemployment Compensation: Federal-State Partnership. Washington, DC Retrieved from http://www.ows.doleta.gov/unemploy/pdf/chronfedlaws.pdf.

England, P. (2005). Gender Inequality in Labor Markets: The Role of Motherhood and Segregation. Social Politics: International Studies in Gender, State and Society(2), 264. Retrieved from http://proxy.mul.missouri.edu/login?url=http://search.ebscohost.com/login.aspx?d irect=true \&db=edspmu\&AN=edspmu.S1468289305202649\&site=edslive\&scope $=$ site

England, P. (2010). The gender revolution uneven and stalled. Gender \& society, 24(2), 149-166. 
Farber, H. S., \& Valletta, R. G. (2015). Do Extended Unemployment Benefits Lengthen Unemployment Spells? Evidence from Recent Cycles in the US Labor Market. Journal of Human Resources, 50(4), 873-909. Retrieved from http://proxy.mul.missouri.edu/login?url=http://search.ebscohost.com/login.aspx?d irect $=$ true \&db=edswss \&AN=000364437100002\&site=eds-live\&scope=site

GAO. (2000). Unemployment Insurance Role as Safety Net for Low-Wage Workers is Limited (GAO-01-181). Retrieved from Washington, DC: http://www.gao.gov/products/GAO-01-181

GAO. (2011). Gender Pay Differences: Progress Made, but Women Remain Overrepresented among Low-Wage Workers. Retrieved from Washington, DC:

Ge, S., \& Yang, F. (2013). Accounting for the gender gap in college attainment. Economic Inquiry, 51(1), 478-499.

Golden, L. (2015). Irregular work scheduling and its consequences. Economic Policy Institute Briefing Paper(394).

Gornick, J. C., \& Meyers, M. (2003). Families that work : policies for reconciling parenthood and employment: New York : Russell Sage Foundation, (C2003.

Gould-Werth, A. (2016). Workplace Experiences and Unemployment Insurance Claims: How Personal Relationships and the Structure of Work Shape Access to Public Benefits. Social Service Review, 90(2), 305-352.

Gould-Werth, A., \& Shaefer, H. L. (2012). Unemployment Insurance Participation by Education and by Race and Ethnicity [article] (pp. 28).

Ham, J. C., Li, X., \& Shore-Sheppard, L. (2009). Seam bias, multiple-state, multiple-spell duration models and the employment dynamics of disadvantaged women. Retrieved from

Hill, H. D. (2013). Paid sick leave and job stability. Work and occupations, 40(2), 143173.

Hofferth, S., \& Collins, N. (2000). Child care and employment turnover. Population Research and Policy Review, 19(4), 357-395. 
Hollister, M. N., \& Smith, K. E. (2014). Unmasking the Conflicting Trends in Job Tenure by Gender in the United States, 1983-2008. American Sociological Review, 79(1), 159-181. doi:10.1177/0003122413514584

Jann, B. (2008). The Blinder-Oaxaca decomposition for linear regression models. The Stata Journal, 8(4), 453-479.

Killewald, A., \& Zhou, X. (2015). Mothers' Long-Term Employment Patterns. Available at SSRN 2704875.

Kimmel, J., \& Powell, L. M. (2001). Nonstandard Work and Child Care Choices: Implications for Welfare Reform.

Kuka, E. (2015). Quantifying the Benefits of Social Insurance: Unemployment Insurance and Health. Job Market Paper.

Kukla-Acevedo, S., \& Heflin, C. M. (2014). Unemployment insurance effects on child academic outcomes: Results from the National Longitudinal Survey of Youth. Children and Youth Services Review, 47(Part 3), 246-252. doi:10.1016/j.childyouth.2014.09.019

Lambert, S. J. (2008). Passing the buck: Labor flexibility practices that transfer risk onto hourly workers. Human Relations, 61(9), 1203-1227.

Levanon, A., England, P., \& Allison, P. (2009). Occupational feminization and pay: Assessing causal dynamics using 1950-2000 US census data. Social Forces, 88(2), 865-891.

Lowe, E. D., \& Weisner, T. S. (2004). 'You have to push it—who's gonna raise your kids?': situating child care and child care subsidy use in the daily routines of lower income families. Children and Youth Services Review, 26(2), 143-171. doi:http://dx.doi.org/10.1016/j.childyouth.2004.01.011

Lowe, E. D., Weisner, T. S., \& Geis, S. (2003). Instability in child care: Ethnographic evidence from working poor families in the New Hope intervention. New York: MDRC.

Michaelides, M., \& Mueser, P. R. (2012). Recent trends in the characteristics of unemployment insurance recipients. Monthly Labor Review, 135(7), 28. 
Retrieved from

http://proxy.mul.missouri.edu/login?url=http://search.ebscohost.com/login.aspx?d irect $=$ true \&db=f5h\&AN=79344395\&site=eds-live\&scope=site

Michaelides, M., \& Mueser, P. R. (2013). The role of industry and occupation in recent US unemployment differentials by gender, race, and ethnicity. Eastern Economic Journal, 39(3), 358-386.

Moffitt, R. A. (2013). The Great Recession and the Social Safety Net. Annals of the American Academy of Political and Social Science, 650(1), 143-166. Retrieved from

http://proxy.mul.missouri.edu/login?url=http://search.ebscohost.com/login.aspx?d irect=true \&db=edswss \&AN=000326234000007\&site=eds-live\&scope=site

NELP (Producer). (2010, 7/29/2016). UI Modernization Update. Retrieved from http://nelp.org/content/uploads/UnemploymentInsuranceModernizationUpdate.pd $\mathrm{f}$

Nicholson, W., \& Needels, K. (2006). Unemployment Insurance: Strengthening the Relationship between Theory and Policy, 47.

Nicholson, W., Needels, K., \& Hock, H. (2014). Unemployment Compensation during the Great Recession: Theory and Evidence. National Tax Journal, 67(1), 187-218.

Sahin, A., \& Willis, J. L. (2011). Employment Patterns During the Recovery: Who Are Getting the Jobs and Why? Economic Review-Federal Reserve Bank of Kansas City, 5.

Shaefer, H. L. (2010). Identifying key barriers to unemployment insurance for disadvantaged workers in the United States. Journal of Social Policy, 39(03), 439460.

Shaefer, H. L., \& Wu, L. (2011). Unemployment Insurance and Low-Educated, Single, Working Mothers before and after Welfare Reform, 205.

Stettner, A., Boushey, H., \& Wenger, J. (2005). Clearing the Path to Unemployment Insurance for Low-Wage Workers. Retrieved from 
Valletta, R. G., \& Van Der List, C. (2015). Involuntary part-time work: Here to stay? FRBSF Economic Letter.

Vaughan, D., \& Scheuren, F. (2002). Longitudinal Attrition in SIPP and SPD. US Census Bureau, SIPP Working Paper, 242.

Vroman, W. (1998). Labor Market Changes and Unemployment Insurance Benefit Availability: US Department of Labor, Employment and Training Administration, Unemployment Insurance Service.

Vroman, W. (2002). Low benefit recipiency in state unemployment insurance programs: US Department of Labor, Employment and Training Administration, Office of Policy and Research.

Vroman, W. (2010). The Great Recession, Unemployment Insurance, and Poverty. Reducing Poverty and Economic Distress after ARRA," Washington, DC, January, 15.

Wandner, S. A., \& Stengle, T. (1997). Unemployment Insurance: Measuring who receives it. Monthly Labor Review, July 1997, 15-24.

Watson, L., Frohlich, L., \& Johnston, E. (2014). Collateral Damage: Scheduling Challenges for Workers in Low-Wage Jobs and Their Consequences. Washington, DC: National Women's Law Center. Before joining Urban, Heller worked as a research analyst at a market research.

Whittaker, J. M., \& Isaacs, K. P. (2014). Unemployment insurance: programs and benefits.

Ybarra, M. (2013). Implications of paid family leave for welfare participants. Social Work Research, svt033.

Young, C. (2012). Losing a Job: The Nonpecuniary Cost of Unemployment in the United States. Social Forces, 91(2), 609-634. Retrieved from http://proxy.mul.missouri.edu/login?url=http://search.ebscohost.com/login.aspx?d irect=true $\& d b=b u h \& A N=95750455 \&$ site=eds-live \&scope=site

Yun, M. S. (2000). Decomposition analysis for a binary choice model. 
Yun, M. S. (2004). Decomposing differences in the first moment. Economics Letters, 82(2), 275-280.

Yun, M. S. (2005). A simple solution to the identification problem in detailed wage decompositions. Economic Inquiry, 43(4), 766-772. 


\section{Appendix A}

Table 4. Summary Statistics Full Sample

Group A

Employed
Group B

Unemployed

Gender

$\begin{array}{rrr}\text { Male } & 50.41 \% & 50.09 \% \\ \text { Female } & 49.59 \% & 49.91 \%\end{array}$

Race \& Ethnicity

White Non-Hispanic

Hispanic

Black Non-Hispanic

Asian

Other Race

Age

Educational Attainment

$\begin{array}{rrr}\text { Less than High School } & 7.16 \% & 13.32 \% \\ \text { Graduated High School } & 22.59 \% & 27.44 \% \\ \text { Some College } & 35.16 \% & 39.11 \% \\ \text { Bachelor's Degree or Higher } & 35.11 \% & 20.11 \%\end{array}$

Marital Status

$\begin{array}{rrr}\text { Married } & 65.12 \% & 49.59 \% \\ \text { Never Married } & 20.14 \% & 30.15 \% \\ \text { Divorced/Separated } & 13.69 \% & 19.11 \% \\ \text { Widow } & 1.04 \% & 1.16 \%\end{array}$

Children under 18

$\begin{array}{ccc}\text { Yes } & 52.40 \% & 50.11 \% \\ \text { No } & 47.60 \% & 49.89 \%\end{array}$

Observations (Avg. N)

12,312

527

Notes Quarterly averages from January 2005-December 2007 and October 2009-June 2013. Sample restricted to US civilian population, age 25-55, and continuous participation in the SIPP in the prior five quarters. Group A, individuals with continuous employment during the quarter in which eligibility is estimated and continuous participation in the labor force in the base period; Group B, individuals reporting unemployment in the quarter that eligibility is estimated. 
Table 5. Summary Statistics Less-educated Workers

\begin{tabular}{ccc}
\hline & Group A & Group B \\
Employed & Unemployed \\
\hline
\end{tabular}

Gender

$\begin{array}{rrr}\text { Male } & 56.23 \% & 54.61 \% \\ \text { Female } & 43.77 \% & 45.39 \%\end{array}$

Race \& Ethnicity

$\begin{array}{rrr}\text { White Non-Hispanic } & 61.56 \% & 55.01 \% \\ \text { Hispanic } & 22.32 \% & 25.18 \% \\ \text { Black Non-Hispanic } & 10.99 \% & 14.30 \% \\ \text { Asian } & 2.44 \% & 1.46 \% \\ \text { Other Race } & 2.72 \% & 4.09 \%\end{array}$

Age

$\begin{array}{lll}45 \text { to } 55 & 41.83 \% & 32.13 \% \\ 34 \text { to } 44 & 32.04 \% & 31.39 \% \\ 25 \text { to } 34 & 26.13 \% & 36.48 \%\end{array}$

Educational Attainment

$\begin{array}{rrr}\text { Less than High School } & 24.02 \% & 32.59 \% \\ \text { Graduated High School } & 75.98 \% & 67.41 \%\end{array}$

Marital Status

$\begin{array}{rrr}\text { Married } & 62.42 \% & 49.68 \% \\ \text { Never Married } & 21.39 \% & 30.62 \% \\ \text { Divorced/Separated } & 14.95 \% & 18.40 \% \\ \text { Widowed } & 1.25 \% & 1.29 \%\end{array}$

Children under 18

$\begin{array}{cll}\text { Yes } & 47.86 \% & 54.09 \% \\ \text { No } & 52.14 \% & 45.91 \%\end{array}$

Observations (Avg. N)

3,643

214

Notes Quarterly averages from January 2005-December 2007 and October 2009-June 2013. Sample restricted to US civilian population, age 25-55, with continuous participation in the SIPP in the prior five quarters, and reporting a high school diploma or less as highest level of educational attainment. Group A, individuals with continuous employment during the quarter in which eligibility is estimated and continuous participation in the labor force in the base period; Group B, individuals reporting unemployment in the quarter that eligibility is estimated. 


\section{Appendix B}

I decompose gender differences in monetary eligibility for UI among employed and unemployed workers into a portion explained by distributional differences in men and women's characteristics, such as part-time work, occupation, and industry, and a portion explained by differences in the labor market returns that workers receive for these characteristics. In the case of UI coverage, the outcome variable is binary, the argument is linear in a set of parameters, and the function linking the parameters to the outcomes is a nonlinear probit link, such that:

$$
U I E_{i s t}^{j}=F\left(X^{j} \beta^{j}\right)=F\left(\alpha+W^{j}{ }_{i t} \gamma^{j}+Z^{j}{ }_{i t} \delta^{j}+\pi_{s}^{j}+\varphi_{t}{ }^{j}\right)
$$

In equation $\mathrm{B} 1$, UIE is the probability that a worker in the sample is monetarily eligibility for unemployment insurance; $\mathrm{j}=$ =males or females; $X^{j}$ is a vector of the values of the explanatory variables including demographic, job, state, and time characteristics; $\beta^{j}$ is a vector of coefficients for these characteristics plus an intercept term; and $\mathrm{F}$ is the standard normal cumulative distribution function. Because $\mathrm{F}$ is nonlinear, $F\left(\bar{X}^{j} \hat{\beta}^{j}\right)$ may not equal $\overline{U I E} .{ }^{36}$ Yun (2000, 2004, 2005) suggests writing the difference in the mean outcome for two groups in terms of the sample average $\overline{U I E^{\jmath}}=\overline{F\left(X^{\jmath} \beta^{J}\right)}=($ $\left.1 / n \sum_{i=1}^{n} F\left(X_{i}^{j} \beta_{i}^{j}\right)\right)$, so that

$$
\begin{aligned}
& \overline{U I E^{m}}-\overline{U I E^{f}}=\left[\overline{F\left(X^{m} \beta^{m}\right)}-\overline{F\left(X^{f} \beta^{f}\right)}\right] \\
& {\left[\overline{F\left(X^{m} \beta^{*}\right)}-\overline{F\left(X^{f} \beta^{*}\right)}\right]+\left\{\left[\overline{F\left(X^{f} \beta^{*}\right)}-\overline{F\left(X^{f} \beta^{f}\right)}\right]+\left[\overline{\mathrm{F}\left(X^{m} \beta^{m}\right)}-\overline{\mathrm{F}\left(X^{m} \beta^{*}\right)}\right]\right\} \cdot \text { (eq. B2/ 5) }}
\end{aligned}
$$

In addition to estimating these aggregate terms, in the main body of the text (Figures 2-5), I report the separate contribution of gender differences in workers’

\footnotetext{
${ }^{36}$ In the traditional Blinder-Oaxaca decomposition for linear regression models, $F(X)=X$, so that $\overline{F(X \beta)}=\bar{X} \beta$ (Yun, 2004; Fairlie 2016). Because I use a probit model, $\mathrm{F}$ is the standard normal cumulative distribution function $(\phi)$.
} 
demographic and job characteristics to the overall group difference in UI eligibility. This is often referred to as a “detailed decomposition” (Yun, 2004, 2005). These estimates are obtained by weighting the contribution of each explanatory variable $\left(X_{v}\right)$ to the first term on the right side of eq $\mathrm{B} 2$ :

$\overline{U I E^{m}}-\overline{U I E^{f}}=$

$\sum_{v=1}^{v=k} W_{v}^{\Delta X}\left[\overline{F\left(X^{m} \beta^{*}\right)}-\overline{F\left(X^{f} \beta^{*}\right)}\right]+\left\{\left[\overline{F\left(X^{f} \beta^{*}\right)}-\overline{F\left(X^{f} \beta^{f}\right)}\right]+\left[\overline{\mathrm{F}\left(X^{m} \beta^{m}\right)}-\overline{\mathrm{F}\left(X^{m} \beta^{*}\right)}\right]\right\}$

In equation B3, the weights, $W_{v}^{\Delta x}$, are estimated by evaluating the function $F(\cdot)$ at the average values of $X$, and then using a first order Taylor expansion to linearize $\mathrm{F}(\bar{X} \beta)$ and estimate the individual contribution of each variable in relation to the aggregate term $\bar{X}_{v} \hat{\beta}_{\mathrm{v}} / \bar{X} \beta$ so that

$$
\begin{aligned}
& W_{v}^{\Delta X}=\frac{\left(\bar{X}_{v}^{m}-\bar{X}_{v}^{f}\right) \beta_{v}^{*} f\left(\bar{X}^{m} \beta^{*}\right)}{\left(\bar{X}^{m}-\bar{X}^{f}\right) \beta^{*} f\left(\bar{X}^{m} \beta^{*}\right)^{\prime}}, \\
& \sum_{v=1}^{v=k} W_{v}^{\Delta X}=1,
\end{aligned}
$$

where $f(\cdot)$ is the derivative of the function $F(\cdot)$, and $f(\bar{X} \beta)=\frac{d F(\bar{X} \beta)}{d(\bar{X} \beta)}$. The basic premise of this technique is that $\overline{U I E}$ can be linearized by evaluating the function $F(\cdot)$ at mean values of $\bar{X}$ with the difference between $\overline{F(X \beta)}$ (the average of the nonlinear function) and $F(\bar{X} \beta)$ (the nonlinear function of the average) expressed in a first error term and the difference between $F(\bar{X} \beta)$ and a linear estimation of $\bar{X} \hat{\beta}$ multiplied by the first derivate, $f(\bar{X} \beta)$, expressed in a second error term. 


\section{CHAPTER 4: BRINGING HOME THE BACON OR THE BENEFITS? NEW EVIDENCE ON FEMALE REPRESENTATION AND JOB COMPENSATION FROM THE MEDICAL EXPENDITURES PANEL SURVEY}

Today nearly half of all working women (or men) would have to change jobs in order for the gender distribution of occupations to match the gender distribution of the labor force as a whole (Blau, Brummund, \& Liu, 2013). One consequence of gender sorting across occupations is that workers in predominately female occupations earn less than workers in predominately male occupations and workers in gender integrated occupations (England, 2010). Because these earnings differences explain about half the overall gender gap in wages (England, 2010) and they persist after controlling for important differences in workers' individual and occupational characteristics (England, 1992; England, Allison, \& Wu, 2007; England, Farkas, Kilbourne, \& Dou, 1988; England, Herbert, Kilbourne, Reid, \& Megdal, 1994; Kilbourne, England, Farkas, Beron, \& Weir, 1994; Levanon, England, \& Allison, 2009), scholarly attention continues to be drawn to the central question of why female occupations pay less than male occupations.

The microeconomic theory of compensating differentials offers one possible explanation for why female occupations pay less than male occupations. Compensating differentials holds that wage differences between workers in occupations that require similar levels of skill, experience, and training arise because jobs have different attributes (both good and bad) and workers differ in their willingness to forego wages in order to obtain (or avoid) jobs with certain attributes. Non-pecuniary attributes that are likely to influence wages can range from working conditions, such as physical discomforts and hazards, to flexible work hours, the interest of the work being performed, and the availability of fringe benefits. ${ }^{37}$

\footnotetext{
${ }^{37}$ Fringe benefits can be thought of both as an amenity associated with working in a given job or as another way in which employers may compensate workers for disamenities associated with a certain job, such as hazardous working. In this study, I treat fringe benefits as an amenity that workers pay for through reductions in wages.
} 
Although existing studies have taken into account how compensating differentials might contribute to wage differences between male and female occupations, most have focused on differences in work conditions and skill requirements and have not taken into account fringe benefits. ${ }^{38}$ However, In 2016 fringe benefits accounted for nearly one third of total employment costs (BLS, 2017). Like other non-wage attributes, compensating differentials theory holds that workers substitute fringe benefits for wages. If men and women differ in their preferences for fringe benefits and select into jobs that match these preferences, then it is possible that scholars observe a negative relationship between female representation in an occupation and wages because workers in predominately female occupations receive a greater portion of job compensation in the form of fringe benefits.

Of course, it is also possible that amenities such as fringe benefits augment rather than mediate wage differences between male and female occupations. Along these lines, demand-side theories such as gendered devaluation contend that predominately female occupations pay less than predominately female occupations net of differences in individual and occupational characteristics because employers view work performed by women as less valuable than work performed by men (England, 1992; England et al., 1994). If women's lower social status and weak position in the labor market constrains the labor market rewards to women's work, then it is likely that female representation in an occupation affects total job compensation (i.e. the total costs that employers are willing to pay for an additional worker), not just wages. In this case, we would expect

\footnotetext{
${ }^{38}$ Exceptions include Duncan (1976), Glass (1990), Levy (2006), and Solberg and Laughlin (1995). The results from Duncan (1976) suggest that inclusion of fringe benefits might augment the pay gap, given that the returns to education become even greater when non-pecuniary benefits are included in the wage equation and given the empirical evidence that the returns to education are greater for men than women. Similarly, the results from Glass, suggest that percentage female in an occupation is negatively associated with the amount of fringe benefits a worker receives. On the other hand the studies conducted by Levy (2006); Solberg and Laughlin (1995) both suggest that accounting for compensation paid to workers through fringe benefits would reduce the magnitude of the gender gap in pay. However, Levy (2006) and Solberg and Laughlin (1995) do not focus specifically on the part of the gender gap in pay due to gender sorting in the labor market.
} 
workers in predominately female occupations to have lower wages and fewer benefits than workers in predominately male occupations.

Do workers in predominately female occupations have lower pay but more fringe benefits? Or does female representation limit the wages and benefits of workers in predominately female occupations? In this paper I empirically examine how fringe benefits influence the relationship between female representation in an occupation and wages using individual-level data from the Medical Expenditures Panel Survey Household Component (MEPS-HC) and occupation-level data from the Integrated Public Use Microdata Series (IPUMS) samples drawn from the American Community Survey (ACS) (Ruggles, Genadek, Goeken, Grover, \& Sobek, 2015). In order to identify whether the processes linking gender sorting in the labor market to the gender wage gap are consistent with the theory of compensating differentials or the theory of gendered devaluation, I separately model the relationship between the proportion of females in a detailed occupational category and wages; several measures of non-wage compensation including whether an individual is offered health insurance coverage on the job and whether they have a pension plan, paid vacation, and sick leave; and a measure of total job compensation, that uses the percentage of total employment costs that employers allocate to various fringe benefits as a proxy for the value of a worker's benefit package.

Consistent with prior studies, I find that workers in predominately female jobs (greater than $80 \%$ female) have lower wages than workers in predominately male jobs (less than 20\% female) and workers in gender integrated jobs ( $40 \%$ to $59 \%$ female), holding all other factors constant. Additionally, I find little evidence that workers in predominately female occupations are rewarded for their lower pay with amenities such as fringe benefits. Rather, I find that these workers are less likely to be offered health 
insurance from their employer and are less likely to have paid vacation days or pensions than workers in predominately male jobs and gender integrated jobs.

\section{Compensating Differentials}

In order for fringe benefits to explain why predominately female occupations pay less than predominately male occupations several assumptions must be met. First, benefits must affect wages. Second, men and women must differ in their preferences for fringe benefits and select occupations based on these preferences. Third, employee preferences must structure the compensation package offered so that male and female occupations have different average levels of fringe benefits. ${ }^{39}$

Theoretically, compensating differentials predicts a negative relationship between benefits and wages. The theory assumes that because the total costs of employment are constant, employers are indifferent to how compensation is divided between wages and benefits. The theory also assumes that the utility individuals received from working is positively influenced by both wages and fringe benefits, so that workers select jobs that allocate total compensation in ways that maximize their utility. Workers preferred combinations of wage and benefits should fall along the same line with a slope of -1 , so that those who prefer an addition dollar of fringe benefits should have their wages reduced by a dollar in return (Currie, 1993).

Empirically, it has been difficult to find strong evidence of an inverse relationship between benefits and wages. Early studies using cross-sectional data such as Leibowitz (1983) and Monheit, Hagan, Berk, and Farley (1985) found a positive relationship between wages and benefits, which has been attributed to unobserved preferences and

\footnotetext{
${ }^{39}$ Prior research has shown that differences in workers preferences for benefits (health insurance coverage) affect their choice of jobs (Lehrer \& Pereira, 2007; Monheit \& Vistnes, 1999) and affect employer behavior when it comes to providing benefits (Bundorf, 2002; Levy, 1998).
} 
abilities that affect workers' selection into jobs with more benefits and higher wages (Currie \& Madrian, 1999; Smith \& Ehrenberg, 1983).

Even studies using longitudinal data and quasi-experimental designs in order to address the endogeneity of fringe benefits and problems of omitted variable bias have produced mixed evidence of a wage benefit tradeoff. Both Simon (2001) and Levy and Feldman (2001) examined differences in wages and benefits packages for workers who changed jobs and found that workers who gained wages also gained benefits, while workers who lost wages also lost benefits. Conversely, Jensen and Morrisey (2001) used data from the Health and Retirement Survey and an instrumental variables approach and found evidence that older workers pay for higher health care coverage costs through reduced wages, while Miller (2004) used Consumer Expenditures Survey and individual level fixed effects models and found that having employer provided health insurance led to a $10 \%$ reduction in wages.

Despite mixed evidence that workers substitute benefits for wages, results from prior studies do indicate that women have stronger preferences for benefits than men, and that women are more likely to be employed in jobs that offer fringe benefits. In their sample of single workers from the National Medical Expenditures Survey (NMES), Monheit and Vistnes (1999) found that workers who reported having a strong preferences for employer provided health insurance coverage were more likely to be female. ${ }^{40}$ Similarly, Glass (1990) and Lluis and Abraham (2013) found that female workers were more likely to hold jobs with multiple benefits (health insurance, retirement accounts, and paid leave) than male workers. Lluis and Abraham (2013) also found that female workers

\footnotetext{
${ }^{40}$ Monheit and Vistiness (1999) find that the strength of workers preferences for health insurance influences their likelihoods of working in jobs that do (or does not) offer health insurance coverage. Monheit and Vistness (1999) also find that workers preferences for health insurance are strongly correlated with their actual annual health care expenditures. Given that, on average, women have higher health care costs, it follows that these costs would influence their preference for health care coverage.
} 
in their sample were more likely to move from jobs without health insurance into jobs with health insurance.

There is also some evidence that gender differences in workers preferences for benefits contribute to gender differences in wages. However, most of this literature has only focused on one benefit: health insurance coverage. Olson (2002) instrumented a wife’s probability of having health insurance coverage from her own job with her husband's employment characteristics and found that having health insurance reduced married women’s wages by 20\%. Daneshvary and Clauretie (2007) also used spouse information, including firm size and whether a spouse's insurance offers family coverage, as instruments for identifying the wage effects of health insurance coverage. Similar to Olson (2002), they found that having health insurance coverage reduced women's wages by about $20 \%$ and men's wages by about $17 \%$. Based on these results, they conclude that gender differences in health insurance coverage explain about 3\% of the gender wage gap. $^{41}$

To what extent might gender differences in fringe benefits affect an occupations' average levels of fringe benefits and wages? Theory tells us that the allocation of compensation into wages and benefits in an occupation should correspond with the preferences of the marginal worker in that occupation. If men and women differ in their preferences for benefits, then the supply of fringe benefits in a given occupation may depend on whether the marginal worker is likely to be female or male. ${ }^{42}$ Additionally, Timmerman (2005) argues that occupational choice, not simply job choice, is influenced by a worker's preferences for benefits because selecting into an occupation where most

\footnotetext{
${ }^{41}$ Cowan and Schwab (2016) attribute women’s higher wage health insurance trade off (about \$.50 to \$1.50 per hour) to their higher annual health care coverage costs.

${ }^{42}$ This assumes that employers are responsive to the preferences of workers. Levy (1998) finds evidence that employers use high premium contributions as a way of deterring workers with weak preferences for health insurance coverage from opting-in, and Bundorf (2002) finds that employee preferences affect whether employers are likely to offer a choice of plans, although the relationship is substantively small.
} 
employers provide benefits such as health insurance coverage maximizes the chances of obtaining that benefit from a job within an occupation. ${ }^{43}$ Although Timmerman (2005) finds no evidence that the percentage of white females in an occupation affects average rates of health insurance coverage, he does find that the percentage of black females is positively associated with rates of health care coverage. ${ }^{44}$

\section{Gendered Devaluation}

Demand-side theories, such as gendered devaluation, offer an alternative explanation for why predominately female occupations pay less than predominately male occupations. The theory holds that employers view work performed by women (or women's work) as worth less than work performed by men (or men’s work), so that job compensation in an occupation is depressed when the number of female occupants increases over time (England et al., 2007; Levanon et al., 2009) or when occupations require work that is associated with traditionally "female” traits such as nurturing and care-taking (England, 1992; England, Budig, \& Folbre, 2002; England, Thompson, \& Aman, 2001; Kilbourne et al., 1994). ${ }^{45}$

\footnotetext{
${ }^{43}$ An occupation's average levels of fringe benefits are likely to be influenced by other factors like the tax system, unionization, and historical conventions (England et al., 1994; Lluis \& Abraham, 2013).

Additionally, other characteristics of the occupation may counteract any gender-specific effects on average levels of fringe benefits. For example, the taxation of wage income might lead to a higher average supply of fringe benefits in high paying occupations (high prestige occupations or occupations requiring significant investments in education) because for higher earning workers a marginal dollar of benefits is worth more than a marginal dollar of pay assuming that benefits are not taxed. Conversely, employing a larger number of part-time workers may lead to a lower supply of benefits in an occupation (even among full time workers), since part-time workers may prefer wages to benefits.

${ }^{44}$ These findings may be limited by the authors' use of broad occupational categories to measure occupational segregation, since occupational segregation is more pronounced at more detailed occupational levels. England, et al. (1994) use more detailed occupational categories and find a negative relationship between medical insurance and earnings for men, but not for women.

${ }^{45}$ The literature on devaluation has typically pointed to broader social and cultural process such as gender stereotyping and adherence to gender roles as the mechanisms undergirding the lower relative pay of female jobs. For example, there is evidence that both males and females assign higher pay to work of the same quality when it is done by men than women (Eagly \& Steffen, 1984; Hogue \& Yoder, 2003; Major, 1994), and that women often endorse gender stereotypes used to justify pay disparities and accept them as fair and natural (Jost \& Hamilton, 2005).
} 
Scholars typically cite the negative association between the percentage of female workers in an occupation and wages as evidence of devaluation (England, et al. 1994). This earning differences has been shown to persist after controlling for important differences in workers' human capital such as education, skills, and experience (England, 1992; England et al., 2007; England et al., 1988; England et al., 1994; Kilbourne et al., 1994; Levanon et al., 2009) and after controlling for important differences in occupational characteristics such as skill and education requirements, work conditions, job age, and unionization (Baron \& Newman, 1990; England et al., 1994; England, Reid, \& Kilbourne, 1996; Jacobs \& Steinberg, 1990; Kilbourne et al., 1994). ${ }^{46}$ One exception to this general pattern is Tam (1997) who finds no effect of gender composition on wages after controlling for differences in skill specificity across occupations.

Existing studies of how an occupation's sex composition affects labor market rewards have found that workers in predominately female occupations have lower starting wages (England, Reid, and Kilbourne, 1996) and have slower wage growth over time than workers in predominately male occupations (Levanon, England, and Allison, 2009). These same patterns are likely to hold for fringe benefits. For example, if employers have a strong preferences for male labor and use both wages and fringe benefits to attract male workers, female workers would have to accept lower starting wages and fewer benefits to counteract employer's weaker preferences for hiring them (England, 1992). ${ }^{47}$ This would result in a lower initial supply of fringe benefits to workers in predominately female occupations relative to gender integrated and predominately male occupations.

\footnotetext{
46 See Tam (1997) for an exception. Tam argues that wages vary between female dominated occupations and male dominated occupations because male-dominated occupations are associated with more skill specificity and less transferable skills than female-dominated occupations.

47 This is congruent with Becker's “taste for discrimination” hypothesis, see England (1992).
} 
The supply of fringe benefits to workers in predominately female occupations might decline over time as well. As members of a subordinate group, workers in predominately female (or minority) occupations may lack the political power and market positions necessary to bargain for improvements in compensation or to organize when an employer threatens to withdraw workplace protections such as health insurance coverage and pensions (Catanzarite, 2003; Tomaskovic-Devey, 1993). An increase in representation of a subordinate group, including both women and minorities, in an occupation over time has also been linked to the reorganization of work within the occupation which then influences how work is rewarded. The reorganization of “women’s work” includes deskilling (Baron and Bielby, 1980), limiting opportunities for promotion (Bielby and Baron, 1984), and moving toward nonstandard work arrangements characterized by fewer hours and fewer to no benefits (Kalleberg et al., 1997; Kalleberg, Reskin, \& Hudson, 2000). ${ }^{48}$

\section{Current Study and Contribution}

This paper examines the degree to which fringe benefits explain why predominately female occupations pay less than predominately female occupation. Although a few economic studies have examined how gender differences in fringe benefits contribute to the overall gender wage gap (Cowan \& Schwab, 2016; Daneshvary \& Clauretie, 2007; Levy, 2006; Solberg \& Laughlin, 1995), none of which I am aware directly examines how fringe benefits affect the lower relative pay of female occupations. ${ }^{49}$ Additionally, although sociological studies have often taken into account

\footnotetext{
${ }^{48}$ Workers in predominately female jobs might also have lower levels of fringe benefits because a largely female workforce may represent an adverse risk pool. While this would not particularly be due to a devaluation process, it could further lead to devaluation since the association of an occupation with lower wages and fewer benefits would reduce its prestige and status.

${ }^{49}$ Solberg and Laughlin (1995) find that pay differences between male and female workers within the same occupation are reduced when job compensation is measured in terms of both wages and benefits, but they do not consider whether occupational differences in pay are reduced. Currie and Chaykowski (1992) use Canadian data to examine how the female representation in a bargaining unit (union) affects benefits. In the
} 
how differences in work conditions and skill requirements might contribute to wage differences between predominately female and predominately male occupations (England, 1992; England et al., 2007; England et al., 1994; Glass, 1990; Kilbourne et al., 1994; Levanon et al., 2009), few have considered the role of fringe benefits. ${ }^{50}$

In order to contribute to research in this area, in the following section I empirically examine how the percentage of female workers in an occupation affects wage and benefits using individual-level data from the Medical Expenditures Panel SurveyHousehold Component (MEPS-HC) and occupation-level data from the Integrated Public Use Microdata Series (IPUMS) obtained from the American Community Survey (ACS) (Ruggles et al., 2015).

To the extent that female representation in an occupation positively affects fringe benefits and negatively affects wages, the results of the analysis will be consistent with the argument that wage differences between male and female-dominated occupations are explained by differences in non-wage compensation. In this case, failure to account for non-wage compensation would lead to biased estimates of how much gender sorting in the labor market contributes to the gender pay gap. Conversely, to the extent that the female representation in an occupation negatively affects level of benefits and wages, then the results will be consistent with the argument that women's lower social status depresses compensation in predominately female jobs relative to predominately male jobs and gender integrated jobs. In this case, wage compensation is a suitable proxy for total

private sector they find that unionized workers in female jobs have lower pay, are less likely to have pensions, and are more likely to have unpaid leave. In the public sector they find that unionized workers in female jobs have lower pay, are less likely to have pensions, but are more likely to have paid and unpaid leave.

${ }^{50}$ Exceptions include Glass (1990) who finds a negative association between the percentage of female workers in an occupation and fringe benefits, England et al. (1994) who find that amenities (including health insurance) explain less than $1 \%$ of the pay gap between male and female occupations. 
compensation and an appropriate measure of how occupational segregation contributes to the gender pay gap.

Whether the results are consistent with compensating differentials or devaluation theory, this study highlights how measuring the effects of female representation in an occupation on wages without consideration of other sources of job compensation risks not telling the full story of how the occupational structure contributes to or mediates gender inequality in the labor market. and, therefore, risks not properly informing policy regarding how to best address issues of gender inequalities in employment.

\section{Data and Methods}

Data. The primary source of data for this project is the 2007 - 2013 Medical Expenditures Household Survey Household Component (MEPS-HC) full year consolidated files. The MEPS-HC is a nationally representative longitudinal survey conducted by the Agency for Healthcare Research and Quality designed to gather detailed data about individual and household medical expenditure (AHRQ, 2015a). What makes the survey particularly useful for this paper is detailed information on fringe benefits, including employer provided health care coverage. The sample for the MEPS household survey is drawn from the larger sample used in the National Health Interview survey. Approximately 30,000 individuals in 13,000 households are interviewed for the MEPS-HC for a total of five rounds over two years, and a new panel of households is selected each year (AHRQ, 2015b).

The MEPS-HC full year consolidated files are annual level files that contain data and health expenditures information collected from individuals participating in rounds 3 $-4-5$ of the longitudinal survey panel that began the prior year (panel y) and individuals participating in rounds $1-2-3$ of the longitudinal survey panel that began in the current 
year (panel x) (AHRQ, 2015a). The questions asked in rounds 1 and 3, 4 and 2, and 3 and 5 align so that researchers can draw from a larger sample to conduct annual-level analysis related to health care expenditures, health insurance coverage, and health behaviors.

Sample. For each of the MEPS-HC full year consolidated files from 2007 to 2013, I identify all individual ages 16 to 65 that were employed and had not previously been retired in December of the survey year. ${ }^{51}$ This results in a total of 99,826 personyear observations with an average of 14,261 person observations per year. I further restrict the sample to individuals who were employed in full-time year-round jobs for at least six months at the end of the reference period and who did not have missing observations for any of the variables used in the analysis. This results in 54,887 personyear observations with an average of 7,841 person observations per year. Although this excludes a large number of workers from the main sample, workers in full-time yearround jobs are those most likely to be offered fringe benefits (Kalleberg, Reskin, and Hudson, 2000). As a result, the analysis should provide conservative estimates of how the gender distribution of an occupation affects workers access to fringe benefits.

I define a full-time worker as an individual who reported working 35 or more hours per week at their current main job at the end of the survey reference period (December year). ${ }^{52}$ I exclude part-time workers from the analysis because working less than 35 hours might change a workers’ eligibility for benefits. I would expect part-time workers to have less generous or fewer benefits than full-time workers. Additionally, part-time workers likely have a different set of preferences regarding wages and benefits that influence their employment decisions and job seeking behaviors relative to full-time

\footnotetext{
${ }^{51}$ December of the survey year corresponds with the end of the survey reference period for round 5 for individuals in survey panel y and round 3 for individuals in survey panel $\mathrm{x}$ for years 2007 to 2013.

${ }^{52}$ This definition of full time is used by the bureau of labor statistics. If an individual estimated working 35 hours or more per week and did not provide an exact amount of hours, they were coded as working 40 hours in the MEPS, see MEPS Full Year Consolidate Data File Documention for additional information (AHRQ, 2015a).
} 
workers. It is important to note that excluding part-time workers (22\% of the sample) eliminates more female observations than male observations because $30 \%$ of employed females in the sample worked part time and only $15 \%$ of employed males in the sample worked part time.

I define an individual as employed year-round if their employment status is not seasonal or temporary. Approximately $8 \%$ of individuals who reported employment at the end of the survey reference period reported seasonal or temporary employment. Similar to part-time workers, I exclude seasonal and temporary workers because they are likely to have a different set of preferences when it comes to wages and fringe benefits and/or are unlikely to be offered fringe benefits by their employers.

Finally, I restrict the sample to individuals employed for more than six months, because newly employed workers may have a probationary period of up to six months before benefits come into effect. This would be unlikely to affect responses about whether an employer offered benefits, such as health insurance, but may affect responses to whether someone holds employer benefits such as vacation or sick leave and a pension. Survey questions related to benefits such as pension, paid vacation, and sick leave ask whether the person had the given benefit at the main job, not whether it was offered at their main job. I measure job tenure as months between the start date of the individual's current main job and the end date of the reference period (in the case of the consolidated full year files, the end date is December of the survey year). About 86.68\% of all workers employed at the end of the survey year had been employed for more than six months. 
I treat observations from each annual file as though a new nationally representative sample of individuals was drawn from the population in that year. ${ }^{53}$ However, because of the panel structure of the MEPS-HC survey, individuals in some panels contribute observations to more than one annual consolidated file and these individuals were included in the sample in each year that the above conditions were observed. As a result, 34,695 individuals contribute an average of 1.5 person-years to the 54,887 person-year observations used in the main analysis presented below.

Explanatory variables. The primary explanatory variable of interest in this study is the percentage of female workers in an occupation. Prior studies have demonstrated that the magnitude of the relationship between the gender composition of occupations and wages increases with more detailed job classifications (Bielby \& Baron, 1986; Blau et al., 2013; Cohen \& Huffman, 2003; Huffman, Velasco, \& Bielby, 1996). Therefore, in order to obtain estimates of female representation at the detailed occupation level, I match the four-digit occupations of individuals in the MEPS to highly precise one-year estimates of the percentage of female workers ages 16 to 65 in a detailed four-digit occupation group from the Integrated PublicUse MicroData Series (IPUMS) (Ruggles et al., 2015). ${ }^{54}$

Using the IPUMS estimates of the percentage of females in an occupation, I create five binary indicators that capture the effect of female representation on wage and non-wage compensation at different levels of female representation. These categories include less than 20\% female, 20 to 39\% female, 40 to 59\% female, 60 to $79 \%$ female, and greater than or equal to $80 \%$ female. Table 1 shows that predominately male

\footnotetext{
${ }^{53}$ Employed in a full-time year-round job for more than six months at the end of the reference period (December, year).

${ }^{5454}$ In 2002, the Census Bureau changed from coding 3-digit occupations to 4-digit occupations in order to facilitate the process of adding new occupational groups. In many cases the $4^{\text {th }}$ digit is simply zero and acts as a place holder, while in some places the $4^{\text {th }}$ digit represents a new or changing detailed occupation. 4digit occupation codes for MEPS participants were made available to the author in a secure computing environment.
} 
occupations (less than 20\% female) include grounds maintenance workers, carpenters, construction laborers and truck drivers, whereas predominately female occupations (greater than 20\% female) include elementary and middle school teachers, registered nurses, home health aides, maids and housekeeping cleaners, childcare workers, and secretaries and administrative assistants.

Table 1. Large Occupational Groups ${ }^{\mathrm{a}}$ by Female Representation

\begin{tabular}{llll}
\hline Female Representation & Code & Name & N \\
\hline$<20 \%$ Female & 4250 & Grounds Maintenance Workers & 1070 \\
& 6230 & Carpenters & 1023 \\
& 6260 & Construction Laborers & 1213 \\
& 9130 & Driver/Sales Workers and Truck Drivers & 2393 \\
20 to 39 \% Female & 10 & Chief Executives and Legislators & 1185 \\
& 430 & Miscellaneous Managers & 1938 \\
40 to 59\% Female & 4220 & Janitors and Building Cleaners & 2039 \\
& 4020 & Cooks & 1962 \\
& 4700 & First-Line Supervisors of Retail Sales Workers & 1909 \\
60 to 79\% Female & 4760 & Retail Salespersons & 2255 \\
& 4110 & Waiters and Waitresses & 1511 \\
& 4720 & Cashiers & 2701 \\
$>=80 \%$ Female & 5240 & Information and Record Clerks & 1445 \\
& 2310 & Elementary and Middle School Teachers & 1474 \\
& 3255 & Registered Nurses & 1077 \\
& 3600 & Nursing, Psychiatric, \& Home Health & 2084 \\
& 4230 & Maids and Housekeeping Cleaners & 1810 \\
& 4600 & Childcare Workers & 1085 \\
& 4610 & Personal Care Aides & 1177 \\
& 5700 & Secretaries and Administrative Assistants & 2078 \\
\hline
\end{tabular}

Notes: ${ }^{\text {a }}$ Occupational groups including at least 1000 observations from the main sample.

${ }^{b}$ Includes funeral service managers, postmasters, and mail superintendents.

In using this approach, I break with the convention in the literature, which has been to use percentage (proportion) female workers (Catanzarite, 2003; Cohen \& Huffman, 2003; England et al., 1996; Glass, 1990; Kilbourne et al., 1994) or the log of 
the percentage female workers (England et al., 2007; Levanon et al., 2009). ${ }^{55}$ However, these five binary indicators better capture the nonlinearity of the relationship between female representation and wages, which is not often addressed in the existing literature. ${ }^{56}$ As shown in Figure 1, average hourly wages vary considerable with the gender distribution of an occupation and within each of the categories of female representation. At less than $40 \%$ female representation in an occupation average wages often reach $\$ 50$ per hour and in some cases surpass $\$ 60$ per hour. Average wages reach beyond $\$ 40$ per hour with considerably less frequency at more than $40 \%$ female representation.

Figure 1. Average Wages by Female Representation in a Detailed Occupation Group

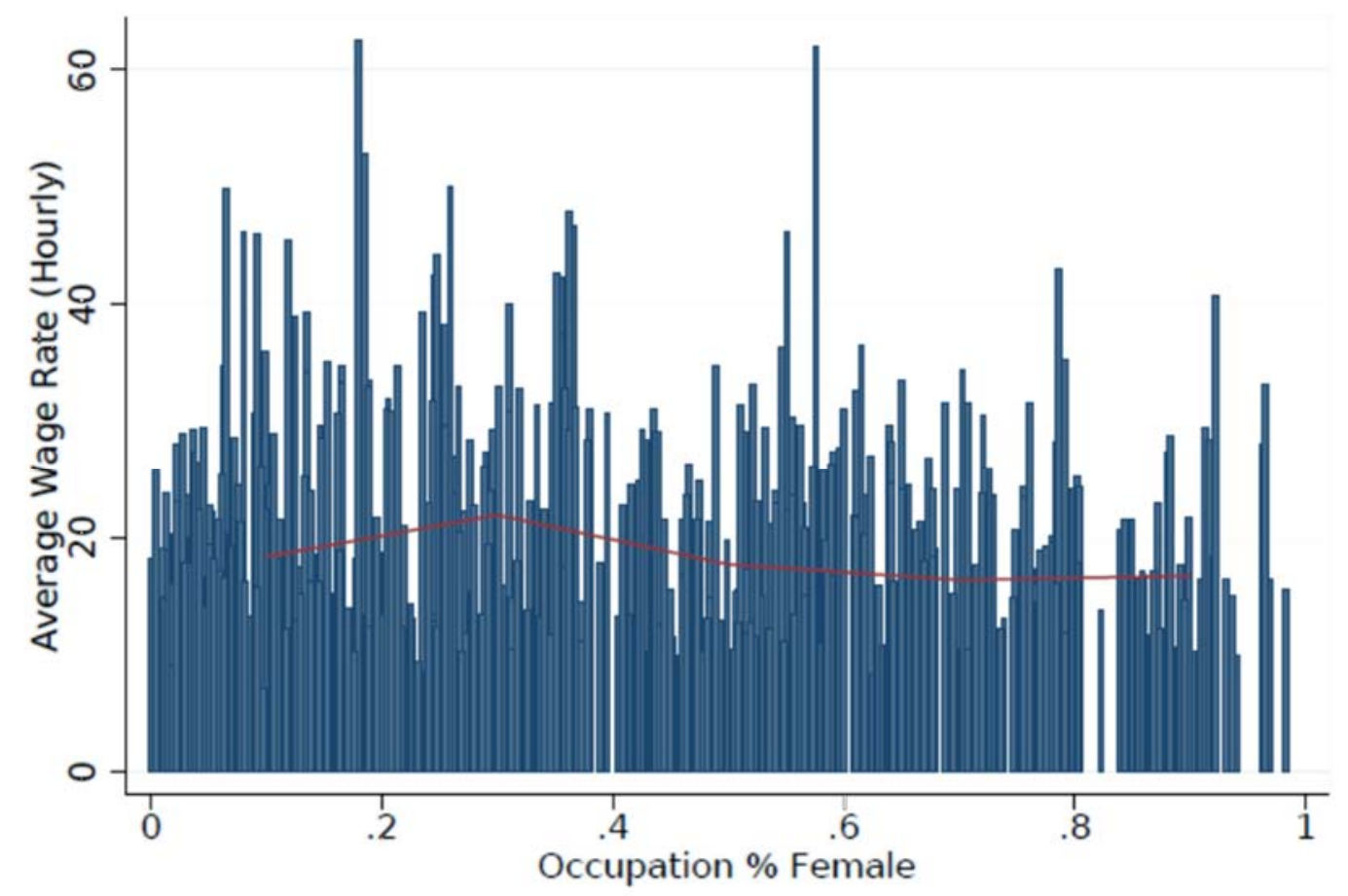

Notes: Red line shows average hourly wage at <20\% female, 20 to 39\% female, 40 to 59\% female, 60 to $79 \%$ female and $>=80 \%$ female.

\footnotetext{
${ }^{55}$ A few studies have used dummy variables as indicators of female representation such as Kmec (2003), who uses a binary indicator of majority female (female representation $>50 \%$ ); Jacobs and Steinberg (1990), who compare occupations with less than $10 \%$ female workers to occupations with more than $66 \%$ female workers; and England et al. (2007) who use three categories of female representation ( $<33 \%$ female, 33\% to $66 \%$ female, and $>66 \%$ ) in their sensitivity analysis. Regression results using these alternative measures of female representation are also shown in the appendix.

${ }^{56}$ For further discussion and evidence of the nonlinear relationship between percentage female in an occupation and wages see Cotter, Hermsen, and Vanneman (2004).
} 
Table 2. Sample Characteristics

\begin{tabular}{|c|c|c|c|}
\hline & & $\begin{array}{l}\text { All } \\
\text { Employed }\end{array}$ & $\begin{array}{l}\text { Main } \\
\text { Sample a }\end{array}$ \\
\hline & & $\%$ & $\%$ \\
\hline \multirow[t]{2}{*}{ Sex } & Male & 51.07 & $53.55^{* * *}$ \\
\hline & Female & 48.93 & $46.45^{* * *}$ \\
\hline \multirow[t]{6}{*}{ Race } & White & 71.54 & $70.65^{* * *}$ \\
\hline & Black & 17.97 & $18.38 * * *$ \\
\hline & American Indian / Alaskan Native & 0.86 & 0.87 \\
\hline & Asian & 7.60 & $8.20^{* * *}$ \\
\hline & Native Hawaiian / Pacific Islander & 0.39 & $0.44 * *$ \\
\hline & Multiple Races & 1.64 & $1.46^{* * *}$ \\
\hline \multirow[t]{2}{*}{ Hispanic Ethnicity } & Yes & 27.49 & $25.97^{* * *}$ \\
\hline & No & 72.51 & $74.03^{* * *}$ \\
\hline \multirow[t]{5}{*}{ Age } & 16 to 24 & 13.77 & $6.43^{* * *}$ \\
\hline & 25 to 34 & 24.04 & $23.69 * *$ \\
\hline & 35 to 44 & 24.13 & $26.73^{* * *}$ \\
\hline & 45 to 54 & 23.67 & $26.99 * * *$ \\
\hline & 55 to 65 & 14.38 & $16.16^{* * *}$ \\
\hline \multirow[t]{5}{*}{ Marital Status } & Married & 53.60 & $59.11^{* * *}$ \\
\hline & Widowed & 1.34 & $1.40^{*}$ \\
\hline & Divorced & 10.86 & $11.83^{* * *}$ \\
\hline & Separated & 2.89 & 2.82 \\
\hline & Never Married & 31.32 & $24.84^{* * *}$ \\
\hline \multirow[t]{5}{*}{ Education } & No Degree & 16.57 & $12.91^{* * *}$ \\
\hline & GED or High School Diploma & 41.59 & $41.27 *$ \\
\hline & Associate's Degree & 14.79 & $15.05 *$ \\
\hline & Bachelor's Degree & 17.52 & $19.82 * * *$ \\
\hline & Master's or Doctoral Degree & 8.7 & $10.20^{* * *}$ \\
\hline \multirow[t]{2}{*}{ Born in United States } & Yes & 66.71 & $67.50 * * *$ \\
\hline & No & 33.29 & $32.50^{* * *}$ \\
\hline \multirow[t]{2}{*}{ Children < 18} & Yes & 50.09 & $48.95^{* * *}$ \\
\hline & No & 49.91 & $51.05^{* * *}$ \\
\hline \multirow[t]{5}{*}{ Female Representation } & $<20 \%$ Female & 20.17 & $21.29 * * *$ \\
\hline & 20 to $39 \%$ Female & 19.79 & $21.93^{* * *}$ \\
\hline & 40 to $59 \%$ Female & 19.84 & $19.34^{* * *}$ \\
\hline & 60 to $79 \%$ Female & 19.89 & $18.53^{* * *}$ \\
\hline & $>=80 \%$ Female & 20.29 & $18.91^{* * *}$ \\
\hline Total Observations & & 99826 & 54887 \\
\hline Average N (per year) & & 14261 & 7841 \\
\hline
\end{tabular}

Notes: a Main sample defined as employed in full-time year-round main job at end of survey year.

T-test for differences in means, statistically significant at ${ }^{* * *} \mathrm{p}<0.001,{ }^{* *} \mathrm{p}<0.01,{ }^{*} \mathrm{p}<0.05$ 
Control variables include binary indicators of sex (female=1), race (white, black, American Indian/Alaskan Native, Asian, Native Hawaiian/Pacific Islander, and multiple races), Hispanic ethnicity (yes=1), age (16 to 24,25 to 34,35 to 44,45 to 54 , and 55 to 65), marital status (married, widowed, divorced, separated, and never married), education (no degree, GED or HS diploma, associate's degree, bachelor's degree, and master's degree or higher,), nativity (born in the United States=1), children under 18 in the household (yes=1), union status (union member=1), and industry (12 categories). I also control for state of residence and survey year.

Distributional differences between all employed workers ages 16 to 65 and the main sample of workers employed in full-time year-round jobs are reported in Table $2 .{ }^{57}$ Compared to all employed workers, full-time year-round workers in the sample are more likely to be male and slightly less likely to be of Hispanic ethnicity. Workers in the main sample are also slightly older and more educated than all employed workers, and although slightly more are married (59.11\% compared 53.60\%) fewer have children under 18.

Dependent variables. The outcomes of interest in this study are measures of compensation, including wages, fringe benefits, and total compensation. According to estimates from the BLS National Compensation Survey (NCS), in 2016 two thirds of total compensation (total employment costs) went to wages, while slightly less than one third (31.6\%) of total compensation went to fringe benefits including health and other forms of insurance, paid leave, and retirement contributions (BLS, 2017). The largest employer expenditure on non-wage compensation was by far employer provided health insurance coverage (EPHI) which accounted for $8.3 \%$ of total employment costs. Paid leave and pensions (retirement and savings contributions) were also important sources of

\footnotetext{
${ }^{57}$ The estimates reported in Table 1 are averages of the distribution of workers in each category in each year.
} 
non-wage compensation. Together paid leave amounted to $7.1 \%$ of total employment costs in 2016 (6.0\% to vacation, holiday, and personal leave and 1.1\% to sick leave); and pensions (retirement and savings), including defined benefit and defined contributions, amounted to $5.4 \%$ of total employment costs (BLS, 2017).

In order to measure wage compensation, I use the natural log of hourly wages. ${ }^{58}$ In order to measure non-wage compensation, I use binary indicators of whether an individual's employer offers health insurance coverage and whether an individual holds a pension plan, paid sick leave, and paid vacation from their current main job. I also create a "back of the envelope” measure of total job compensation equal to a worker's hourly wage plus the value of each of the fringe benefits, based on NCS estimates of wages and benefits as percentage of total employment costs in an aggregate occupation group and year. $^{59}$

As shown in Table 3, in each survey year, on average, workers in the main sample had median hourly wages of \$16.57, average hourly wages of \$20.57, and average total compensation of $\$ 25.51$. Slightly more than $70 \%$ of workers in the sample reported that their employer offered health insurance coverage, while nearly 80\% reported having paid vacation, 69.23\% reported having sick leave, and 58.47\% reported having a pension plan from their main job.

Also shown in Table 3, male workers had higher median hourly wages than female workers in the sample (\$17.50 compared to $\$ 15.09$ ) they also had higher average total compensation (\$27.26 compared to \$23.49). However, more females than males were offered health insurance coverage by their employers (70.45\% and 69.71\% respectively), and more females than males had paid vacation (81.22\% compared to

\footnotetext{
${ }^{58}$ Hourly wages are top coded at greater than $\$ 70$ per hour (AHRQ, 2015a).

${ }^{59}$ The calculation of total compensation is discussed in Appendix B.
} 
77.65\%), sick pay (74.58\% compared to $64.59 \%)$, and pensions (60.03\% compared to 57.11\%). If having a fringe benefit is an indication of a worker's preference for that benefit, than these descriptive results provide some evidence of differences in men and women’s benefit preferences. ${ }^{60}$

Table 3. Job Compensation by Gender and Female Representation ${ }^{\mathrm{a}}$

\begin{tabular}{|c|c|c|c|c|c|c|c|}
\hline & \multicolumn{2}{|c|}{ Hourly Wages } & $\begin{array}{c}\text { Total } \\
\text { Compensation }\end{array}$ & $\begin{array}{c}\text { Health } \\
\text { Insurance }\end{array}$ & $\begin{array}{c}\text { Paid } \\
\text { Vacation }\end{array}$ & $\begin{array}{c}\text { Sick } \\
\text { Leave }\end{array}$ & Pension \\
\hline & Median & Mean & Mean & $\%$ & $\%$ & $\%$ & $\%$ \\
\hline All Workers & 16.57 & 20.57 & 25.51 & 70.05 & 79.30 & 69.23 & 58.47 \\
\hline \multicolumn{8}{|l|}{ Sex } \\
\hline Male & 17.50 & $22.02 * * *$ & $27.26^{* * *}$ & $69.71^{* * *}$ & $77.64 * * *$ & $64.59 * * *$ & $57.11^{* * *}$ \\
\hline Female & 15.09 & 18.90 & 23.49 & 70.45 & 81.22 & 74.58 & 60.03 \\
\hline \multicolumn{8}{|c|}{ Female Representation } \\
\hline$<20 \%$ & 17.00 & $19.91^{* * *}$ & $24.45^{* * *}$ & $65.77 * * *$ & $72.64 * * *$ & $54.65^{* * *}$ & $51.69 * * *$ \\
\hline $20 \%$ to $39 \%$ & 18.69 & $24.17 * * *$ & $30.21^{* * *}$ & $74.27 * * *$ & $85.31^{* * *}$ & $72.52 * * *$ & $63.49 * * *$ \\
\hline $40 \%$ to $59 \%$ & 15.87 & $20.07 * * *$ & $24.69 * * *$ & $68.81^{* *}$ & 79.86 & 68.98 & $57.46^{*}$ \\
\hline $60 \%$ to $79 \%$ & 16.35 & $19.73^{* * *}$ & $24.70^{* * *}$ & 70.35 & 79.73 & $73.88 * * *$ & $60.09^{* * *}$ \\
\hline$>=80 \%$ & 15.14 & $18.46^{* * *}$ & $22.90 * * *$ & 70.97* & 78.84 & $77.55^{* * *}$ & $59.71^{* *}$ \\
\hline
\end{tabular}

Notes: Authors own calculations from MEPS consolidated annual files 2007 to 2013.

${ }^{a}$ Main sample defined as employed in full-time year-round main job at end of survey year.

T-test for differences in group means, statistically significant at ${ }^{* * *} \mathrm{p}<0.001,{ }^{* *} \mathrm{p}<0.01,{ }^{*} \mathrm{p}<0.05$

Workers in predominately male occupations (less than 20\% female workers) had median hourly wages of $\$ 17.00$, while workers in $20 \%$ and $39 \%$ female occupations had median hourly wages of $\$ 18.69$, workers in gender integrated occupations (40 to 60\% female workers) had median hourly wages of $\$ 15.87$, workers in 60 to $79 \%$ female occupations had median hourly wages of $\$ 16.35$, and workers in predominately male occupations (greater than $80 \%$ female workers) had median hourly wages of $\$ 15.14$. Average total job compensation was lowest in predominately female occupations, $\$ 22.90$ per hour, and highest in occupations with 21 to $40 \%$ female workers, \$30.21. For

\footnotetext{
${ }^{60}$ It is likely that these estimates are only partial indicators of preferences because of "imperfect sorting" in the labor market. See Levy (1998) for a discussion of imperfect sorting as it applies to workers preferences for health insurance coverage and how these preferences affect employer behavior when it comes to the supply of benefits.
} 
predominately male occupations, gender integrated occupations, and 60 to $70 \%$ female occupations, average total compensation was around between \$24 and \$25 dollar, \$4 to $\$ 5$ higher than average wages at the same levels of female representation.

The percentage of workers with offers of employer provided health insurance coverage was highest in 20 to 39\% female occupations (74.27\%) and lowest in predominately male occupations (65.77\%). The percentage of workers with paid vacation was also the highest in 20 to 39\% female occupations (85.31) and the lowest in predominately male occupations (72.64\%). For gender integrated occupations and predominately female occupations, the percentage of workers with paid vacation was not statistically significant from the overall group mean.

The percentage of workers with sick pay was the highest in predominately female occupations (77.55\%) and the lowest in predominately male occupations (54.65\%), whereas in 20 to $39 \%$ female occupations $72.52 \%$ of workers had sick leave and in 60 to $79 \%$ female occupations $73.88 \%$ of workers had sick leave. Similar to employer provided health insurance coverage and paid vacation, however, the percentage of workers with pensions was the highest in 20 to 39\% female occupations (63.49\%) and the lowest in predominately male occupations (51.69\%). In predominately female occupations and 40 to $60 \%$ female occupations around $60 \%$ of workers had pensions, whereas in gender integrated occupations the percentage was slightly lower, 57.46\%.

If one compares predominately female occupations (greater than $80 \%$ female) to predominately male occupations (less than $20 \%$ female), these unadjusted estimates provide some evidence that non-wage compensation is influenced by an occupation's sex composition. Average wages of predominately female workers are lower than average wages of predominately male workers (\$18.46 compared to $\$ 19.91$ ); however the percentages of workers with offers of employer provided health insurance coverage, paid 
vacation, sick leave, and pensions are all greater in predominately female occupations relative to predominately male occupations. Although a greater percentage of workers reported having fringe benefits in predominately female occupations relative to predominately male occupations, the average level of total job compensation was slightly lower in predominately female occupations (\$22.90 relative to \$24.45). ${ }^{61}$

Models. In order to further examine the relationship between female representation and both wage and non-wage compensation, I separately model each compensation outcome as a function of female representation controlling for demographic, job, state, and time characteristics. When the compensation outcome is continuous (i.e. hourly wages or total job compensation), I use linear regression and when the outcome is discrete, I use probit regression analysis and report marginal effects.

$$
Y_{i j s t}^{\text {compensation }}=\alpha+X_{j} \beta+W_{i} \gamma+\sigma_{s}+\varphi_{t}+\varepsilon_{i s t}
$$

In equation 1a, $Y_{i j s t}^{\text {compensation }}$ is equal to the natural log of hourly wages or total job compensation for person $i$ in occupation $j$ at state $s$ at time $t$. $X_{j}$ is a vector of five indicators of female representation is a vector of coefficients for the five indicators of the proportion of female workers in occupation $j$ (less than 20\% female, 20 to 39\% female, 40 to $59 \%$ female, 60 to $79 \%$ female, and greater than or equal to $80 \%$ female) and $\beta$ is a vector of coefficients on the indictors of female representation. $W_{i}$ is a vector of binary variables controlling for gender, race, education, marital status, age, the presence of children under 18 in the home, union status, and industry, and $\gamma$ is a vector of coefficients for each of these control variables. $\alpha$ is an intercept term, $\sigma_{s}$ is a vector of state indicators, $\varphi_{t}$ is a vector of time indicators, and $\varepsilon_{i j s t}$ is the error term.

\footnotetext{
${ }^{61}$ However, this measure is heavily dependent on average hourly wages, which are higher in predominately female occupations and predominately male occupations.
} 
Equation $1 \mathrm{~b}$ shows the specification of model 1 when the outcome is a binary indicator of non-wage compensation:

$$
\operatorname{Pr}\left(Y_{i j s t}^{\text {benefit }}=1\right)=\phi\left(\alpha+X_{j} \beta+W_{i} \gamma+\sigma_{s}+\varphi_{t}\right) .
$$

Here benefit indicates one of four possible measures of non-wage compensation including whether an individual's employer offers health insurance, and whether an individual has a pension, paid vacation or sick leave from their current main job. The explanatory variables are the same as in equal 1.

In a second model, I add a vector of controls for whether an individual receives other fringe benefits to the wage and compensation equations specified in model 1 . The purpose of this exercise is to examine how the magnitudes of the coefficients on female representation $(\beta)$ change once non-wage compensation is taken into account.

$$
Y_{i j s t}^{\text {compensation }}=\alpha+X_{j} \beta+W_{i} \gamma+Z_{i} \delta+\sigma_{s}+\varphi_{t}+\varepsilon_{i s t}
$$

In equation $2, Z_{i}$ is a vector of other fringe benefits (sources of non-wage compensation) which includes whether a worker is offered employer health insurance and whether an individual has paid leave (both or either of sick pay and/or paid vacation), and a pension plan from their current main job; $\delta$ is a vector of coefficients for each of these indicators. Although the coefficients on fringe benefits $(\delta)$ should capture the individuallevel tradeoff between fringe benefits and wages, they are likely to be biased due to unobserved differences in ability and productivity that affect workers' selection into jobs with better pay and more benefits. Nevertheless, if fringe benefits are important for the interpretation of the wage effect of female representation, then we would expect the coefficients on female representation $(\beta)$ to be sensitive to the inclusion of benefits $\left(Z_{i}\right)$. 


\section{Results}

In Table 4, I report coefficients from regression models predicting the relationship between female representation and wages and total compensation based on equation 1a. I report marginal effects from probit regression models predicting the relationship between female representation and fringe benefits based on equation 1b. The marginal effects can be interpreted as the expected change in the likelihood of having a given fringe benefit due to a discrete change in the category of the independent variable (i.e. a change from less than $20 \%$ female to 20 to $39 \%$ female), holding all other variables at their means. ${ }^{62}$

Table 4. The Effects of Female Representation on Job Compensation ${ }^{\text {a }}$

\begin{tabular}{|c|c|c|c|c|c|c|}
\hline & $\begin{array}{l}\text { Hourly } \\
\text { Wages } \\
\text { (log) }\end{array}$ & $\begin{array}{c}\text { Health } \\
\text { Insurance }^{\text {b }}\end{array}$ & $\begin{array}{c}\text { Paid } \\
\text { Vacation }\end{array}$ & $\begin{array}{c}\text { Sick } \\
\text { Leave }\end{array}$ & Pension & $\begin{array}{c}\text { Total } \\
\text { Compensation } \\
(\log ) \\
\end{array}$ \\
\hline \multicolumn{7}{|l|}{$\begin{array}{l}\text { Female } \\
\text { Representation } \\
(<20 \% \text { female })\end{array}$} \\
\hline 20 - 39\% female & $\begin{array}{l}0.026^{* *} \\
(0.008)\end{array}$ & $\begin{array}{l}0.022 * * \\
(0.007)\end{array}$ & $\begin{array}{l}0.044^{* * *} \\
(0.007)\end{array}$ & $\begin{array}{l}0.055^{* * *} \\
(0.007)\end{array}$ & $\begin{array}{l}0.027 * * * \\
(0.008)\end{array}$ & $\begin{array}{l}0.026^{* *} \\
(0.009)\end{array}$ \\
\hline 40 - 59\% female & $\begin{array}{l}-0.046 * * * \\
(0.008)\end{array}$ & $\begin{array}{l}-0.015 \\
(0.008)\end{array}$ & $\begin{array}{l}-0.002 \\
(0.007)\end{array}$ & $\begin{array}{l}0.038 * * * \\
(0.008)\end{array}$ & $\begin{array}{l}-0.008 \\
(0.008)\end{array}$ & $\begin{array}{l}-0.056 * * * \\
(0.009)\end{array}$ \\
\hline $60-79 \%$ female & $\begin{array}{l}-0.095 * * * \\
(0.009)\end{array}$ & $\begin{array}{l}-0.009 \\
(0.009)\end{array}$ & $\begin{array}{l}-0.000 \\
(0.008)\end{array}$ & $\begin{array}{l}0.046 * * * \\
(0.008)\end{array}$ & $\begin{array}{l}0.000 \\
(0.009)\end{array}$ & $\begin{array}{l}-0.093 * * * \\
(0.010)\end{array}$ \\
\hline$>=80 \%$ female & $\begin{array}{l}-0.126 * * * \\
(0.010)\end{array}$ & $\begin{array}{l}-0.037^{* * *} \\
(0.010)\end{array}$ & $\begin{array}{l}-0.031^{* * *} \\
(0.008)\end{array}$ & $\begin{array}{l}0.012 \\
(0.009)\end{array}$ & $\begin{array}{l}-0.037^{* * *} \\
(0.010)\end{array}$ & $\begin{array}{l}-0.133^{* * *} \\
(0.011)\end{array}$ \\
\hline \multicolumn{7}{|l|}{$\begin{array}{l}\text { Sex } \\
\text { (male) }\end{array}$} \\
\hline female & $\begin{array}{l}-0.107 * * * \\
(0.006)\end{array}$ & $\begin{array}{l}-0.021^{* * *} \\
(0.006)\end{array}$ & $\begin{array}{l}0.022 * * * \\
(0.005)\end{array}$ & $\begin{array}{l}0.019 * * * \\
(0.006)\end{array}$ & $\begin{array}{l}0.004 \\
(0.006)\end{array}$ & $\begin{array}{l}-0.106 * * * \\
(0.006)\end{array}$ \\
\hline Constant & $\begin{array}{l}2.422 * * * \\
(0.019)\end{array}$ & $-{ }^{c}$ & - & - & - & $\begin{array}{l}2.517^{* * * *} \\
(0.020)\end{array}$ \\
\hline Observations & 54,887 & 54,887 & 54,887 & 54,887 & 54,887 & 54,887 \\
\hline Clusters & 34,695 & 34,695 & 34,695 & 34,695 & 34,695 & 34695 \\
\hline $\mathrm{R}^{2}$ (Pseudo) & 0.45 & 0.15 & 0.15 & 0.21 & 0.21 & 0.47 \\
\hline Wald Chi2 & & $5200 * * *$ & $4600 * * *$ & $6700 * * *$ & $7300 * * *$ & \\
\hline
\end{tabular}

Notes: ${ }^{a}$ Controls for race, Hispanic ethnicity, age, marital status, education, children under 18, nativity, union membership, industry, state, and year included in regression analysis. ${ }^{b}$ For probit regressions (columns 2-5) marginal effects are reported with cluster robust standard errors in parentheses. ${ }^{\mathrm{c}}$ Constant term not shown. Estimates statistically significant at $* * * \mathrm{p}<0.001,{ }^{* *} \mathrm{p}<0.01,{ }^{*} \mathrm{p}<0.05$. Sample includes workers ages 16-65 in full-time year-round jobs for more than six months in December of the survey year.

${ }^{62}$ I include person-level weights constructed specifically for the annual level consolidated files in each of the models so that estimates are nationally representative of workers employed in full-time year round jobs for more than six months. I cluster standard errors at the person-level to account for repeated personobservations across years. 
The results from Table 4 show the expected negative relationship between female representation and wages (measured as the natural log of hourly wages). The coefficient on sex (female=1) in the wage equation indicates that net of the sex composition of a worker's occupation, females have average wages that are $10.7 \%$ lower than males. When it comes to the wage effect of female representation, relative to predominately male occupations, average wages are 4.6\% lower in gender integrated occupations, 9.5\% lower in 60 to $79 \%$ female occupations, and $12.6 \%$ lower in predominately female occupations. Average wages are $2.6 \%$ higher in 20 to 39\% female occupations than in predominately male occupations.

In terms of non-wage compensation, the results from Table 4 show that female workers in the main sample are 2.1 percentage points less likely to be offered health insurance coverage on the job than male workers, net of the sex composition of the occupation in which they work. However, workers in 20 to 39\% female occupations are 2.2 percentage points more likely to be offered health insurance by their employers relative to workers in predominately male occupations, whereas workers in predominately female occupations are 3.7 percentage points less likely to be offered health insurance coverage by their employers. Although the estimates of the health insurance effects of working in a 40 to $59 \%$ female occupation and a 60 to $79 \%$ female occupation do have a negative sign, they are not statistically significant.

Proponents of compensating differentials theory have also hypothesized that women may choose family friendly jobs because of their responsibilities for household production and therefore more likely to prefer benefits such as paid leave, although there is little empirical evidence to support this hypothesis (England, et al. 1994). The results in Table 4 show that female workers are 2.2 percentage points more likely to report having paid vacation; however, the coefficients on female representation suggest that employers 
in predominately female occupations are not necessarily more likely to supply this benefit to their largely female workforce; the likelihood of having paid vacation is 3.1 percentage points lower in predominately female occupations relative to predominately male occupations. The results once again show that workers in 20 to 39\% female occupations, who appear to be among the most advantaged workers in the labor market in terms of wage compensation, are also 4.4 percentage points more likely to have paid vacation than workers in predominately male occupations.

When it comes to access to sick leave, female workers are 1.9 percentage points more likely to have sick leave than male workers, net of the sex composition of the occupation in which they work. However, here the association between female representation in an occupation and sick leave shows a different pattern than the association between female representation and paid vacation. Not only are workers in 20 to $39 \%$ female occupations 5.5 percentage points more likely to have sick leave, workers in 40 to $59 \%$ female occupations and 60 to $70 \%$ female occupations are also more likely to have sick leave (by 3.8 and 4.6 percentage points respectively). Although the direction of the association between working in a predominately female occupation (greater than $80 \%$ female) and having sick leave is positive, the estimate is not statistically significant.

Unlike with health insurance coverage, paid leave, and sick leave, female workers do not appear to have statistically different probabilities of having pensions than male workers, net of other individual and occupational characteristics. However, the results in Table 4 show that workers in predominately female occupations are 3.7 percentage points less likely to have pension plans than workers in predominately male occupations, whereas workers in 20 to $39 \%$ female occupations are 2.7 percentage points more likely to have pension plans than workers in predominately male occupations. The coefficients on $40-59 \%$ female and 60 to $79 \%$ female are not statistically significant. 
In Table 4 I also report estimates of the association between female representation and estimated total job compensation (measured as the natural log to hourly total job compensation). The results are largely consistent with the results from the wage equation. Relative to occupations that are predominately male, average total compensation is $5.6 \%$ lower in gender integrated occupations, 9.3\% lower in 60 to $79 \%$ female occupations, and $13.3 \%$ lower in predominately female occupations. In contrast, the average total compensation is $2.6 \%$ higher in 20 to $39 \%$ female occupations relative to predominately male occupations.

In Table 5 I include dummy indicators for having fringe benefits into the wage and total compensation equations (see equation 2). This allows me to further examine whether accounting for the relationship between fringe benefits and compensation changes the relationship between female representation in an occupation and compensation. When it comes to wage compensation, I find that the coefficients on 40 to $59 \%$ female, 60 to $79 \%$ female, and predominately female occupations change very little and remain strongly statistically significant after controlling for employer provided health insurance, paid leave, and pensions. However, I do find that accounting for fringe benefits reduces the positive returns to working in an occupation with 20 to $30 \%$ female workers relative to a predominately male occupation. I also find that female wages remain around $10.8 \%$ lower than male wages.

In terms of the coefficients on fringe benefits, consistent with prior studies using cross-sectional data, rather than observing an inverse relationship between benefits and wages, I observe that workers whose employers offer health insurance coverage have average wages that are $11.3 \%$ greater than workers whose employers do not offer health insurance coverage, ceteris paribus. Workers who have paid leave (either sick or 
vacation) have wages that are $10.20 \%$ greater than those without paid leave, and workers who have pensions have wages that are $19.6 \%$ greater than those without pensions.

Table 5. The Effects of Female Representation on Hourly Wages and Total Compensation Controlling for Fringe Benefits ${ }^{a}$

Hourly Wages

$(\log )$
Total Compensation

$(\log )$

Female Representation

$(<20 \%$ female $)$

$$
\begin{array}{rll}
20-39 \% \text { female } & 0.013 & 0.006 \\
& (0.008) & (0.008) \\
40-59 \% \text { female }-0.045^{* * *} & -0.054^{* * *} \\
(0.008) & (0.008) \\
60-79 \% \text { female }-0.095^{* * *} & -0.092^{* * *} \\
(0.009) & (0.009) \\
>=80 \% \text { female }-0.113^{* * *} & -0.113^{* * *} \\
(0.010) & (0.010)
\end{array}
$$

\section{Sex}

(male)

$$
\begin{array}{cl}
\text { female }-0.108^{* * *} & -0.107^{* * *} \\
(0.006) & (0.006)
\end{array}
$$

Fringe Benefits

$$
\begin{aligned}
\text { EPHI offered } & 0.113^{* * *} \\
& (0.006) \\
\text { Paid leave } & 0.102 * * * \\
& (0.007) \\
\text { Pension } & 0.196 * * * \\
& (0.006)
\end{aligned}
$$

Constant
$0.231 * * *$

Notes: a Controls for race, Hispanic ethnicity, age, marital status, education, children under 18, nativity, union membership, industry, state, and year included in regression analysis, but suppressed in output. ${ }^{b}$ For probit regressions (columns 2-5) marginal effects are reported with cluster robust standard errors in parentheses. ${ }^{c}$ Constant term not shown. Estimates statistically significant at $* * * p<0.001,{ }^{* *} \mathrm{p}<0.01$, * $\mathrm{p}<0.05$. Sample restricted to workers ages $16-65$ employed in full-time year-round jobs for more than six months in December of the survey year. 
Consistent with the results in Table 4, the impacts of female representation on total compensation mirror the impacts of female representation on wages after controlling for fringe benefits. However, the coefficients on fringe benefits suggest that net of the sex composition of a worker's occupation and net of a worker's sex, having employer health insurance offered on the job increases total compensation by $23.1 \%$, having paid leave increases total compensation by $18.3 \%$, and having a pension increases total compensation by $25.6 \%$.

Sensitivity Analysis. One way to further investigate the relationship between female representation and compensation is to examine whether the wage and benefit effects of working in a predominately female occupations differ for men and women. For this additional analysis, I rerun models based on equation 1 for all compensation measures with interactions between sex (female=1) and explanatory variables. This technique is mathematically equivalent to running the regression equations separately for male and female workers. For simplicity, I report only the coefficients and interaction terms for female and female representation in Table 6. For ease of interpretation of the interaction terms, linear probability model were used in place of probit models to examine gender differences the benefit effects of female representation.

In Table 6 the female coefficient is statistically significant at a 95\% confidence level. This suggests that in terms of total compensation, female workers in predominately male jobs earn about $10 \%$ less than male workers in predominately male jobs. In terms of female representation, the results appear to support England's devaluation hypothesis in that female representation in an occupation similarly affects the wages of male and female workers and therefore, for the most part appears separate from the negative effect of sex on wages. 
Table 6. The Effects of Female Representation on Job Compensation by Gender

\begin{tabular}{|c|c|c|c|c|c|c|}
\hline & $\begin{array}{l}\text { Hourly } \\
\text { Wages } \\
(\log )\end{array}$ & $\begin{array}{c}\text { Health } \\
\text { Insurance }\end{array}$ & $\begin{array}{c}\text { Paid } \\
\text { Vacation } \\
\end{array}$ & $\begin{array}{c}\text { Sick } \\
\text { Leave }\end{array}$ & Pension & $\begin{array}{c}\text { Total } \\
\text { Compensation } \\
\text { (log) } \\
\end{array}$ \\
\hline \multicolumn{7}{|l|}{ Sex (male) } \\
\hline \multirow[t]{2}{*}{ female } & -0.082 & $-0.090 *$ & 0.002 & -0.015 & -0.007 & $-0.098^{*}$ \\
\hline & $(0.042)$ & $(0.040)$ & $(0.037)$ & $(0.041)$ & $(0.042)$ & $(0.045)$ \\
\hline \multicolumn{7}{|l|}{$\begin{array}{l}\text { Female } \\
\text { Representation } \\
(<20 \% \text { female })\end{array}$} \\
\hline \multirow[t]{2}{*}{20 to $39 \%$} & $0.030 * * *$ & $0.021^{* *}$ & $0.041^{* * *}$ & $0.066^{* * *}$ & $0.035 * * *$ & $0.031^{* *}$ \\
\hline & (0.009) & (0.008) & $(0.007)$ & $(0.009)$ & (0.009) & (0.010) \\
\hline \multirow[t]{2}{*}{40 to $59 \%$} & $-0.037 * * *$ & -0.011 & -0.003 & $0.048 * * *$ & -0.001 & $-0.046 * * *$ \\
\hline & $(0.010)$ & $(0.009)$ & $(0.008)$ & $(0.010)$ & $(0.010)$ & $(0.011)$ \\
\hline \multirow[t]{2}{*}{60 to $79 \%$} & $-0.087 * * *$ & $-0.028 *$ & -0.010 & $0.035^{* *}$ & 0.010 & $-0.088 * * *$ \\
\hline & $(0.013)$ & $(0.012)$ & $(0.011)$ & $(0.012)$ & $(0.012)$ & $(0.014)$ \\
\hline \multirow[t]{2}{*}{$>=80 \%$} & $-0.141 * * *$ & -0.033 & $-0.036^{*}$ & 0.023 & -0.009 & $-0.149 * * *$ \\
\hline & $(0.018)$ & $(0.017)$ & $(0.017)$ & $(0.016)$ & $(0.018)$ & (0.019) \\
\hline \multicolumn{7}{|l|}{ Interactions } \\
\hline \multirow{2}{*}{ Female*20 to 39\% } & -0.009 & 0.000 & -0.030 & $-0.057^{*}$ & $-0.061 * *$ & -0.015 \\
\hline & $(0.025)$ & $(0.022)$ & $(0.017)$ & $(0.023)$ & $(0.023)$ & $(0.026)$ \\
\hline \multirow[t]{2}{*}{ Female*40 to59\% } & -0.013 & -0.013 & -0.019 & $-0.058^{*}$ & $-0.059 *$ & -0.019 \\
\hline & $(0.025)$ & $(0.022)$ & $(0.018)$ & $(0.023)$ & $(0.024)$ & $(0.027)$ \\
\hline \multirow[t]{2}{*}{ Female*60 to $79 \%$} & -0.011 & 0.020 & -0.010 & -0.032 & $-0.071 * *$ & -0.012 \\
\hline & $(0.026)$ & $(0.023)$ & $(0.019)$ & $(0.023)$ & $(0.024)$ & $(0.028)$ \\
\hline \multirow[t]{2}{*}{ Female* $>=80 \%$} & 0.008 & -0.008 & -0.015 & -0.047 & $-0.091 * *$ & 0.004 \\
\hline & $(0.029)$ & $(0.026)$ & (0.023) & $(0.026)$ & $(0.028)$ & $(0.031)$ \\
\hline \multirow[t]{2}{*}{ Constant } & $2.379 * * *$ & $0.450 * * *$ & $0.463 * * *$ & $0.430 * * *$ & $0.231^{* * *}$ & $2.490 * * *$ \\
\hline & $(0.026)$ & $(0.024)$ & $(0.024)$ & $(0.025)$ & $(0.025)$ & $(0.028)$ \\
\hline Observations & 54887 & 54887 & 54887 & 54887 & 54887 & 54887 \\
\hline Clusters & 34695 & 34695 & 34695 & 34695 & 34695 & 34695 \\
\hline $\mathrm{R}^{2}$ & 0.45 & 0.18 & 0.16 & 0.24 & 0.25 & 0.47 \\
\hline
\end{tabular}

Notes: ${ }^{\text {a }}$ Controls and interaction terms with sex (female $=1$ ) for race, Hispanic ethnicity, age, marital status, education, children under 18, nativity, union membership, industry, state, and year included in regression analysis. ${ }^{b}$ For probit regressions marginal effects are reported with cluster robust standard errors in parentheses. ${ }^{c}$ Constant term not shown. Estimates statistically significant at $* * * p<0.001$, ${ }^{* *} p<0.01$, * $\mathrm{p}<0.05$. Sample of workers ages $16-65$ employed in full-time year-round jobs for more than six months.

The interaction terms show that wage differences between female workers at each of the levels of female representation are not statistically different from wage differences between male workers at each of the levels of female representation relative to male and female workers in predominately male jobs. The results are similar when total job 
compensation is used as the outcome. None of the coefficients on the interactions between female and female representation in an occupation is significant.

It also does not appear that the effects of female representation in an occupation on employer offers of health insurance coverage differ by sex. Differences in health insurance coverage offers between female workers in predominately male occupations and female workers at each of the levels of female representation are not statistically different from differences in health insurance coverage offers between male workers in predominately male occupations and male workers at each of the level of female representation.

However, this pattern changes slightly when it comes to sick leave and pensions. In this case, gender appears to play a significant role in strengthening or weakening the impact of female representation. For example, a male worker in a 20 to 39\% female occupation is 6.6 percentage points more likely to have sick leave relative to a male workers in a predominately male occupation, whereas a female worker in a 20 to 39\% female occupation is less than one percentage point more likely to have sick leave than a female worker in a predominately male occupation (the coefficient on predominately male is 0.066 and the coefficient on the interaction term is -0.057 ; the effect of working in a predominately male jobs for females only is $0.066+-0.057=.009$ ).

Additionally, while male workers in gender integrated occupations are more likely to have sick leave than male workers in predominately male jobs, female workers in gender integrated jobs are less likely to have sick leave than female workers in predominately male jobs. Finally, in terms of pensions, at greater levels of female representation, male workers do not appear more likely to have pensions than their counterparts in predominately male jobs (with the exception of 20 to 39\% female 
occupations); however, female workers appear less to have pensions at all levels of female representation than female workers in predominately male jobs.

\section{Discussion}

Although many studies have documented a persistent negative relationship between female representation in an occupation and wages, proposed policy solutions to address the lower relative pay of female jobs, such as comparable worth (pay equity), remain contentious due to competing theoretical explanations for why predominately female occupations pay less. Compensating differentials theory holds that workers in predominately female jobs select into jobs due to preferences for certain types of market work. Gendered devaluation theory holds that wages and compensation of workers in these jobs are constrained of the lower status of women and women's work in society.

By focusing on the relationship between female representation in an occupation and wage and non-wage compensation, this paper makes a further attempt to identify whether the processes linking gender sorting in the labor market to the gender wage gap are consistent with compensating differentials theory or devaluation theory. Contrary to the predictions based on compensating differentials theory, I find little evidence that higher fringe benefits explain why predominately female occupations pay less than predominately male occupations. Rather, the results suggest that in addition to lower wages, workers in predominately female occupations are less likely to be offered employer health insurance coverage and are less likely to have paid vacation or pension plans relative to workers in predominately female occupations and gender integrated occupations.

Given that workers in predominately female jobs do not appear to receive a larger proportion of total compensation in the form of fringe benefits than workers in 
predominately male occupations, these results provide some evidence in support of devaluation theory and the argument that working in an occupation with more female representation reduces the labor market rewards for that work. However, to the extent that other non-pecuniary factors (amenities or disamenities) that have not been included in the present study affect wages and systematically differ across predominately male and female occupations, the possibility that compensating differentials theory explains pay differences between male and female occupations cannot be ruled out.

Additionally, further investigation is needed to identify the mechanisms contributing to the lower supply of fringe benefits in female occupations. The results here cannot distinguish whether average levels of fringe benefits are lower in predominately female jobs because of female representation in an occupation, or because women are more likely to select occupations where the work is not well rewarded relative to the education and skills required. However, the results do suggest that scholars will want to continue to account for fringe benefits when measuring job compensation. The negative association between female representation in an occupation and both wages and benefits suggest that the inequalities between predominately female occupations and predominately male occupations might be greater than when measured only by wage compensation.

Furthermore, continued attention to the separate influence of sex and the sex composition of an occupation on wages and benefit is warranted, because studies that have examined the wage benefit tradeoff such as Duncan (1976), Levy (2006), and Solberg and Laughlin (1995) have produced mixed evidence regarding whether benefits augment or reduce gender inequality in the labor market. Although the tradeoffs between wages and fringe benefits may not contribute to the part of the gender gap explained by occupational segregation (as indicated in this analysis and in Glass (1990) and England et 
al. (1994), the tradeoff may still contribute to individual-level gender differences in wages. Daneshvary and Clauretie (2007) find that the tradeoff between wages and health insurance coverage explains about 3\% of gender differences in wages.

Limitations. This analysis is not free from limitations, the largest of which is the reliance on cross-sectional data. It is possible that both unobserved occupation-level factors, such as amenities and disamenities, and unobserved individual-level factors, such as abilities and preferences, affect wage and benefits and are correlated with a worker's sex and with the sex composition of an occupation. The existing literature suggests several possible ways to cope with such selection bias. One common approach in both the economic and sociological literature has been to use occupation and individual fixed effects to cope with time invariant unobservable factors that affect benefits and wages. ${ }^{63}$ The longitudinal nature of the MEPS data and the presence of workers in more than one annual consolidated survey year provide the opportunity to examine how changes in female representation affect changes in wages and benefits net of individual-level and occupation-level characteristics. ${ }^{64}$ Accounting for self-rated health status is another possible approach to addressing unobservable factors that may influence a worker's preference for a job that offers health insurance coverage and may influence whether workers are willing to forgo wages to obtain health benefits (Lluis \& Abraham, 2013).

At the occupation-level, some scholars may be concerned that the analysis does not control for other occupational characteristics (such as work conditions) that may affect wages and vary with an occupation's sex composition. However, several studies find a wage penalty associated with jobs with poorer working conditions and physical disamenities, regardless of whether an occupation is predominately female or

\footnotetext{
63 There is some concern that unobserved productivity and ability is not actually time invariant (cite).

64 The identifying variation here would be from individuals whose fringe benefits changed between survey years (or survey waves). It would also be possible to limit the analysis only to job changers, as several prior studies have done, to examine how job changes affect wages and benefits.
} 
predominately male (England et al., 2002; England et al., 1988; Jacobs \& Steinberg, 1990; Kilbourne et al., 1994). Consequently, if omitted working conditions affect wages but do not vary by gender, their inclusion in the analysis would likely make the estimates of female representation more precise, but their exclusion would not bias the estimates of female representation on wages and fringe benefits. ${ }^{65}$

Scholars may also be concerned with the study's use of data from the Great Recession, and question whether selection into employment during a major economic downturn influences the results of the analysis (particularly the inclusion restriction regarding job tenure) and limits the generalizability of the findings to other time periods. Yet, because the study documents the distribution of gender, wages, and benefits beginning in 2007, prior to the financial crisis, through 2013 and because year fixed effects are included in the models, one could argue that the results tell an important and timely story about variation in the protective effects of employment across male and female occupations in the new economy.

Admittedly, the extent of job shedding during the most recent recession was far reaching and led to considerable job loss among male workers in high paying jobs that probably also had good benefits. However, because the absence of male workers with high wages and good benefits from the sample would likely systematically affect average levels of wages and benefits in occupations with a greater percentage of male workers, this would mean that the present results underestimate the relationship between female representation and compensation, rather than over estimate them. The jobs loss experience by males in the Great Recession does, however, point to an important avenue for future research: given that recent trends suggest that male workers who experienced job loss during the moved into previously female jobs, future studies will want to

${ }^{65}$ Of course, it is possible that employers compensate for disamenities such as onerous working conditions through benefit compensation rather than wage compensation. 
examine how an increase in male occupations in traditionally female occupations affects wages and benefits. ${ }^{66}$

\section{Conclusion}

The vast literature on women and work has put forth several theories to explain why predominately female occupations pay less than predominately male occupations. Differences in the assumptions underlying these theories largely centers on whether workers in predominately female occupations choose their jobs based on their nonpecuniary attributes and their preferences for certain types of market work or whether they face constraints that limit the labor market rewards (wage and benefits) they receive for doing women's work. In this study, I find that workers in predominately female jobs have lower wages than workers in predominately male jobs, holding all other factors constant. I also find that workers in predominately female jobs are less likely to have benefits such as health insurance, pensions, and paid leave relative to workers in predominately male occupations and workers in gender integrated occupations. Although these findings cannot completely rule out compensating differentials as an explanation for the lower relative pay of female occupations, they do shed light onto how the structure of the labor market and the uneven distribution of men and women across occupations contributes to disparities in wages and in access to important social benefits such as paid leave, health insurance coverage, and pensions, all of which have been shown to have significant protective effects for individuals and their households.

\footnotetext{
${ }^{66}$ The results may also capture job lock that occurred during the recession and recovery, if male and female workers who were poorly matched to a job in terms of their wage and benefit preferences were unable to (or chose not to) shop for better job matches because of high rates of unemployment.
} 


\section{References}

AHRQ. (2015a). Medical Expenditures Panel Survey 2013 Full Year Consolidated Data File Documentation.

AHRQ. (2015b, 9/23/2015). MEPS-HC Sample Sizes. Retrieved from https://meps.ahrq.gov/mepsweb/survey_comp/hc_sample_size.jsp

Baron, J. N., \& Newman, A. E. (1990). For What It's Worth: Organizations, Occupations, and the Value of Work Done by Women and Nonwhites. American Sociological Review, 55(2), 155-175. doi:10.2307/2095624

Bielby, W. T., \& Baron, J. N. (1986). Sex Segregation Within Occupations. American Economic Review, 76(2), 43. Retrieved from http://proxy.mul.missouri.edu/login?url=http://search.ebscohost.com/login.aspx?d irect $=$ true $\& \mathrm{db}=\mathrm{buh} \& \mathrm{AN}=4496351 \&$ site=eds-live \&scope $=$ site

Blau, F. D., Brummund, P., \& Liu, A. Y.-H. (2013). Trends in Occupational Segregation by Gender 1970-2009: Adjusting for the Impact of Changes in the Occupational Coding System. Demography, 50(2), 471-492. doi:10.1007/s13524-012-0151-7

BLS. (2017). Employer Costs for Employee Compensation [Press release]. Retrieved from https://www.bls.gov/news.release/ecec.nr0.htm

Bundorf, M. K. (2002). Employee demand for health insurance and employer health plan choices. Journal of Health Economics, 21(1), 65-88.

Catanzarite, L. (2003). Race-Gender Composition and Occupational Pay Degradation. Social Problems, 50(1), 14-37. doi:10.1525/sp.2003.50.1.14

Cohen, P. N., \& Huffman, M. L. (2003). Individuals, Jobs, and Labor Markets: The Devaluation of Women's Work. American Sociological Review, 68(3), 443-463. doi:10.2307/1519732

Cotter, D. A., Hermsen, J. M., \& Vanneman, R. (2004). Gender inequality at work.

Cowan, B., \& Schwab, B. (2016). Employer-sponsored health insurance and the gender wage gap. Journal of Health Economics, 45, 103-114. 
Currie, J. (1993). Gender gaps in benefits coverage. Retrieved from

Currie, J., \& Chaykowski, R. (1992). Male jobs, female jobs, and gender gaps in benefits coverage. Retrieved from

Currie, J., \& Madrian, B. C. (1999). Health, health insurance and the labor market. Handbook of labor economics, 3, 3309-3416.

Daneshvary, N., \& Clauretie, T. M. (2007). GENDER DIFFERENCES IN THE VALUATION OF EMPLOYER-PROVIDED HEALTH INSURANCE. Economic Inquiry, 45(4), 800-816.

Duncan, G. J. (1976). Earnings functions and nonpecuniary benefits. Journal of Human Resources, 462-483.

Eagly, A. H., \& Steffen, V. J. (1984). Gender stereotypes stem from the distribution of women and men into social roles. Journal of Personality and Social Psychology, 46(4), 735.

England, P. (1992). Comparable worth: Theories and evidence: Transaction Publishers.

England, P. (2010). The gender revolution: Uneven and stalled. Gender \& society, 24(2), 149-166.

England, P., Allison, P., \& Wu, Y. (2007). Does bad pay cause occupations to feminize, Does feminization reduce pay, and How can we tell with longitudinal data? Social Science Research, 36(3), 1237-1256.

England, P., Budig, M., \& Folbre, N. (2002). Wages of virtue: The relative pay of care work. Social Problems, 49(4), 455-473.

England, P., Farkas, G., Kilbourne, B. S., \& Dou, T. (1988). Explaining occupational sex segregation and wages: Findings from a model with fixed effects. American Sociological Review, 544-558.

England, P., Herbert, M. S., Kilbourne, B. S., Reid, L. L., \& Megdal, L. M. (1994). The gendered valuation of occupations and skills: Earnings in 1980 census occupations. Social Forces, 65-100. 
England, P., Reid, L. L., \& Kilbourne, B. S. (1996). The effect of the sex composition of jobs on starting wages in an organization: Findings from the NLSY. Demography, 33(4), 511-521.

England, P., Thompson, J., \& Aman, C. (2001). The sex gap in pay and comparable worth Sourcebook of labor markets (pp. 551-565): Springer.

Glass, J. (1990). The impact of occupational segregation on working conditions. Social Forces, 779-796.

Hogue, M., \& Yoder, J. D. (2003). The role of status in producing depressed entitlement in women's and men's pay allocations. Psychology of Women Quarterly, 27(4), 330-337.

Huffman, M. L., Velasco, S. C., \& Bielby, W. T. (1996). WHERE SEX COMPOSITION MATTERS MOST: COMPARING THE EFFECTS OF JOB VERSUS OCCUPATIONAL SEX COMPOSITION ON EARNINGS. Sociological Focus, 29(3), 189-207. Retrieved from http://www.jstor.org/stable/20831785

Jacobs, J. A., \& Steinberg, R. J. (1990). Compensating Differentials and the Male-Female Wage Gap: Evidence from the New York State Comparable Worth Study. Social Forces, 69(2), 439-468. doi:10.2307/2579667

Jensen, G. A., \& Morrisey, M. A. (2001). Endogenous fringe benefits, compensating wage differentials and older workers. International Journal of Health Care Finance and Economics, 1(3-4), 203-226.

Jost, J. T., \& Hamilton, D. L. (2005). Stereotypes in our culture. On the nature of prejudice, 208-225.

Kalleberg, A. L., Rasell, E., Cassirer, N., Reskin, B. F., Hudson, K., Webster, D., . . . Spalter-Roth, R. M. (1997). Nonstandard work, substandard jobs. Flexible work arrangements in the US: ERIC.

Kalleberg, A. L., Reskin, B. F., \& Hudson, K. (2000). Bad Jobs in America: Standard and Nonstandard Employment Relations and Job Quality in the United States. American Sociological Review, 65(2), 256-278. doi:10.2307/2657440 
Kilbourne, B. S., England, P., Farkas, G., Beron, K., \& Weir, D. (1994). Returns to Skill, Compensating Differentials, and Gender Bias: Effects of Occupational Characteristics on the Wages of White Women and Men. American Journal of Sociology, 100(3), 689-719. Retrieved from http://www.jstor.org/stable/2782402

Kmec, J. A. (2003). Minority Job Concentration and Wages. Social Problems, 50(1), 3859. doi:10.1525/sp.2003.50.1.38

Leibowitz, A. (1983). Fringe benefits in employee compensation The measurement of labor cost (pp. 371-394): University of Chicago Press.

Levanon, A., England, P., \& Allison, P. (2009). Occupational feminization and pay: Assessing causal dynamics using 1950-2000 US census data. Social Forces, 88(2), 865-891.

Levy, H. (1998). Who Pays for Health Insurance? Employee Contributions to Health Insurance Premiums. Retrieved from

Levy, H. (2006). Health insurance and the wage gap. Retrieved from

Levy, H., \& Feldman, R. (2001). Does the Incidence of Group Health Insurance Fall on Individual Workers? International Journal of Health Care Finance and Economics, 1(3-4), 227-247.

Lluis, S., \& Abraham, J. (2013). The Wage-Health Insurance Trade-off and Worker Selection: Evidence From the Medical Expenditure Panel Survey 1997 to 2006. Industrial Relations: A Journal of Economy and Society, 52(2), 541-581.

Major, B. (1994). From social inequality to personal entitlement: The role of social comparisons, legitimacy appraisals, and group membership. Advances in Experimental Social Psychology, 26, 293-355.

Miller, R. D. (2004). Estimating the compensating differential for employer-provided health insurance. International Journal of Health Care Finance and Economics, 4(1), 27-41.

Monheit, A. C., Hagan, M. M., Berk, M. L., \& Farley, P. J. (1985). The employed uninsured and the role of public policy. Inquiry, 348-364. 
Monheit, A. C., \& Vistnes, J. P. (1999). Health Insurance Availability at the Workplace: How Important are Worker Preferences? Journal of Human Resources, 770-785.

Olson, C. A. (2002). Do workers accept lower wages in exchange for health benefits? Journal of Labor Economics, 20(S2), S91-S114.

Ruggles, S., Genadek, K., Goeken, R., Grover, J., \& Sobek, M. (2015). Integrated Public Use Microdata Series: Version 6.0 [dataset]. Minneapolis: University of Minnesota.

Simon, K. I. (2001). Displaced Workers and Employer-Provided Health Insurance: Evidence of a Wage/Fringe Benefit Tradeoff? International Journal of Health Care Finance and Economics, 1(3-4), 249-271.

Smith, R. S., \& Ehrenberg, R. G. (1983). Estimating wage-fringe trade-offs: Some data problems The measurement of labor cost (pp. 347-370): University of Chicago Press.

Solberg, E., \& Laughlin, T. (1995). The gender pay gap, fringe benefits, and occupational crowding. ILR Review, 48(4), 692-708.

Tam, T. (1997). Sex Segregation and Occupational Gender Inequality in the United States: Devaluation or Specialized Training? 1. American Journal of Sociology, 102(6), 1652-1692.

Timmerman, J. (2005). Determinants of Access to Job-related Health Insurance. Eastern Economic Journal, 31(4), 671-680.

Tomaskovic-Devey, D. (1993). The gender and race composition of jobs and the male/female, white/black pay gaps. Social Forces, 45-76. 


\section{Appendix A}

Table 7. The Effects of Female Representation on Job Compensation a using Five Indicators of Female Representation (Integrated Jobs Omitted)

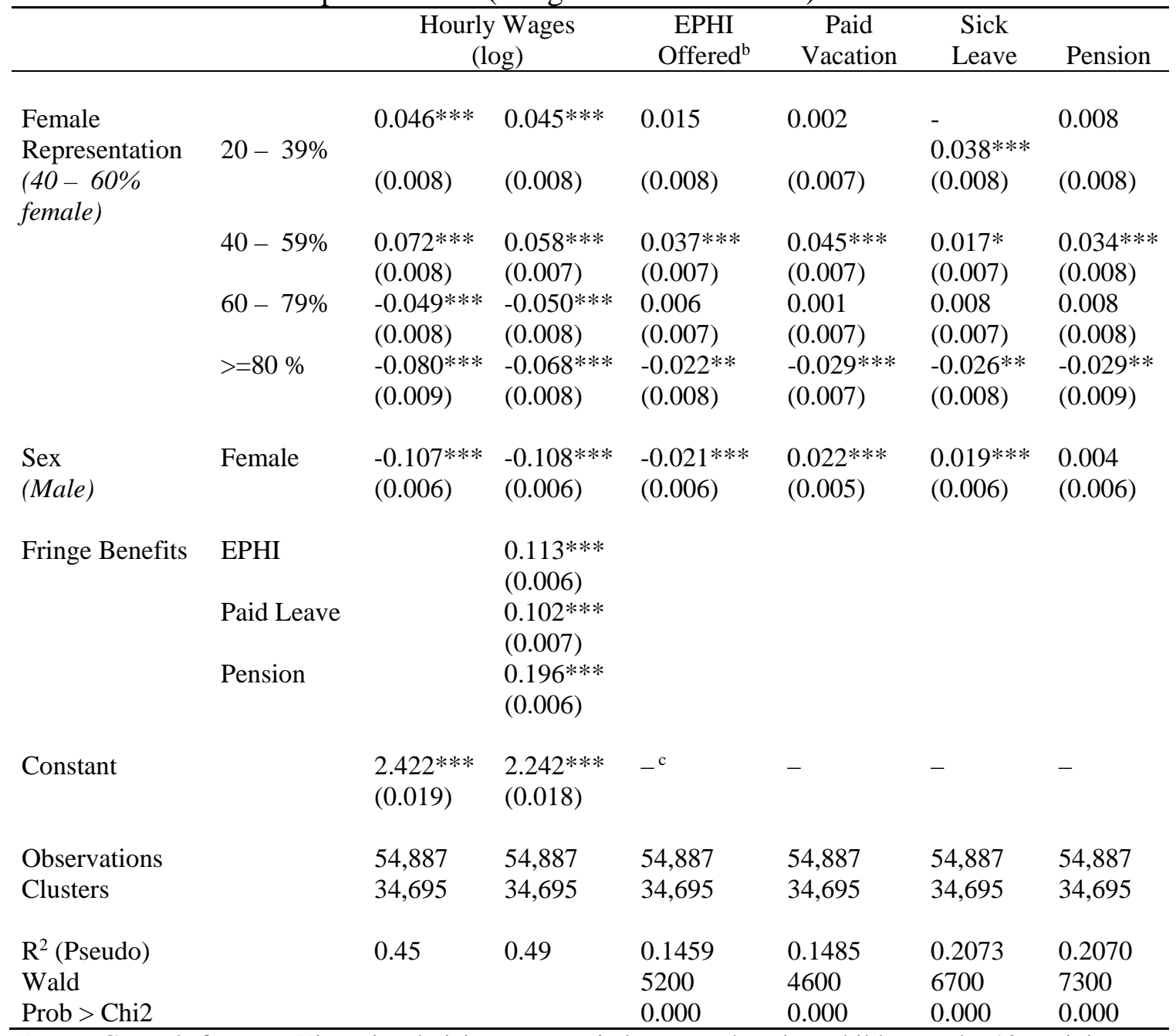

Notes: ${ }^{a}$ Controls for race, Hispanic ethnicity, age, marital status, education, children under 18, nativity, union membership, industry, state, and year included in regression analysis, but suppressed in output. ${ }^{b}$ For probit regressions (columns 2-5) marginal effects are reported. For all columns, clustered robust standard errors are reported in parentheses. ${ }^{\mathrm{c}}$ Constant term not shown. Estimates statistically significant at $* * *$ $\mathrm{p}<0.001,{ }^{* *} \mathrm{p}<0.01,{ }^{*} \mathrm{p}<0.05$. Sample restricted to workers ages $16-65$ employed in full-time year round positions for more than six months in December of the data file year. 
Table 8. The Effects of Female Representation on Job Compensation ${ }^{\text {a }}$ using Three Indicators of Female Representation (Predominately Male Jobs Omitted)

\begin{tabular}{|c|c|c|c|c|c|c|c|}
\hline & & Hour & $\begin{array}{l}\text { Wages } \\
\text { g) }\end{array}$ & $\begin{array}{c}\text { EPHI } \\
\text { Offered }^{\mathrm{b}}\end{array}$ & $\begin{array}{c}\text { Paid } \\
\text { Vacation }\end{array}$ & $\begin{array}{c}\text { Sick } \\
\text { Leave }\end{array}$ & Pension \\
\hline \multirow{3}{*}{$\begin{array}{l}\text { Female } \\
\text { Representation } \\
(<33 \% \\
\text { female })\end{array}$} & $33-66 \%$ & $-0.044 * * *$ & $-0.041^{* * *}$ & $-0.015 *$ & $-0.011 *$ & $0.021 * * *$ & -0.007 \\
\hline & $>66 \%$ & $-0.140 * * *$ & $-0.123 * * *$ & $-0.041 * * *$ & $-0.040 * * *$ & -0.011 & - \\
\hline & & (0.008) & (0.008) & $(0.007)$ & $(0.007)$ & $(0.007)$ & (0.008) \\
\hline $\begin{array}{l}\text { Sex } \\
\text { (male) }\end{array}$ & Female & $\begin{array}{l}-0.106^{* * *} \\
(0.006)\end{array}$ & $\begin{array}{l}-0.108^{* * *} \\
(0.006)\end{array}$ & $\begin{array}{l}-0.020^{* * *} \\
(0.006)\end{array}$ & $\begin{array}{l}0.023 * * * \\
(0.005)\end{array}$ & $\begin{array}{l}0.025 * * * \\
(0.005)\end{array}$ & $\begin{array}{l}0.006 \\
(0.006)\end{array}$ \\
\hline \multirow{3}{*}{$\begin{array}{l}\text { Fringe } \\
\text { Benefits }\end{array}$} & EPHI & & $0.113^{* * *}$ & & & & \\
\hline & Paid Leave & & $\begin{array}{l}(0.006) \\
0.102 * * * \\
(0.007)\end{array}$ & & & & \\
\hline & Pension & & $\begin{array}{l}0.196 * * * \\
(0.006)\end{array}$ & & & & \\
\hline Constant & & $\begin{array}{l}2.436 * * * \\
(0.018)\end{array}$ & $\begin{array}{l}2.296 * * * \\
(0.018)\end{array}$ & $-{ }^{c}$ & - & - & - \\
\hline Observations & & 54,887 & 54,887 & 54,887 & 54,887 & 54,887 & 54,887 \\
\hline Clusters & & 34,695 & 34,695 & 34,695 & 34,695 & 34,695 & 34,695 \\
\hline R² (Pseudo) & & 0.45 & 0.49 & 0.15 & 0.15 & 0.21 & 0.21 \\
\hline Wald & & & & 5200 & 4600 & 6700 & 7300 \\
\hline Prob $>$ Chi2 & & & & 0.000 & 0.000 & 0.000 & 0.000 \\
\hline
\end{tabular}

Notes: ${ }^{a}$ Controls for race, Hispanic ethnicity, age, marital status, education, children under 18, nativity, union membership, industry, state, and year included in regression analysis, but suppressed in output. ${ }^{b}$ For probit regressions (columns 2-5) marginal effects are reported. For all columns, clustered robust standard errors are reported in parentheses. ${ }^{\mathrm{C}}$ Constant term not shown. Estimates statistically significant at $* * *$ $\mathrm{p}<0.001,{ }^{* *} \mathrm{p}<0.01,{ }^{*} \mathrm{p}<0.05$. Sample restricted to workers ages $16-65$ employed in full-time year round positions for more than six months in December of the data file year. 
Table 9. The Effects of Female Representation on Compensation ${ }^{\mathrm{a}}$ using Percentage Female (Continuous)

\begin{tabular}{|c|c|c|c|c|c|c|c|}
\hline & & $\begin{array}{r}\text { Hourl } \\
(\end{array}$ & $\begin{array}{l}\text { Wages } \\
\text { g) }\end{array}$ & $\begin{array}{c}\text { EPHI } \\
\text { Offered }^{\mathrm{b}}\end{array}$ & $\begin{array}{c}\text { Paid } \\
\text { Vacation }\end{array}$ & $\begin{array}{c}\text { Sick } \\
\text { Leave }\end{array}$ & Pension \\
\hline \multirow{2}{*}{$\begin{array}{l}\text { Female } \\
\text { Representation }\end{array}$} & $\%$ Female & $-0.193 * * *$ & $-0.170 * * *$ & $-0.062 * * *$ & $-0.052 * * *$ & 0.009 & $-0.058 * * *$ \\
\hline & & $(0.012)$ & $(0.011)$ & $(0.011)$ & $(0.010)$ & $(0.011)$ & $(0.011)$ \\
\hline Sex & Female & $\begin{array}{l}-0.103 * * * \\
(0.006)\end{array}$ & $\begin{array}{l}-0.105^{* * *} \\
(0.006)\end{array}$ & $\begin{array}{l}-0.017 * * \\
(0.006)\end{array}$ & $\begin{array}{l}0.024^{* * *} \\
(0.005)\end{array}$ & $\begin{array}{l}0.021^{* * *} \\
(0.006)\end{array}$ & $\begin{array}{l}0.007 \\
(0.006)\end{array}$ \\
\hline \multirow[t]{3}{*}{ Other Benefits } & EPHI & & $\begin{array}{l}0.113^{* * *} \\
(0.006)\end{array}$ & & & & \\
\hline & Paid Leave & & $\begin{array}{l}0.103^{* * *} \\
(0.007)\end{array}$ & & & & \\
\hline & Pension & & $\begin{array}{l}0.196 * * * \\
(0.006)\end{array}$ & & & & \\
\hline Constant & & $\begin{array}{l}2.464 * * * \\
(0.019)\end{array}$ & $\begin{array}{l}2.319 * * * \\
(0.019)\end{array}$ & $-{ }^{c}$ & - & - & - \\
\hline Observations & & 54,887 & 54,887 & 54,887 & 54,887 & 54,887 & 54,887 \\
\hline Clusters & & 34,695 & 34,695 & 34,695 & 34,695 & 34,695 & 34,695 \\
\hline $\mathrm{R}^{2}$ (Pseudo) & & 0.45 & 0.49 & 0.15 & 0.15 & 0.21 & 0.21 \\
\hline Wald & & & & 5200 & 4600 & 6700 & 7300 \\
\hline Prob > Chi2 & & & & 0.000 & 0.000 & 0.000 & 0.000 \\
\hline
\end{tabular}

Notes: ${ }^{a}$ Controls for race, Hispanic ethnicity, age, marital status, education, children under 18, nativity, union membership, industry, state, and year included in regression analysis, but suppressed in output. ${ }^{b}$ For probit regressions (columns 2-5) marginal effects are reported. For all columns, clustered robust standard errors are reported in parentheses. ${ }^{\mathrm{c}}$ Constant term not shown. Estimates statistically significant at $* * *$ $\mathrm{p}<0.001,{ }^{* *} \mathrm{p}<0.01,{ }^{*} \mathrm{p}<0.05$. Sample restricted to workers ages $16-65$ employed in full-time year round positions for more than six months in December of the data file year. 
Table 10. The Effects of Female Representation on Compensation ${ }^{\mathrm{a}}$ using Percentage Female (Quadratic)

\begin{tabular}{|c|c|c|c|c|c|c|c|}
\hline & & \multicolumn{2}{|c|}{$\begin{array}{c}\text { Hourly Wages } \\
\text { (log) }\end{array}$} & $\begin{array}{c}\text { EPHI } \\
\text { Offered }^{\mathrm{b}}\end{array}$ & $\begin{array}{c}\text { Paid } \\
\text { Vacation } \\
\end{array}$ & Sick Leave & Pension \\
\hline \multirow{4}{*}{$\begin{array}{l}\text { Female } \\
\text { Representation }\end{array}$} & $\%$ Female & -0.065 & $-0.115 * * *$ & 0.053 & $0.103^{* * *}$ & $0.318^{* * *}$ & $0.121 * * *$ \\
\hline & & $(0.036)$ & $(0.034)$ & $(0.034)$ & $(0.030)$ & $(0.033)$ & $(0.036)$ \\
\hline & $\%$ Female $^{2}$ & $-0.132 * * *$ & -0.057 & & $-0.159 * * *$ & $-0.324 * * *$ & $-0.184 * * *$ \\
\hline & & $(0.035)$ & $(0.033)$ & $\begin{array}{l}0.118 * * * \\
(0.033)\end{array}$ & $(0.030)$ & $(0.032)$ & $(0.035)$ \\
\hline $\begin{array}{l}\text { Sex } \\
\text { (male) }\end{array}$ & Female & $\begin{array}{l}-0.104^{* * *} \\
(0.006)\end{array}$ & $\begin{array}{l}-0.106 * * * \\
(0.006)\end{array}$ & $\begin{array}{l}-0.018^{* *} \\
(0.006)\end{array}$ & $\begin{array}{l}0.023 * * * \\
(0.005)\end{array}$ & $\begin{array}{l}0.019 * * * \\
(0.006)\end{array}$ & $\begin{array}{l}0.006 \\
(0.006)\end{array}$ \\
\hline \multirow[t]{3}{*}{ Fringe Benefits } & EPHI & & $\begin{array}{l}0.113^{* * *} \\
(0.006)\end{array}$ & & & & \\
\hline & Paid Leave & & $\begin{array}{l}0.103^{* * * *} \\
(0.007)\end{array}$ & & & & \\
\hline & Pension & & $\begin{array}{l}0.196 * * * \\
(0.006)\end{array}$ & & & & \\
\hline Constant & & $\begin{array}{l}2.449 * * * \\
(0.019)\end{array}$ & $\begin{array}{l}2.313^{* * *} \\
(0.019)\end{array}$ & $-{ }^{c}$ & - & - & - \\
\hline Observations & & 54,887 & 54,887 & 54,887 & 54,887 & 54,887 & 54,887 \\
\hline Clusters & & 34,695 & 34,695 & 34,695 & 34,695 & 34,695 & 34,695 \\
\hline $\mathrm{R}^{2}$ (Pseudo) & & 0.45 & 0.49 & 0.15 & 0.15 & 0.21 & 0.21 \\
\hline Wald & & & & 5200 & 4600 & 6700 & 7300 \\
\hline Prob > Chi2 & & & & 0.000 & 0.000 & 0.000 & 0.000 \\
\hline
\end{tabular}

Notes: ${ }^{a}$ Controls for race, Hispanic ethnicity, age, marital status, education, children under 18, nativity, union membership, industry, state, and year included in regression analysis, but suppressed in output. ${ }^{\mathrm{b}}$ For probit regressions (columns 2-5) marginal effects are reported. For all columns, clustered robust standard

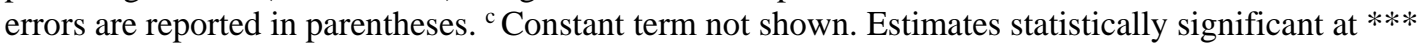
$\mathrm{p}<0.001, * * \mathrm{p}<0.01,{ }^{*} \mathrm{p}<0.05$. Sample restricted to workers ages $16-65$ employed in full-time year round positions for more than six months in December of the data file year. 
Table 11. The Effects of Female Representation on Compensation ${ }^{\mathrm{a}}$ using a binary indicator of Percentage Female ( $<50 \%$ Female Omitted)

\begin{tabular}{|c|c|c|c|c|c|c|c|}
\hline & & Hourl & $\begin{array}{l}\text { Wages } \\
\text { g) }\end{array}$ & $\begin{array}{c}\text { EPHI } \\
\text { Offered }^{\mathrm{b}}\end{array}$ & $\begin{array}{c}\text { Paid } \\
\text { Vacation }\end{array}$ & $\begin{array}{c}\text { Sick } \\
\text { Leave }\end{array}$ & Pension \\
\hline $\begin{array}{l}\text { Female } \\
\text { Representation } \\
(<50 \% \text { Female })\end{array}$ & $>50 \%$ & $\begin{array}{l}-0.100^{* * *} \\
(0.006)\end{array}$ & $\begin{array}{l}-0.087^{* * *} \\
(0.006)\end{array}$ & $\begin{array}{l}-0.029 * * * \\
(0.006)\end{array}$ & $\begin{array}{l}-0.042^{* * *} \\
(0.005)\end{array}$ & $\begin{array}{l}-0.011^{*} \\
(0.006)\end{array}$ & $\begin{array}{l}-0.031^{* * *} \\
(0.006)\end{array}$ \\
\hline $\begin{array}{l}\text { Sex } \\
\text { (male) }\end{array}$ & Female & $\begin{array}{l}-0.114^{* * *} \\
(0.006)\end{array}$ & $\begin{array}{l}-0.115^{* * *} \\
(0.006)\end{array}$ & $\begin{array}{l}-0.022^{* * *} \\
(0.005)\end{array}$ & $\begin{array}{l}0.026 * * * \\
(0.005)\end{array}$ & $\begin{array}{l}0.027 * * * \\
(0.005)\end{array}$ & $\begin{array}{l}0.004 \\
(0.006)\end{array}$ \\
\hline Fringe Benefits & $\begin{array}{l}\text { EPHI } \\
\text { Offered } \\
\text { Paid } \\
\text { Leave } \\
\text { Pension }\end{array}$ & & $\begin{array}{l}0.113^{* * *} \\
(0.006) \\
0.102^{* * *} \\
\\
(0.007) \\
0.196 * * * \\
(0.006)\end{array}$ & & & & \\
\hline Constant & & $\begin{array}{l}2.417 * * * \\
(0.018)\end{array}$ & $\begin{array}{l}2.277 * * * \\
(0.018)\end{array}$ & $--^{c}$ & - & - & - \\
\hline $\begin{array}{l}\text { Observations } \\
\text { Clusters }\end{array}$ & & $\begin{array}{l}54,887 \\
34,695\end{array}$ & $\begin{array}{l}54,887 \\
34,695\end{array}$ & $\begin{array}{l}54,887 \\
34,695\end{array}$ & $\begin{array}{l}54,887 \\
34,695\end{array}$ & $\begin{array}{l}54,887 \\
34,695\end{array}$ & $\begin{array}{l}54,887 \\
34,695\end{array}$ \\
\hline $\begin{array}{l}\mathrm{R}^{2} \text { (Pseudo) } \\
\text { Wald } \\
\text { Prob > Chi2 }\end{array}$ & & 0.45 & 0.49 & $\begin{array}{l}0.15 \\
5200 \\
0.000\end{array}$ & $\begin{array}{l}0.15 \\
4600 \\
0.000\end{array}$ & $\begin{array}{l}0.21 \\
6700 \\
0.000\end{array}$ & $\begin{array}{l}0.21 \\
7300 \\
0.000\end{array}$ \\
\hline
\end{tabular}

Notes: ${ }^{a}$ Controls for race, Hispanic ethnicity, age, marital status, education, children under 18, nativity, union membership, industry, state, and year included in regression analysis, but suppressed in output. ${ }^{b}$ For probit regressions (columns 2-5) marginal effects are reported. For all columns, clustered robust standard errors are reported in parentheses. ${ }^{\mathrm{c}}$ Constant term not shown. Estimates statistically significant at $* * *$ $\mathrm{p}<0.001, * * \mathrm{p}<0.01, * \mathrm{p}<0.05$. Sample restricted to workers ages $16-65$ employed in full-time year round positions for more than six months in December of the data file year. 
Table 12. The Effects of Female Representation on Compensation ${ }^{\mathrm{a}}$ using the Log Odds of Percentage Female (Continuous)

\begin{tabular}{|c|c|c|c|c|c|c|c|}
\hline & & Hourl & $\begin{array}{l}\text { Wages } \\
\text { g) }\end{array}$ & $\begin{array}{c}\text { EPHI } \\
\text { Offered }^{\mathrm{b}}\end{array}$ & $\begin{array}{c}\text { Paid } \\
\text { Vacation }\end{array}$ & $\begin{array}{c}\text { Sick } \\
\text { Leave }\end{array}$ & Pension \\
\hline $\begin{array}{l}\text { Female } \\
\text { Representation }\end{array}$ & $\begin{array}{l}\text { Log Odds } \\
\% \text { Female }\end{array}$ & $\begin{array}{l}-0.027^{* * *} \\
(0.002)\end{array}$ & $\begin{array}{l}-0.024^{* * *} \\
(0.002)\end{array}$ & $\begin{array}{l}-0.010^{* * *} \\
(0.002)\end{array}$ & $\begin{array}{l}-0.005^{* *} \\
(0.002)\end{array}$ & $\begin{array}{l}0.005^{* *} \\
(0.002)\end{array}$ & $\begin{array}{l}-0.008^{* * *} \\
(0.002)\end{array}$ \\
\hline $\begin{array}{l}\text { Sex } \\
\text { (male) }\end{array}$ & Female & $\begin{array}{l}-0.112^{* * *} \\
(0.006)\end{array}$ & $\begin{array}{l}-0.113^{* * *} \\
(0.006)\end{array}$ & $\begin{array}{l}-0.019 * * * \\
(0.006)\end{array}$ & $\begin{array}{l}0.017 * * * \\
(0.005)\end{array}$ & $\begin{array}{l}0.015^{* *} \\
(0.005)\end{array}$ & $\begin{array}{l}0.004 \\
(0.006)\end{array}$ \\
\hline Fringe Benefits & $\begin{array}{l}\text { EPHI } \\
\text { Paid Leave } \\
\text { Pension }\end{array}$ & & $\begin{array}{l}0.113^{* * *} \\
(0.006) \\
0.105^{* * *} \\
(0.007) \\
0.196 * * * \\
(0.006)\end{array}$ & & & & \\
\hline Constant & & $\begin{array}{l}2.362 * * * \\
(0.018)\end{array}$ & $\begin{array}{l}2.229 * * * \\
(0.017)\end{array}$ & $--^{c}$ & - & - & - \\
\hline $\begin{array}{l}\text { Observations } \\
\text { Clusters }\end{array}$ & & $\begin{array}{l}54,887 \\
34,695\end{array}$ & $\begin{array}{l}54,887 \\
34,695\end{array}$ & $\begin{array}{l}54,887 \\
34,695\end{array}$ & $\begin{array}{l}54,887 \\
34,695\end{array}$ & $\begin{array}{l}54,887 \\
34,695\end{array}$ & $\begin{array}{l}54,887 \\
34,695\end{array}$ \\
\hline $\begin{array}{l}\mathrm{R}^{2} \text { (Pseudo) } \\
\text { Wald } \\
\text { Prob > Chi2 }\end{array}$ & & 0.45 & 0.49 & $\begin{array}{l}0.15 \\
5200 \\
0.000\end{array}$ & $\begin{array}{l}0.15 \\
4600 \\
0.000\end{array}$ & $\begin{array}{l}0.21 \\
6700 \\
0.000\end{array}$ & $\begin{array}{l}0.21 \\
7300 \\
0.000\end{array}$ \\
\hline
\end{tabular}

Notes: a Controls for race, Hispanic ethnicity, age, marital status, education, children under 18, nativity, union membership, industry, state, and year included in regression analysis, but suppressed in output. ${ }^{b}$ For probit regressions (columns 2-5) marginal effects are reported. For all columns, clustered robust standard errors are reported in parentheses. ${ }^{\mathrm{c}}$ Constant term not shown. Estimates statistically significant at $* * *$ $\mathrm{p}<0.001,{ }^{* *} \mathrm{p}<0.01,{ }^{*} \mathrm{p}<0.05$. Sample restricted to workers ages $16-65$ employed in full-time year-round jobs for more than six months in December of the survey year. 


\section{Appendix B}

I measure total job compensation based on National Compensation Survey (NCS) estimates of wages and benefits as percentage of total employment costs in an aggregate occupation group and year. For example, if a worker has an hourly wage rate of \$12 and on average wages represent $68.4 \%$ of total employment costs in a workers occupation group in a given year, then the maximum total hourly employment costs for this worker is approximately $\$ 17.50$ (total employment costs= hourly wage*100/wage \% of total employment costs). Then, I use the average percentage of total employment costs that employers allocate to each fringe benefit to calculate the value of each benefit (fringe benefit value $=$ total employment costs* benefit $\%$ of total employment costs) conditional on whether a worker receives that benefit on the job. For example, if the individual earning \$12 reports having health insurance coverage than the value of this coverage is calculated as $8.4 \%$ of total employment costs or $\$ 1.45$ per hour $\left(17.5^{*} .083\right)$. If the individual has only health insurance coverage and no other benefits, then then their total job compensation is $\$ 13.45$ (hourly wages + value of health insurance benefit). This is a rough approximation of total job compensation and an imperfect measure of the true value of any given benefit to a worker. A more accurate measure of the value of a given benefit would be what that worker would have to pay out of pocket in order to obtain that benefit from another source. The tax system is also likely to influence the value that workers places on benefits, since at higher levels of income a marginal dollar of benefits is worth more than a marginal dollar of wages (assuming benefits are not taxed). 


\section{CHAPTER 5: CONCLUSION}

Each of the essays in this dissertation used survey data drawn from nationally representative samples of the US population in order to empirically examine how workers' characteristics and their positions in the labor market affect their access to employee benefits. The first two essays focused on access to the unemployment insurance program, and the third focused on access to employer provided health insurance, paid leave, and pensions. Together these chapters identified barriers and pathways between employment and benefits after the Great Recession and highlighted ways in which policy makers can broaden the protective effects of employment in the new economy.

\section{Barriers to Benefits}

Unemployment insurance and employer provided health insurance, paid leave, and pensions together represent two different ways in which the characteristics of workers and their jobs determine the benefits received from working. Access to unemployment insurance depends on an individual's work history, earnings, and reasons for exiting employment, whereas access to health insurance coverage, paid leave, and a pension depends on whether or not an employer offers the benefit.

Yet, workers who face barriers in one form of access more than likely face barriers in the other form of access. For instance, I reported in chapters 2 and 3 that women are less likely to have unemployment insurance coverage. Chapter 4 also shows that women have lower wages than men and that they are less likely to have health insurance coverage (net of the gender composition of the occupation in which they work). In chapters 2 and 3, I also show that workers with lower levels of education are less likely to have unemployment insurance coverage. Although I do not report on rates of health insurance coverage and pensions by level of education in Chapter 4, Kalleberg, Reskin, 
and Hudson (2000) report that having less than a high school diploma increases the chance that someone works in a job that pays a wage below \$6.00 (in 1995 dollars) and does not offer health insurance coverage or a pension by $18 \%$ for males and by $16 \%$ for females (p. 268).

When it comes to other demographic differences in UI coverage among employed workers, I found that rates of UI coverage were also lower for younger workers (those who are 25 to 34 relative to 45 to 55), never married workers (relative to married workers), and workers with children under the age of 18 in the home (relative to those without children). Additionally, the results indicate unique barriers in access to UI for Hispanic workers. In chapter 2, I found that Hispanic workers were more likely to be covered by UI, but studies by Gould-Werth and Shaefer (2012) and Michaelides and Mueser (2012) suggest they are less likely to receive (or take up) UI benefits.

Additionally, the results demonstrate that it is not simply the characteristics of workers but also the characteristics of the jobs in which they work that form barriers to coverage. For example, I found a difference in rates of monetary eligibility between working men and women of 2.4 percentage points which accounting only for demographic characteristics, but this difference reduced to 1.1 percentage points after accounting for their job characteristics (i.e. part-time work status, occupation, and industry). I also found that for less-educated workers, who were less likely to be covered by UI than those with a bachelor's degree or higher, the magnitudes of the differences in UI coverage shrunk (from 4.4 to 1.3 and from 3.0 to 1.0 percentage points respectively) after I accounted for job characteristics.

Job characteristics that appeared particularly important for reducing the likelihood that a worker was covered by UI were part-time work and work in certain service-related industries and occupations. The difference in monetary eligibility between part-time 
workers and full-time workers was 5.3 percentage points. Additionally workers in service industries (professional, scientific, management, and administrative services, arts, entertainment, and recreation services, and other services) had rates of monetary eligibility about 2 percentage points lower than workers in manufacturing (the omitted category), and workers in service occupations (personal care and service) had rates of monetary eligibility about 2 percentage points lower than workers in production occupations.

The importance of these job characteristics was further confirmed in chapter 3, when I used decomposition analysis to examine how the differences in the demographic and job characteristics of male and female workers interacted to contribute to gender differences in UI coverage (monetary eligible for UI). This analytic approach allowed me to dig deeper into the labor market determinants of access to social insurance and ask: Is it simply that some demographic groups of workers are more likely to work in a given job that explains differential access to social insurance programs such as UI? Or is it that some demographic groups of workers receive different labor market returns for doing that same or similar work that affects access?

I found that women's over representation among part-time workers explained roughly $30 \%$ of employed women and $16 \%$ of unemployed women's lower rates of UI coverage relative to employed and unemployed men. I also found that gender differences across occupations explained $6 \%$ of employed women and $13 \%$ of unemployed women's lower rates of UI coverage relative to employed and unemployed men. However, most of the gender differences in UI coverage (between 64 and 84\%) were unexplained by differences in men and women's job characteristics, suggesting that an important barrier in access to social programs is differential returns to a given set of job characteristics for different demographic groups. 
That access to benefits stems partly from the differential returns to work for different demographics groups is echoed once more in the third chapter, which documents differences in wages and fringe benefits between male and female occupations. I found that workers in predominately female jobs had lower wages than workers in predominately male jobs, holding all other factors constant. I also found that workers in predominately female jobs were less likely to have benefits such as health insurance, pensions, and paid leave relative to workers in predominately male occupations and workers in gender integrated occupations. Although these findings cannot rule out an alternative explanation for the lower levels of pay and fringe benefits in female occupations relative to male occupations, they are consistent with the argument that working in a predominately female occupation reduces the labor market rewards for that work.

\section{Pathways to Benefits \& Directions for Future Research}

In identifying the groups of workers with limited or no access to employmentbased benefits, I also identified pathways to UI (i.e. the characteristics of workers and jobs that are more likely to have access to social insurance) and opportunities for expanding access. In the case of the UI program, the findings in chapters 1 demonstrate that using an alternative method for calculating monetary eligibility for UI when workers fail to qualify under the traditional method for calculating monetary eligibility increases rates of UI coverage. Additionally, Chapters 2 and 3 both indicate that programmatic changes such as separate provisions for part-time workers and lowering the thresholds needed to qualify for monetary eligibility would expand coverage to more workers.

These findings suggest several directions for future research on the protective effects of the UI program. First, when it comes to adopting provisions for part-time workers, some states chose to expand UI to part-time workers following the Great 
Recession while others did not. This change typically had to do with allowing UI claimants to receive benefits if they were only seeking part-time work. ${ }^{67}$ Consequently, an evaluation of how part-time workers who received benefits because of state programmatic changes fared following their job loss relative to part-time workers who did not receive benefits would shed further light onto the effectiveness of expansion in access to UI. Relevant employment outcomes would include duration of unemployment, the likelihood of exits from the labor force versus returns to employment following unemployment, and subsequent changes in job quality and earnings for individuals who returned to employment. A similar study could be conducted comparing employment and earnings outcomes of female workers who received UI benefits to those who were UI eligible but did not receive benefits. Given that such as study found positive impacts of UI participation for female workers, this would provide further evidence of the importance of expanding access to UI.

Second, the UI program received considerable attention following the Great Recession, and with just cause since it is designed to be a counter-cyclical program and program participation and expenditures go up when the economy goes down. However, continued attention to program design and how this affect program access is warranted because receipt of UI benefits had been steadily declining for several decades prior to the recession, and despite increases in program participation during the recession, since 2011 receipt of UI as a percentage of the total unemployment has been less than $30 \%$, an alltime low (DOL, 2017). Additionally, much of the legislation that led to state expansions of eligibility criteria, benefit amounts, and durations (i.e. much of the legislation that made the program more protective) has since expired and several states made other programmatic changes, such as reducing benefit durations from 26 weeks to 13 weeks, in order to offset the increase in program cost from the recession and from expansions in

\footnotetext{
${ }^{67}$ Most states require that UI claimants look for full-time work while receiving benefits.
} 
access to benefits. In chapters 1 and 2, I suggest lowering monetary eligibility thresholds as a tool for increasing access to the program and rates of UI receipt, particularly among disadvantaged workers. Future research could simulate how variation in UI coverage by demographic and job characteristics changes under different criteria, such as when all workers are subject to eligibility criteria from a state such as Connecticut, where the minimum earnings amount needed to qualify for benefits in the year prior to unemployment is only $\$ 600$.

Finally, as noted in the introduction, understanding the protective effects of employment begins with identifying the characteristics of workers who have limited or no access to social insurance programs such as UI. However, broadening the protective effects of employment also requires identifying the ways in which workers benefit from access to such programs. Future studies will want to continue to pay attention to how employment (in)stability affects access to UI, but will also want to pay attention to how UI receipt affects employment (in)stability in later periods. Future studies will also want to evaluate the ways in which receipt of unemployment insurance, especially among more disadvantage workers, mediates individual and household economic instability and protects individuals and household against economic hardship.

Unlike the case of the UI program, in which access can be broadened through programmatic changes, broadening access to employer provided fringe benefits potentially requires broader policy interventions such as publically funding programs to provide benefits such as health insurance (i.e. developing a single payer system), and/or federally mandating that employers provide benefits and subsidizing private nonemployer plans as in the case of the Affordable Care Act.

Therefore, an important extension of this research will be to use future survey years of the MEPS to estimate whether the availability of partially or fully subsidized 
health insurance coverage from state and federal health care marketplaces and the availability of public health insurance to low-wage workers in states that expanded Medicaid affected differences in wages and benefits between male and female workers and between male and female occupations. Recent expansions in Medicaid, the provision of tax subsidies for market insurance, and mandates that employers with fifty or more employees offer a health insurance plan to their employees are likely to have behavioral effects on both workers and employers. Among individuals who would prefer to work less hours but work full-time to receive health benefits through their employer, the availability of subsidies to private insurance plans obtained through the market place could have led to a reduction in work hours. If the behavioral response systematically led to work hour reductions among women in particular, this might augment the gender pay gap. Additionally, some employers could have reduced pay, hiring, or work hours in order to offset the increase in employment costs due to the mandate to provide health insurance coverage. If the behavioral response systematically led to changes in predominately female occupations, where prior to the ACA fewer employers offered health insurance coverage, this too could augment the gender pay gap.

Future research will want to examine the effects of recent expansions in the minimum wage in several states and large cities on workers' access to employment-based benefits. It is possible that increases in the minimum wage would lead employers to limit employee work hours to offset increases in employment costs, making it more difficult for workers to qualify for fringe benefits (if eligibility for benefits depends on full-time work). It is also possible that increases in the minimum wage would lead employers to forego providing benefits in order to cover increases in employment costs. Alternatively, increases in the minimum wage would also lesson the economic burden on households to pay for benefits such as health insurance coverage through the Marketplace when it is unavailable or too expensive to obtain from an employer. When it comes to the UI 
program, it is likely that increases in the minimum wage would help individuals access UI, because increased wages and potentially increased employment stability would increase the likelihood of meeting monetary criteria. Alternatively, if increases in the minimum wage lead to reductions in work hours and increased employment instability for some workers, this would potentially make it more difficult for low-wage workers to access UI.

Policy analysts and policymakers face a complicated set of challenges when it comes to identifying ways in which to expand the protective effects of employment. As the above paragraph highlighted, increases in wage income may lead to reductions in work hours and reductions in access to benefits. On the other hand, as discussed in more detail in Chapter 4, efforts to expand access to fringe benefits, such as federal mandates that employers provide health insurance coverage to their employees, may reduce wage income. The purpose of this dissertation was to identify how the characteristics of workers and their jobs affect access to social insurance and fringe benefits. These chapters provide a baseline for understanding the magnitude of barriers in access for some demographics groups, particularly less-educated women and workers in service related industries and occupations. Although these chapters help policymakers identify where to target strategies for increasing access, more work is needed to evaluate the impact of expansions of UI eligibility criteria, changes in the availability of public and private health insurance coverage under the ACA, and state increases in the minimum wage on the protective effects of employment. 


\section{References}

DOL. (2017). UI Recipiency Rate FY 1972-2016. In US_Recipiency_Rate_FY_Full.png (Ed.). Washington, DC: US Department of Labor, Employment and Training Administration.

Gould-Werth, A., \& Shaefer, H. L. (2012). Unemployment Insurance participation by education and by race and ethnicity. Monthly Lab. Rev., 135, 28.

Kalleberg, A. L., Reskin, B. F., \& Hudson, K. (2000). Bad Jobs in America: Standard and Nonstandard Employment Relations and Job Quality in the United States. American Sociological Review, 65(2), 256-278. doi:10.2307/2657440

Michaelides, M., \& Mueser, P. R. (2012). Recent trends in the characteristics of unemployment insurance recipients. Monthly Lab. Rev., 135, 28. 
VITA

Leslie Hodges, Ph.D., is a research associate at the Institute for Research on Poverty at the University of Wisconsin - Madison. Her research interests include social policy, social demography, policy analysis, and public program evaluation, especially in relation to social and economic inequality, access to the social safety net, health, and wellbeing. Leslie holds a bachelor's degree in English from Truman State University, a master's degree in political science from the TransAtlantic Masters Program at the University of North Carolina at Chapel Hill, and a doctorate in public affairs from the University of Missouri - Columbia. Prior to her doctoral studies, Leslie worked for World View: An International Program for Educators at UNC at Chapel Hill. 